\title{
Finite element simulation of creep behavior in enhanced refractory material for glass furnace
}

Praveen Kumar Kuntamalla

West Virginia University

Follow this and additional works at: https://researchrepository.wvu.edu/etd

\section{Recommended Citation}

Kuntamalla, Praveen Kumar, "Finite element simulation of creep behavior in enhanced refractory material for glass furnace" (2004). Graduate Theses, Dissertations, and Problem Reports. 1497.

https://researchrepository.wvu.edu/etd/1497

This Thesis is protected by copyright and/or related rights. It has been brought to you by the The Research Repository @ WVU with permission from the rights-holder(s). You are free to use this Thesis in any way that is permitted by the copyright and related rights legislation that applies to your use. For other uses you must obtain permission from the rights-holder(s) directly, unless additional rights are indicated by a Creative Commons license in the record and/ or on the work itself. This Thesis has been accepted for inclusion in WVU Graduate Theses, Dissertations, and Problem Reports collection by an authorized administrator of The Research Repository @ WVU. For more information, please contact researchrepository@mail.wvu.edu. 


\title{
FINITE ELEMENT SIMULATION OF CREEP BEHAVIOR IN ENHANCED REFRACTORY MATERIAL FOR GLASS FURNACE
}

\author{
By \\ Praveen Kumar Kuntamalla

\begin{abstract}
A Thesis Submitted to
College of Engineering and Mineral Resources

West Virginia University

in Partial Fulfillment of the Requirements

for the Degree of

Master of Science in Mechanical Engineering
\end{abstract}

Larry E. Banta, Ph.D.

Jacky C. Prucz, Ph.D.

Bruce Kang, Ph.D.

John E. Sneckenberger, Ph.D., Chair

Department of Mechanical and Aerospace Engineering

Morgantown, West Virginia

2004

Keywords: Enhanced Refractory Material, Ceramics, Glass Melting, Creep, and Finite Element Analysis. 


\section{ABSTRACT \\ Finite Element Simulation of Creep Behavior in Enhanced Refractory Material for Glass Furnace}

\section{Praveen Kumar Kuntamalla}

An important focus in the glass melting industry, which is an energy intensive industry, is towards greater output and increased energy efficiency in the glass melting process. Conversion to the oxy-fuel-fired furnace from the traditional air-fuel-fired furnace is one means to achieve greater output and energy efficiency, since the capital cost per ton of glass pulled is approximately 58\% less for the oxy-fuel-fired furnace compared to the air-fuel-fired furnace.

The main disadvantages of the oxy-fuel-fired furnace are its higher operating temperature, possibly to more than $2200^{\circ} \mathrm{F}$, and its alkali partial pressure that hasten the corrosion of refractory materials, particularly in silica refractories. Thus, the refractories used in the oxy-fuel-fired furnace are subjected to high temperatures and stresses during its service life. Considerable creep could occur in the furnace, if the refractory material is not creep resistant.

In order to improve the performance of refractory materials, Oak Ridge National Laboratory (ORNL) is utilizing High Density Infrared (HDI) technology. This technology, which is relatively new to materials processing, is increasingly being researched in the development of coatings and surface modifications for refractory materials.

This thesis studies the creep resistance effectiveness of the HDI surface treatment for refractory materials. In particular, the dependencies of creep strain on operating temperature and applied stress are studied to determine whether the HDI treated refractory materials can be utilized for glass furnace with oxy-fuel environment. 
The ABAQUS finite element program has been used to perform numerical simulation of creep analysis for both untreated and HDI treated refractory materials. Creep user subroutines have been developed in conjunction with a mathematical creep model for both untreated and HDI treated refractory materials. 


\section{ACKNOWLEGEMENTS}

First of all, I would like to thank my parents and sisters for their inspiration and support during the completion of this project. I am also greatly indebted for their love and affection.

I would like to express my sincere gratitude to Dr. John Ed Sneckenberger for his invaluable support, guidance and knowledge. This project would not have been possible without his encouragement, valuable suggestions and motivation.

Much appreciation is extended to Mr. Terry N. Tiegs and Mr. James G. Hemrick of Oak Ridge National Laboratory (ORNL), Mr. Paul Boscarino, Mr. Robert J. Harmon and Mr. Larry Stover of Minteq International, Inc., for their valuable information concerning High Density Infrared (HDI) treatment and refractory plunger models.

I would also like to thank my committee members, Dr. Larry Banta, Dr. Jacky Prucz and Dr. Bruce Kang, for their suggestions and review on my thesis.

Thanks to my roomies, officemates and friends for their support and encouragement, which made my life easier at Morgantown.

I thank Mr. Jeff Herholdt of the West Virginia Development Office (WVDO), who sponsors the Projects with Industry (PWI) program and its Glass Industry Assistance Project (GIAP), for the financial support that made this research project possible. 


\section{TABLE OF CONTENTS}

ABSTRACT ii

ACKNOWLEGEMENTS iv

TABLE OF CONTENTS $\quad$ V

LIST OF FIGURES Ix ix

LIST OF TABLES X xii

LIST OF SYMBOLS xiii

CHAPTER 1. INTRODUCTION 1

1.1 Background 1

1.2 Enhanced Refractories for Glass Melting Furnace 2

1.3 Research Objectives $\quad 4$

CHAPTER 2. LITERATURE REVIEW 5

2.1 Assessment of Degradation Mechanisms of Refractories in Glass Industry 5

2.2 Creep Modeling of Ceramic Refractory Materials 5

$\begin{array}{ll}2.3 \text { Strengthening of Ceramic Materials } & 6\end{array}$

2.3.1 Shot Peening Technology 6

2.3.2 High Density Infrared (HDI) Technology 6

CHAPTER 3. HIGH DENSITY INFRARED TREATMENT 7

$\begin{array}{ll}3.1 \text { Introduction } & 7\end{array}$

3.2 Importance of HDI Technology to Glass Melting Industry 9

$\begin{array}{ll}3.3 \text { Experimental Procedure at ORNL } & 10\end{array}$

$\begin{array}{lr}3.4 \text { Successful Applications } & 10\end{array}$ 


\section{CHAPTER 4. CREEP MECHANISM AND CREEP MODEL}

VALIDATION 12

$\begin{array}{ll}4.1 \text { Introduction } & 12\end{array}$

$\begin{array}{ll}4.2 \text { Creep Mechanism } & 12\end{array}$

4.3 Critical Parameters of an Enhanced Refractory in Glass Furnace 13

$\begin{array}{ll}4.4 \text { Creep Models } & 14\end{array}$

4.5 Creep Dependence on Stress and Temperature 15

4.5.1 Interpretation of Figure 4.2 and Figure 4.3 16

4.6 High Density Infrared Treated Refractory Material Versus Untreated $\begin{array}{ll}\text { Refractory Material } & 16\end{array}$

4.6.1 Interpretation of Figure 4.4, Figure 4.5 and Figure 4.6 17

$\begin{array}{ll}4.7 \text { Validation of Creep Equation } & 17\end{array}$

$\begin{array}{ll}\text { 4.7.1 Experimental Creep Data } & 18\end{array}$

$\begin{array}{ll}\text { 4.7.2 Curve Fit of Experimental Data } & 18\end{array}$

CHAPTER 5. FINITE ELEMENT APPROACH FOR CREEP ANALYSIS 19

$\begin{array}{lll}5.1 \text { Introduction } & 19\end{array}$

5.2 Principles and Analysis Considerations 19

5.3 Procedure for Creep Analysis 20

$\begin{array}{lll}\text { 5.3.1 Static Analysis } & 20\end{array}$

$\begin{array}{ll}\text { 5.3.2 Visco Analysis } & 20\end{array}$

5.4 Reliability of Creep Analysis $\quad 21$

5.4.1 Finite Element Modeling of a Refractory Brick 21

5.4.2 Finite Element Analysis and Validation 22 


\section{CHAPTER 6. REFRACTORY MATERIAL WITHOUT HDI

6.1 Introduction 25

6.2 Design Considerations for Untreated Refractory Material 25

6.2.1 Finite Element Model of Untreated Refractory Material 25

6.2.1.1 Geometry and Material Model 25

$\begin{array}{lll}\text { 6.2.1.2 Boundary Conditions } & 28\end{array}$

6.2.2 Creep Curve Behavior 31

6.2.3 Creep Strain Dependence on Stress 35

6.2.3.1 Creep Strain Dependence on Normal Stress 37

6.2.3.2 Creep Strain Dependence on Shear Stress 38

6.2.4 Creep Strain Dependence on Temperature 39

CHAPTER 7. REFRACTORY MATERIAL WITH HDI TREATMENT 43

$\begin{array}{lll}7.1 & \text { Introduction } & 43\end{array}$

7.2 Design Considerations for HDI Treated Refractory Material 43

7.2.1 Finite Element Model of Untreated Refractory Material 43

7.2.1.1 Geometry and Material Model 43

$\begin{array}{ll}\text { 7.2.1.2 Boundary Conditions } & 45\end{array}$

7.2.2 Creep Curve Behavior 46

7.2.3 Creep Strain Dependence on Stress 48

7.2.3.1 Creep Strain Dependence on Normal Stress 51

7.2.3.2 Creep Strain Dependence on Shear Stress 52

7.2.4 Creep Strain Dependence on Temperature 53

7.2.5 Limitations of the Untreated Refractory Material 56 
8.1 Results Comparison $\quad 57$

$\begin{array}{ll}\text { 8.1.1 Creep Curves Comparison } & 57\end{array}$

8.1.1.1 Extension of Useful Life of Refractory Material 57

8.1.2 Stress Dependence Curves Comparison 58

8.1.2.1 Normal Stress Dependence Curves Comparison 58

8.1.2.1.1 More Glass Output $\quad 58$

8.1.2.2 Shear Stress Dependence Curves Comparison 59

8.1.2.2.1 Increased Productivity $\quad 59$

8.1.3 Temperature Dependence Curves Comparison 60

8.1.3.1 Enhanced Refractory Material for Oxy-Fuel Furnace $\quad 60$

CHAPTER 9. CONTRIBUTIONS AND FUTURE RESEARCH 62

$\begin{array}{ll}9.1 \text { Contributions } & 62\end{array}$

9.2 Future Research 63

$\begin{array}{ll}\text { REFERENCES } & 64\end{array}$

APPENDIX A. Input File and Creep Subroutine of Brick Model 67

APPENDIX B. Input File and Creep Subroutine of Untreated Plunger Model 70

APPENDIX C. Input File and Creep Subroutine of HDI Treated Plunger Model 74 


\section{LIST OF FIGURES}

Figure 1.1 Refractories Commonly used in a Soda-Lime Glass Melt Furnace 3

$\begin{array}{lll}\text { Figure } 3.1 & \text { Principle of HDI Technology } & 7\end{array}$

Figure 3.2 HDI Treatment Processing Facility at ORNL 8

Figure $3.3 \quad$ Flat Glass Production Furnace $\quad 9$

Figure 4.1 Three Parts of a Typical Creep vs Time Curve 13

Figure 4.2 Stress Dependence of Creep Strain Rate 15

Figure 4.3 Temperature Dependence of Creep Strain 15

Figure 4.4 Comparative Creep Curve of HDI Treated Material and Untreated 16 Material

Figure 4.5 Comparative Stress Dependence of HDI and Untreated Materials 17

Figure 4.6 Comparative Temperature Dependence Curves of HDI and Untreated 17 Materials

Figure 4.7 Comparative Experimental and Mathematical Creep Curves 18

Figure 5.1 Finite Element Model of Standard Brick 21

Figure 5.2 Creep Strain Distribution after 50 Hours 22

Figure 5.3 Finite Element Analysis Validation 24

Figure 6.1 Finite Element Model of Untreated Plunger 27

$\begin{array}{lll}\text { Figure 6.2 Loading Profile in a Plunger } & 28\end{array}$

Figure 6.3 Viscosity Variation with Temperature 30

Figure 6.4 Viscosity Variation with Temperature of Soda-Lime Glass 31

Figure 6.5 Creep Strain Contour after 500 Hours 32

Figure 6.6 Creep Curve of Untreated Plunger 34 
Figure 6.7 Creep Strain Contour for Applied Stresses of $\sigma_{w}=6.5 \mathrm{psi}$ and $\tau_{w}=1.76 \mathrm{psi}$ at $2060^{\circ} \mathrm{F}$

Figure 6.8 Creep Strain Contour for Applied Stresses of $\sigma_{w}=7$ psi and $\tau_{w}=2$ psi at $2060{ }^{\circ} \mathrm{F}$

Figure 6.9 Creep Strain Contour for Applied Stresses of $\sigma_{w}=8.5$ psi and $\tau_{w}=2.75$ psi at $2060^{\circ} \mathrm{F}$

Figure 6.10 Creep Strain Contour for Applied Stresses of $\sigma_{w}=10 \mathrm{psi}$ and $\tau_{w}=3.5$ psi at $2060^{\circ} \mathrm{F}$

Figure 6.11 Creep Strain Dependence on Normal Stress

Figure 6.12 Creep Strain Dependence on Shear Stress

Figure 6.13 Creep Strain Contour at $2010^{\circ} \mathrm{F}$ after 500 Hours

Figure 6.14 Creep Strain Contour at $2060^{\circ} \mathrm{F}$ after 500 Hours

Figure 6.15 Creep Strain Contour at $2200^{\circ} \mathrm{F}$ after 500 Hours

Figure 6.16 Creep Strain Dependence on Temperature

Figure 7.1 Finite Element Model of HDI Treated Plunger

Figure 7.2 Magnified View of Finite Element Model

Figure 7.3 Creep Strain Contour after 500 Hours

Figure 7.4 Creep Curve of HDI Treated Plunger

Figure 7.5 Creep Strain Contour for Applied Stresses of $\sigma_{w}=6.5$ psi and $\tau_{w}=1.76 \mathrm{psi}$ at $2060^{\circ} \mathrm{F}$

Figure 7.6 Creep Strain Contour for Applied Stresses of $\sigma_{w}=7$ psi and $\tau_{w}=2$ psi at $2060^{\circ} \mathrm{F}$

Figure 7.7 Creep Strain Contour for Applied Stresses of $\sigma_{w}=8.5$ psi and $\tau_{w}=2.75$ psi at $2060^{\circ} \mathrm{F}$

Figure 7.8 Creep Strain Contour for Applied Stresses of $\sigma_{w}=10 \mathrm{psi}$ and $\tau_{w}=3.5$ psi at $2060^{\circ} \mathrm{F}$

Figure 7.9 Creep Strain Dependence on Normal Stress

Figure 7.10 Creep Strain Dependence on Shear Stress 
Figure 7.11 Creep Strain Contour at $2010^{\circ} \mathrm{F}$ after 500 Hours

Figure 7.12 Creep Strain Contour at $2060{ }^{\circ} \mathrm{F}$ after 500 Hours

Figure 7.13 Creep Strain Contour at $2200{ }^{\circ} \mathrm{F}$ after 500 Hours

Figure 7.14 Creep Strain Dependence on Temperature

Figure 8.1 Creep Curves Comparison of HDI and Untreated Refractory Materials

Figure 8.2 Creep Strain Dependence on Normal Stress of HDI and Untreated Refractory Materials

Figure 8.3 Creep Strain Dependence on Shear Stress of HDI and Untreated Refractory Materials

Figure 8.4 Creep Strain Dependence on Temperature of HDI and Untreated Refractory Materials 


\section{LIST OF TABLES}

Table 4.1 Critical Parameters of an Enhanced Refractory Material in Glass

Furnace

$\begin{array}{lll}\text { Table 4.2 Experimental Creep Data } & 18\end{array}$

Table 5.1 FEA Creep Strain Data 23

Table 6.1 Online Catalog Showing Standard Plunger Dimensions 26

Table 6.2 Critical Range of Key Parameters of an Enhanced Refractory Plunger 29

Table 6.3 FEA Creep Strain Data $\quad 32$

Table 6.4 Creep Strain Data with Variation of Normal Stress $\left(\sigma_{w}\right)$ at $2060{ }^{\circ} \mathrm{F} \quad 37$

Table 6.5 Creep Strain Data with Variation of Normal Stress $\left(\sigma_{w}\right)$ at $2010^{\circ} \mathrm{F} \quad 38$

Table 6.6 Creep Strain Data with Variation of Shear Stress $\left(\tau_{w}\right)$ at $2060^{\circ} \mathrm{F} \quad 38$

Table 6.7 Creep Strain Data with Variation of Shear Stress $\left(\tau_{w}\right)$ at $2010^{\circ} \mathrm{F} \quad 39$

Table 6.8 Creep Strain Data after 50 Hours 41

Table 6.9 Creep Strain Data after 250 Hours 41

Table 6.10 Creep Strain Data after 500 Hours 42

$\begin{array}{lll}\text { Table 7.1 } & \text { FEA Creep Strain Data } & 47\end{array}$

Table 7.2 Creep Strain Data with Variation of Normal Stress $\left(\sigma_{w}\right)$ at $2060{ }^{\circ} \mathrm{F} \quad 51$

Table 7.3 Creep Strain Data with Variation of Normal Stress $\left(\sigma_{w}\right)$ at $2010{ }^{\circ} \mathrm{F} \quad 51$

Table 7.4 Creep Strain Data with Variation of Shear Stress $\left(\tau_{w}\right)$ at $2060^{\circ} \mathrm{F} \quad 52$

Table 7.5 Creep Strain Data with Variation of Shear Stress $\left(\tau_{w}\right)$ at $2010^{\circ} \mathrm{F} \quad 52$

Table 7.6 Creep Strain Data after 50 Hours 55

Table 7.7 Creep Strain Data after 250 Hours 55

Table 7.8 Creep Strain Data after 500 Hours 55 


\section{LIST OF SYMBOLS}

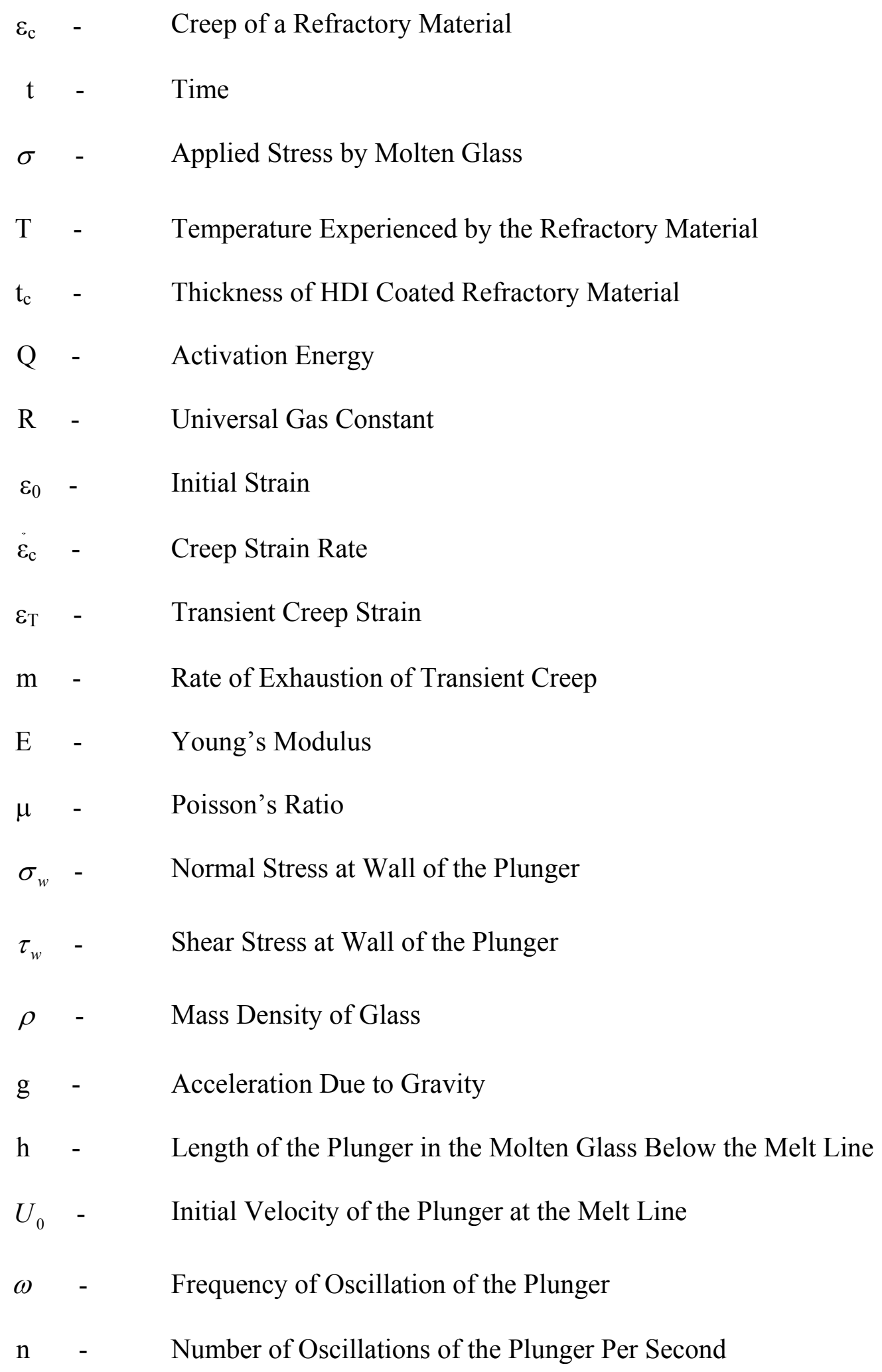


$\mu \quad-\quad$ Coefficient of Viscosity of the Molten Glass

a1, b1, c1 - Material Constants of a Substrate Material

a2, b2, c2 - Material Constants of a Coating Material 


\section{CHAPTER 1. INTRODUCTION}

\subsection{Background}

A large amount of natural gas is expended while melting glass in the glass industry ${ }^{1}$. Unfortunately, degradation of furnace refractories decreases the performance of the furnace due to penetration of molten glass, which is caused by porosity of the refractory material and corrosion by the molten glass ${ }^{4}$. Materials used for furnace refractory vary from common firebricks to highly specialized materials for specific environments.

Refractory materials play a crucial role in glass melting industries. There is an ongoing research at Oak Ridge National Laboratory (ORNL) to develop new high performance refractory materials as well as surface treatment technologies for refractory materials to extend the life of furnaces for glass melting ${ }^{5}$. Improved refractory materials will also reduce heat losses from furnaces, thereby reducing the energy required for industrial heating processes.

Furnace designers recognize that increased optimization of furnace design through advanced refractories is needed as glass production furnaces are driven toward greater output and increased energy efficiency ${ }^{5}$. The conversion to oxy-fuel from traditional airfuel firing is one means to meet the above mentioned objectives. Refractories for both oxy-fuel and air-fuel fired furnaces are subjected to high temperatures and stresses during service and may appreciably creep if the refractory material is not creep resistant ${ }^{5}$. Economically viable breakthroughs in refractory research are needed in corrosion/erosion resistance, improved strength, improved stiffness, reduced surface porosity and last but not the least increased creep resistance ${ }^{4}$.

As a method to improve the performance of refractory materials, ORNL is utilizing High Density Infrared (HDI) technology, which is relatively new to the materials processing, and is gradually being used in coatings and surface modifications of refractory materials ${ }^{10}$. To date, HDI treatment has mainly been applied to the treatment 
of metals. However, recently it has been applied to the surface treatment of ceramic

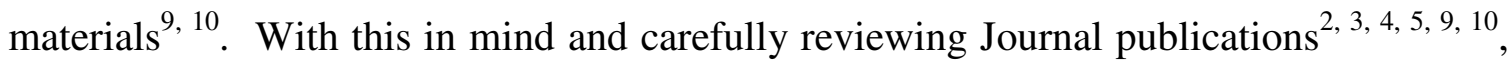
this thesis is focused on the study of creep resistance effectiveness of HDI treatment of refractory material.

The essential requirement for furnace designers and manufacturers is to have appropriate engineering creep models for predicting the structural integrity of the

Furnace. According to the information available from Journals ${ }^{2,5}$, published engineering creep data are essentially non-existent for almost all commercially available refractories used for glass furnaces. Thus, there is a need to build a creep model for the enhanced refractory material studied. Current research funded by the West Virginia Development Office (WVDO) Glass Industry Assistance Project in association with an ORNL ongoing applied refractory project is focused to study creep resistance reliability of HDI treatment of refractory material to promote HDI treated refractory material as an enhanced furnace material.

\subsection{Enhanced Refractories for Glass Melting Furnace}

Ceramic refractories are widely found in high-temperature, chemically demanding applications. These materials are critical construction materials for glass melting industry, which is one of the energy intensive industries ${ }^{4}$. Ceramic refractories have exceptional properties such as high hardness enabling them to wear less and last longer, ability to operate at very high temperatures because of their high melting temperatures and capacity to withstand very harsh and corrosive environments such as acids, alkalis and organic solvents ${ }^{14}$. These refractory materials have remained largely unchanged for many years. The degradation of these materials due to penetration, corrosion and creep failure by molten glass demands the pursuit of new refractory materials. In the process of exploring new techniques for enhancing the existing materials, ORNL developed a unique method called HDI treatment for surface modification of ceramic refractory materials. However, this method was mainly applied to the surface treatment of metals 
before exploring its application to ceramics to reduce surface porosity and reduce molten glass penetration ${ }^{9,10}$.

The term enhanced refractory material refers to the fact that HDI treatment is employed to enhance the material properties of existing commercial refractories. The enhanced refractory material is being proved by ORNL to have better corrosion resistance and reduced surface porosity. Hence it could be a candidate refractory material in use for Oxyfuel technology in the glass industry.

In the glass industry, alumina-zirconia-silica (AZS) refractories have been used for many years for glass contact applications. Previous work at the ORNL in association with University of Missouri Rolla (UMR) has shown that corrosion resistance is better with increasing zirconia content and also has demonstrated that zirconia-rich coatings can be formed on the surfaces of AZS refractories using HDI thermal treatment ${ }^{10}$. Typical uses of AZS refractory materials for sidewall and bottom blocks are shown in the Figure 1.1. Other uses include expendable feeder parts such as plungers, feeder tubes, spouts and orifice rings.

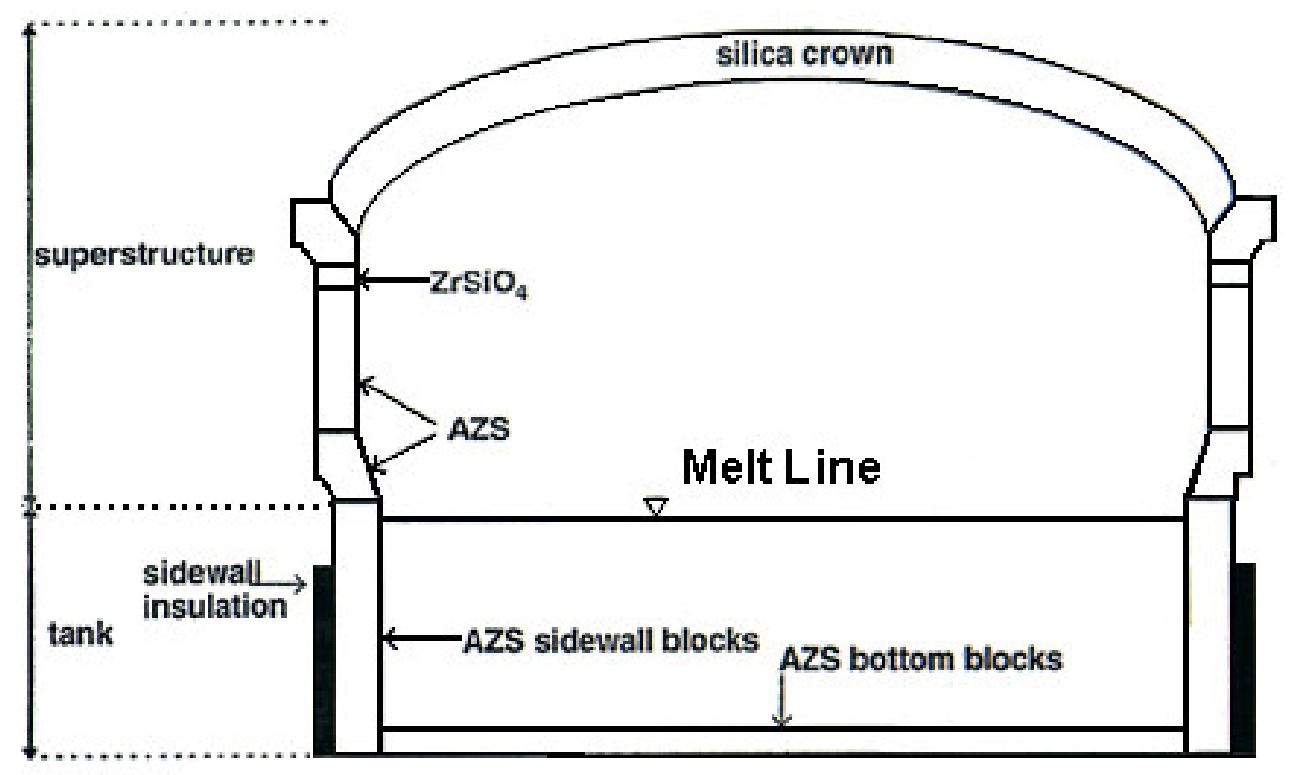

Figure 1.1 Refractories Commonly Used in a Soda-Lime Glass Melt Furnace 


\subsection{Research Objectives}

Comparative creep curves of both untreated and HDI treated refractory materials have to be developed with appropriate mathematical creep models. With the information available from creep curves, creep resistance effectiveness of HDI treatment has to be determined. Temperature and stress dependence of creep strain are also explored to account for the shift of conventional natural gas firing to oxy-fuel firing. An attempt is made to predict better material constants for the mathematical creep model being employed to study the creep response of untreated refractory material. The material constants of the untreated refractory material are obtained through regression of the experimental data collected from masters' thesis at Alfred University ${ }^{23}$. Material constants of the coating material for the HDI treated refractory material are assumed so that the coating material would have better properties compared to the substrate material. A finite element program using ABAQUS has been implemented to study the creep behavior of untreated and HDI treated refractory materials. The five main objectives of this research are as listed below.

1. Identifying critical range for key parameters that control creep strain of HDI treated refractory material such as time, temperature, stress and percentage of HDI treatment.

2. Developing creep curves for both untreated and HDI treated refractory materials.

3. Studying the creep resistance effectiveness of HDI treatment of refractory materials.

4. Determining temperature dependence of creep strain to effectively utilize the HDI treated refractory material for glass furnace with oxy-fuel environment.

5. Determining stress dependence of creep strain to see the possibility of improving furnace efficiency. 


\section{CHAPTER 2. LITERATURE REVIEW}

\subsection{Assessment of Degradation Mechanisms of Refractories in Glass Industry}

The Handbook of Industrial Refractories Technology ${ }^{16}$ published by William Andrew provides a good insight into refractory zones in the glass-melting furnace and constitutive laws of elasticity and plasticity of Ceramic materials. This information was critical in knowing the temperatures, aggressive environment and severity of damage at different refractory zones within the furnace. The reasons for degradation of refractories are due to penetration and corrosion by molten glass and creep ${ }^{4,16}$. Furnace designers recognize that increased optimization of furnace design through advanced refractories are needed as glass production furnaces are driven toward greater output and increased energy efficiency. The conversion to oxy-fuel from traditional air-fuel firing is one means to meet the above mentioned objectives. Refractories for both oxy-fuel and air-fuel fired furnaces are subjected to high temperatures and stresses during service and may appreciably creep if the refractory material is not creep resistant ${ }^{5}$. Economically viable breakthroughs in refractory research are needed in corrosion/erosion resistance, improved strength, improved stiffness, reduced surface porosity and last but not the least increased creep resistance ${ }^{4}$. The Handbook of Industrial Refractories Technology and other literature $^{20,21,22}$ describe the temperature and stress dependence of creep behavior of ceramic materials.

\subsection{Creep Modeling of Ceramic Refractory Materials}

Creep of refractories is an important mechanical property to be considered at elevated temperatures in order to understand the structural behavior of refractory material. Creep response of refractory materials has been expressed using different mathematical models. In the literature, one popular form of the creep mathematical model, defining the total percent of creep strain of ceramic materials is the Power Law ${ }^{20,21,22,23}$. The mathematical model employed in this thesis accounts for stress and temperature dependence in addition to time dependence. There are also other forms of Power Law 
mathematical models, but these models are simpler without implementing the temperature dependence of creep strain. This thesis concentrates on static analysis of a cylindrical plunger that is used to control molten glass flow in bottle and jar manufacturing. The plunger experiences multiaxial loading as well as variable thermal loading during its service life and the mathematical creep model employed is supposed to be the best available model to implement actual environment experienced by the plunger.

\subsection{Strengthening of Ceramic Materials}

The industry goal to increase the energy efficiency of glass melting by applying new technologies has led to the following surface treatment technologies for strengthening refractory materials.

\subsubsection{Shot Peening Technology}

Shot peening technology application to strengthen ceramic materials is a new advancement in materials processing investigated by researchers at Franunhofer Institute for Werkstoffmechanik, Germany ${ }^{12}$. The researchers proved dramatic increase in the near surface strength of the refractory.

\subsubsection{High Density Infrared (HDI) Technology}

Surface treatment of materials by HDI heating is also relatively new to the materials processing area. HDI treatment has mainly been applied to the treatment of metals. However, recently it has been applied to the surface treatment of ceramic materials ${ }^{9,10}$. This treatment has proved to improve corrosion resistance and reduced porosity preventing penetration by molten glass. In this thesis, the focus is to study the effectiveness of HDI treatment in controlling creep of ceramic refractory material for use in glass furnace. The emphasis is on HDI treatment because there is an extensive research going on at ORNL and extension of this treatment to all the commercial refractory materials including those used for glass melting furnace. 


\section{CHAPTER 3. HIGH DENSITY INFRARED TREATMENT}

\subsection{Introduction}

Surface treatment of materials by High Density Infrared (HDI) technology is relatively new to materials processing. The HDI technique has been applied to the surface treatment of both metals and ceramic materials ${ }^{9,10}$. The HDI material processing facility at Oak Ridge National Laboratory (ORNL) utilizes a plasma arc lamp to produce extremely high-power densities of up to $3.5 \mathrm{KW} / \mathrm{cm}^{2}$. See Figure 3.1. A controlled and contained plasma generated between two tungsten electrodes within a water-cooled quartz tube is utilized for HDI treatment of materials. The plasma arc generated beam can be scanned across a surface of the refractory material, which can generate extremely high heating and cooling rates.

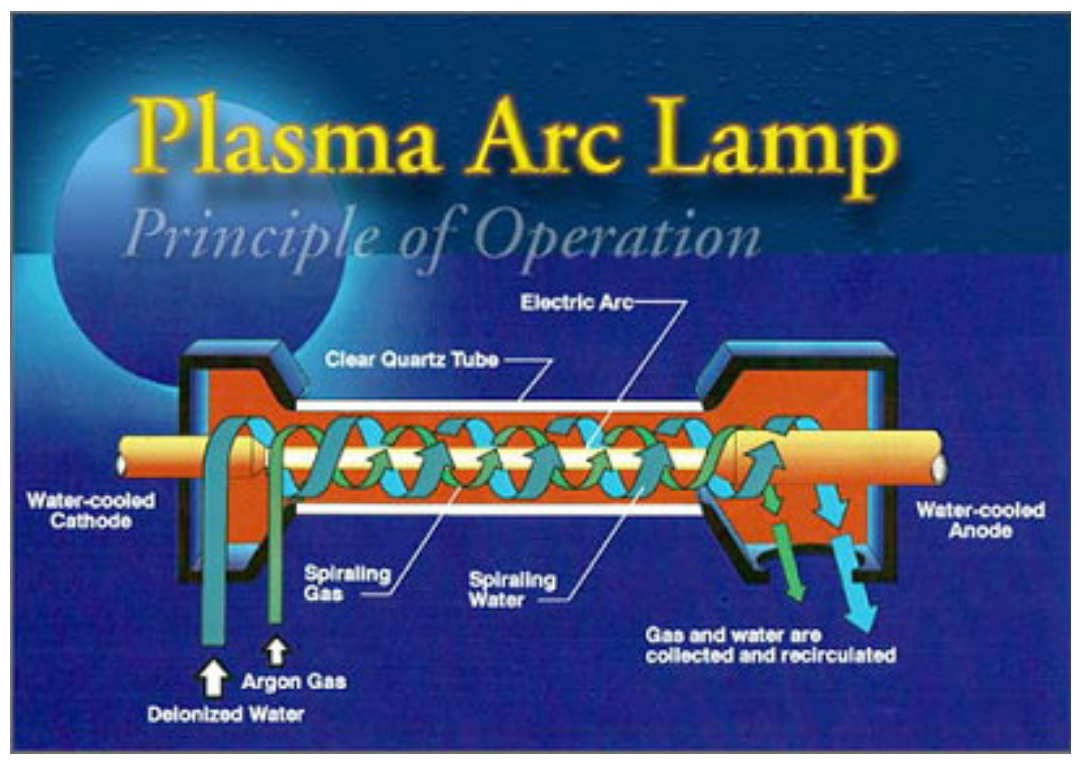

Figure 3.1 Principle of HDI Technology

Prior studies on surface treatment of refractories have examined the surface modification of refractories using short wavelength radiation about $10.6 \mu \mathrm{m}^{10}$. For the most part, these studies have relied on laser melting of the surface. With the laser technology, the area being treated is quite small in the order of with usual spot sizes less than $6 \mathrm{~mm}$ in diameter. To surface treat a large area, the laser must be scanned across the 
part at speeds of 0.05 to $0.5 \mathrm{~cm} / \mathrm{sec}$ with typically a 20 to $50 \%$ overlay from the previous scan. To do a large area requires several minutes up to hours. In addition, the overlapping of the scans also affects the resulting microstructure and causes significant micro cracking of the surface. Thus, laser melting technique is of limited interest.

On the other hand, HDI is capable of much larger area coverage, up to $35 \mathrm{~cm}$ across at a reasonable scan speed of $1 \mathrm{~cm} / \mathrm{sec}$. The radiant energy spectrum is between 0.2 and 1.4 $\mu \mathrm{m}$. This advancement in surface treatment technology makes HDI treatment a viable industrial technique that is capable of continuously processing a larger number of parts. See Figure 3.2, which shows the HDI surface treatment facility at ORNL. Earlier research at ORNL has shown that HDI processing can be applied to refractory materials to reduce surface porosity by $90 \%$ and the X-ray Diffraction of the specimen showed very little to no penetration of molten glass into the refractory $\mathrm{y}^{9,10}$.

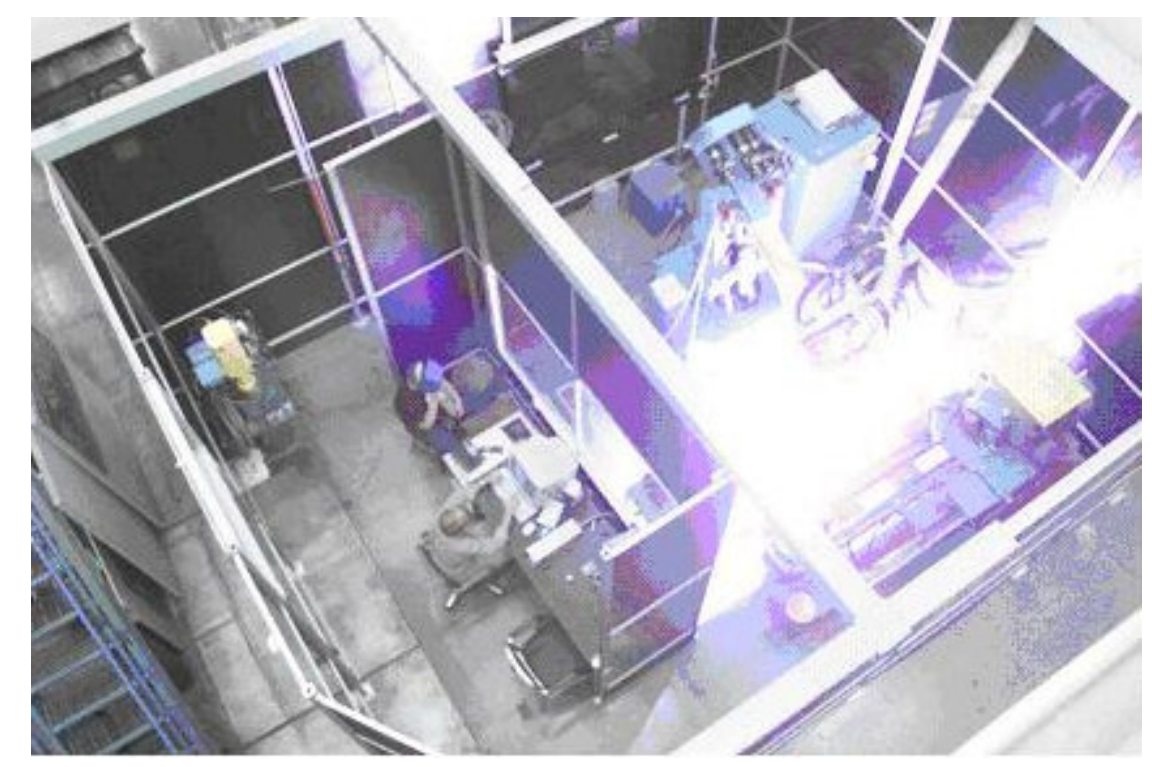

Figure 3.2 HDI Treatment Processing Facility at ORNL

The five main advantages of the HDI technology over laser technology are:

1. It can cover larger areas at scan speed of $1 \mathrm{~cm} / \mathrm{sec}$ compared to Laser technology, which has a scan speed in the range of 0.05 to $0.5 \mathrm{~cm} / \mathrm{sec}$.

2. It consists of short wavelength radiation $(0.2-1.2 \mu \mathrm{m})$ compared to $10.6 \mu \mathrm{m}$. 
3. It has ability to produce fast heating and cooling rates.

4. It is capable of attaining very high power densities of up to $3.5 \mathrm{~kW} / \mathrm{cm}^{2}$.

5. It has potential for continuous processing.

\subsection{Importance of HDI Technology to Glass Industry}

The successful extension of HDI technology to the surface treatment of ceramic materials has provided a means for enhancing material properties, such as increased corrosion resistance and reduced surface porosity of existing commercial refractory materials. The enhanced material properties of HDI treated ceramic materials make them candidate materials for use in oxy-fuel-fired furnaces. The use of oxy-fuel-fired furnaces for glass production has following four benefits ${ }^{5}$.

1. The elimination of regenerative structures shown in the Figure 3.3.

2. The $\mathrm{NO}_{\mathrm{X}}$ emission is less for oxy-fuel-fired furnaces compared to air-fuel-fired furnaces.

3. The particulate level is much less compared to that of air-fuel-fired furnaces.

4. The capital cost per ton of glass pulled is approximately $58 \%$ less for oxy-fuelfired furnaces compared to air-fuel-fired furnaces ${ }^{5}$.

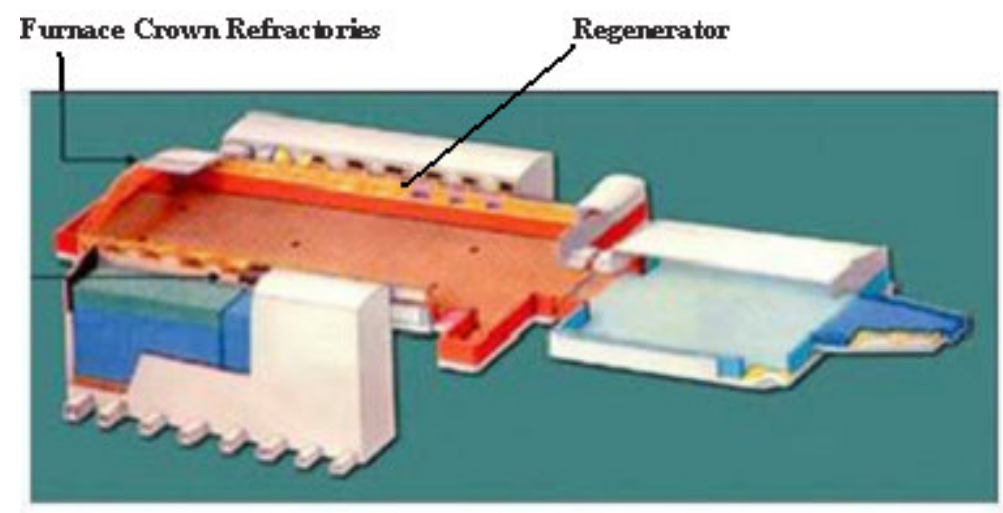

Figure 3.3 Flat Glass Production Furnace

The main disadvantage of an oxy-fuel-fired furnace is its higher operating temperature and alkali partial pressure that hasten the corrosion of refractory materials, particularly in 
silica refractories ${ }^{5}$. This disadvantage necessitates that both increased creep- and corrosion-resistant refractories be used.

In the glass industry, Alumina-Zirconia-Silica (AZS) refractories are commonly used in glass contact applications ${ }^{10}$, such as sidewall and bottom blocks of the furnace and in expendables - plungers, feeder tubes, spouts and orifice rings. HDI surface treatment of AZS refractories with Zirconia-rich coatings would extend their useful life in oxy-fuelfired furnaces.

\subsection{Experimental Procedure at ORNL}

The plasma arc lamp used in the HDI surface modification of ceramics at ORNL consists of $3.175 \mathrm{~cm}$-diameter quartz tube that is $11.5 \mathrm{~cm}$ long. The quartz tube is cooled by a film of water on the inner diameter and a flow of argon through the tube. The plasma arc is generated between two tungsten electrodes inside the tube. Figure 3.1 shows the principle of plasma arc generation. The lamp is typically configured with a reflector to produce different areas of uniform irradiance and also the distance between the lamp and the sample can be changed to vary the intensity of radiation impinging on the surface of the refractory material. However, at ORNL the lamp is operated in a stationary mode with the plasma arc beam defocused to produce a uniform irradiance over the surface of the refractory material ${ }^{9,}{ }^{10}$. Only the power of the lamp and the position of the refractory product are varied to control the irradiation intensity at the surface of the refractory material.

\subsection{Successful Applications}

The four glass industry refractories that have been surface treated using HDI at ORNL are as follows:

1. High Alumina Castable, with a composition of $88 \% \mathrm{Al}_{2} \mathrm{O}_{3}, 4 \% \mathrm{SiO}_{2}, 4 \%$ calcium aluminate cement, $4 \% \mathrm{MgO}$. 
2. Aluminosilicate, with a composition of $88 \% \mathrm{Al}_{2} \mathrm{O}_{3}, 12 \% \mathrm{SiO}_{2}$.

3. Fused cast AZS, with $33 \% \mathrm{ZrO}_{2}$ (referred to as F. C. AZS-33).

4. Cast and sintered AZS, with $20 \% \mathrm{ZrO}_{2}$ (referred to as C. S. AZS-20).

The coatings for refractories 3 and 4 above are made with slurries of $\mathrm{ZrO}_{2}\left(3 \% \mathrm{Y}_{2} \mathrm{O}_{3}\right)$ powder and ethanol. The weight of powder applied to the surface of the refractory material is estimated to produce a well bonded dense coating of Zirconia, approximately $200 \mu \mathrm{m}$ thick. 


\section{CHAPTER 4. CREEP MECHANISM AND CREEP MODEL VALIDATION}

\subsection{Introduction}

Thermal stresses and creep would result in the failure of refractory materials. If the thermal stresses and creep are calculated for different controlling parameters such as temperature, time, applied stress and percent of HDI treatment, it may be possible to optimize these parameters to enhance the life expectancy of the refractories, and therefore, the furnace.

The operating life of a furnace will last until the refractories need replacement due to mechanical failure and corrosion. The lifetime of the glass-melting furnace largely depends on the thermo-mechanical behavior of the refractory that forms the furnace. Corrosion resistance, mechanical strength, maximum service temperature, increased creep resistance and resistance to thermal shock are some of the factors that are important in the selection of the refractories for different parts of the furnace ${ }^{23}$.

Refractories are subject to heat-up stresses, long term deformations under steady state temperature, and applied stresses. Stresses develop due to temperature gradients and restraint of a structural steel framework.

\subsection{Creep Mechanism}

Creep of refractories is a mechanical phenomenon that plays an important role in understanding the structural behavior of the refractory lining system ${ }^{22}$. Refractories are often in operation under stress at elevated temperatures for considerable time periods. Refractory creep rate increases at high temperatures. It is important to understand high temperature creep behavior in order to estimate the service reliability of refractory materials. The creep threshold temperature, the temperature at which refractory creep should be considered, varies among different types of refractory materials. 
The classic definition of creep is a thermally activated deformation process that occurs when materials are exposed to high temperatures ( $>0.5$ melting point) under a constant stress, resulting in permanent deformation of the material. The creep response of materials is usually expressed in three parts: primary, secondary and tertiary creep. Tertiary creep is generally not modeled since it leads quickly to failure. The primary creep and secondary creep strains are typically expressed by separate and distinct equations. The initial non-linear portion of the strain versus time curve represents primary creep. The secondary creep strain typically continues to increase linearly as a function of time.

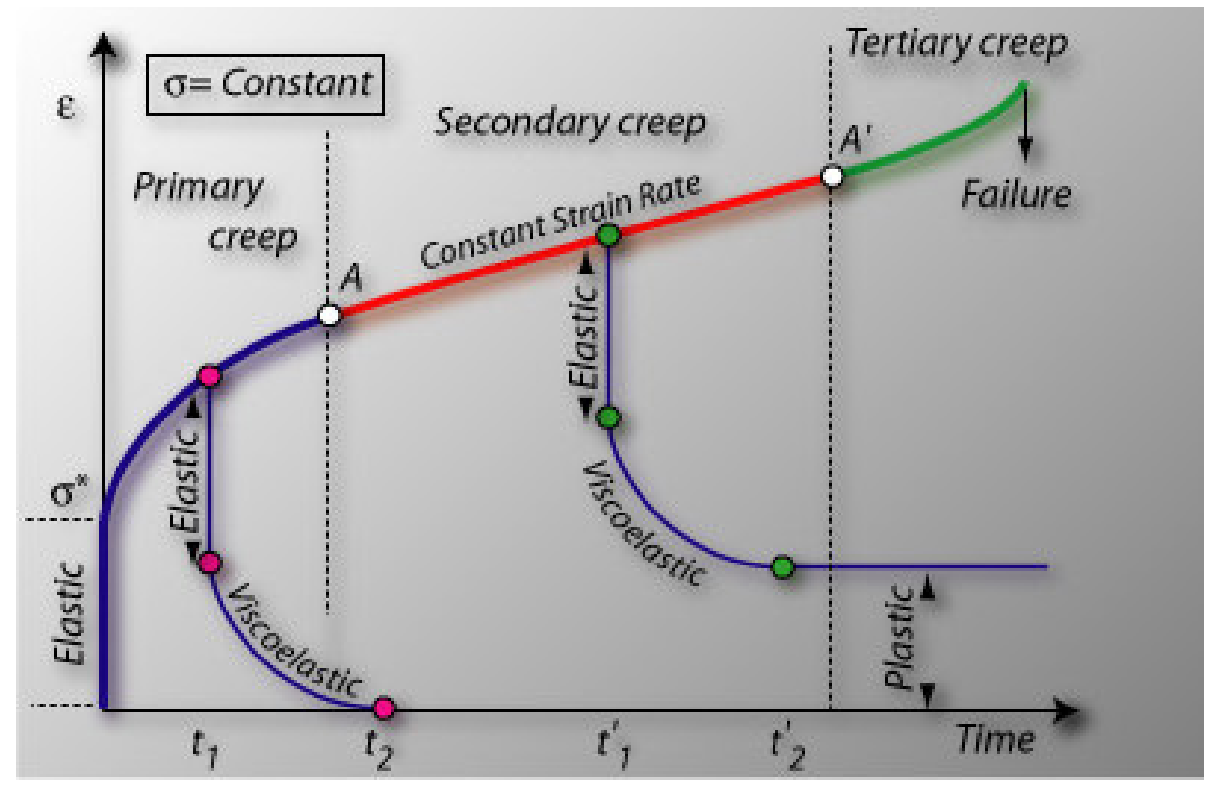

Figure 4.1 Three Parts of a Typical Creep vs Time Curve

Creep data are commonly obtained by holding a specimen at a constant stress and temperature and measuring strain vs. time. For the present finite element analysis, experimental primary creep data on fused cast alumina was obtained from a masters' thesis at Alfred University ${ }^{23}$.

\subsection{Critical Parameters of an Enhanced Refractory Material in Glass Furnace}

Table 4.1 lists the critical parameters that affect the creep behavior of an enhanced refractory material. 
Table 4.1 Critical Parameters of an Enhanced Refractory Material in Glass Furnace

\begin{tabular}{|l|c|}
\hline \multicolumn{1}{|c|}{ Critical Parameters } & Symbol (Units) \\
\hline $\begin{array}{l}\text { Creep of a Refractory } \\
\text { Material }\end{array}$ & $\varepsilon_{\mathrm{c}}$ (in./in.) \\
\hline Time & $\mathrm{t}$ (hours) \\
\hline $\begin{array}{l}\text { Applied Stress by Molten } \\
\text { Glass }\end{array}$ & $\sigma(\mathrm{psi})$ \\
\hline $\begin{array}{l}\text { Temperature Experienced } \\
\text { by the Plunger }\end{array}$ & $\mathrm{T}\left({ }^{\circ} \mathrm{F}\right)$ \\
\hline $\begin{array}{l}\text { Thickness of HDI Coated } \\
\text { Material }\end{array}$ & $\mathrm{t}_{\mathrm{c}}(\mu \mathrm{m})$ \\
\hline
\end{tabular}

\subsection{Creep Models}

The creep response of refractory materials has been expressed by many different equations. In a recent study $^{22}$, various creep equation forms were developed in the analysis of a given set of creep data to provide a comparison of the relative effectiveness of these expressions in representing transient strain-time behavior. One popular form of the primary creep equation, defining the total percent of creep strain $\left(\varepsilon_{\mathrm{c}}\right)$, is:

$$
\varepsilon_{c}=e^{a} t^{b} \sigma^{c} \exp (-Q / R T)
$$

where $\mathrm{a}, \mathrm{b}$ and $\mathrm{c}$ are constants unique to the refractory material under consideration, $\mathrm{e}$ is the constant 2.71828, $\mathrm{t}$ is the time of interest, $\sigma$ is the applied stress, $\mathrm{Q}$ is the activation energy, $\mathrm{R}$ is the universal gas constant and $\mathrm{T}$ is the absolute temperature.

A number of different types of creep curves have been recorded for ceramic materials ${ }^{21}$. With most ceramics of engineering significance, after the initial strain on loading $\left(\varepsilon_{0}\right)$, the primary stage is found in which the creep rate decreases continuously with time until a steady state or secondary stage is reached when the creep rate, $\dot{\varepsilon}_{\mathrm{c}}$, is essentially constant. Because of the difficulties of obtaining reliable strain readings as a function of time, most creep studies of ceramics have reported only the steady-state 
behavior. Nevertheless, it appears that the change in creep strain, $\varepsilon$, with time, $t$, through primary and secondary creep can be accurately described as

$$
\varepsilon=\varepsilon_{0}+\varepsilon_{\mathrm{T}}\left(1-\mathrm{e}^{-\mathrm{mt}}\right)+\dot{\varepsilon}_{\mathrm{c}} \mathrm{t}
$$

where $\varepsilon_{\mathrm{T}}$ is the primary creep and $\mathrm{m}$ relates to the rate of exhaustion of transient creep. With engineering ceramics, the primary creep is usually small and, at low strain rates, a secondary creep can be attained immediately after loading.

\subsection{Creep Dependence on Stress and Temperature}

The dependence of $\varepsilon_{\mathrm{c}}$ on the applied stress, $\sigma$, and the operating temperature, T, during long-term creep tests can be described as ${ }^{21}$

$$
\varepsilon_{\mathrm{c.}}=\mathrm{K} \sigma^{\mathrm{n}} \exp (-\mathrm{Q} / \mathrm{RT})
$$

where $\mathrm{K}$ and $\mathrm{n}$ are constants. The wide variation in the values of $\mathrm{n}$ and $\mathrm{Q}$ reported for ceramic materials can be rationalized according to the type of ceramic and test conditions.

Figures 4.2 and 4.3 show the predicted creep behavior of a ceramic refractory material as a function of stress and temperature with temperature and time as parameters. These creep behavior curves can be used to optimize the parameters, stress and temperature.

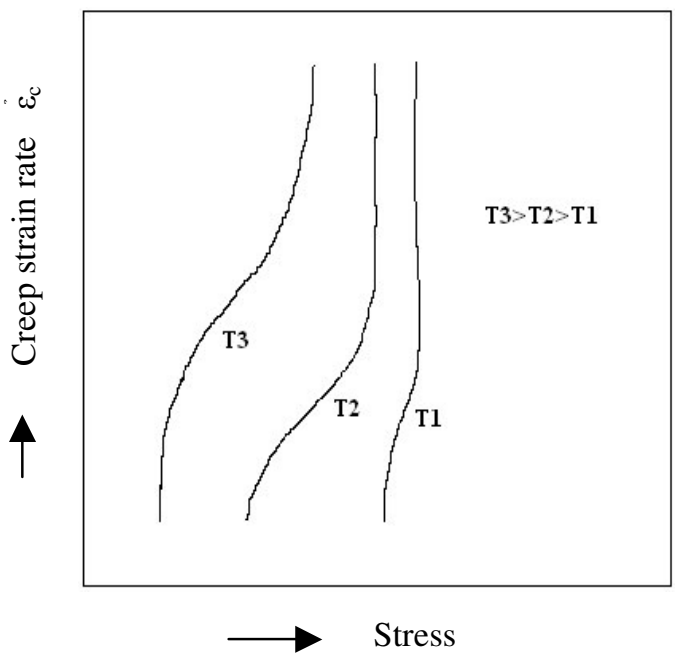

Figure 4.2 Creep Strain Rate Dependence on Stress

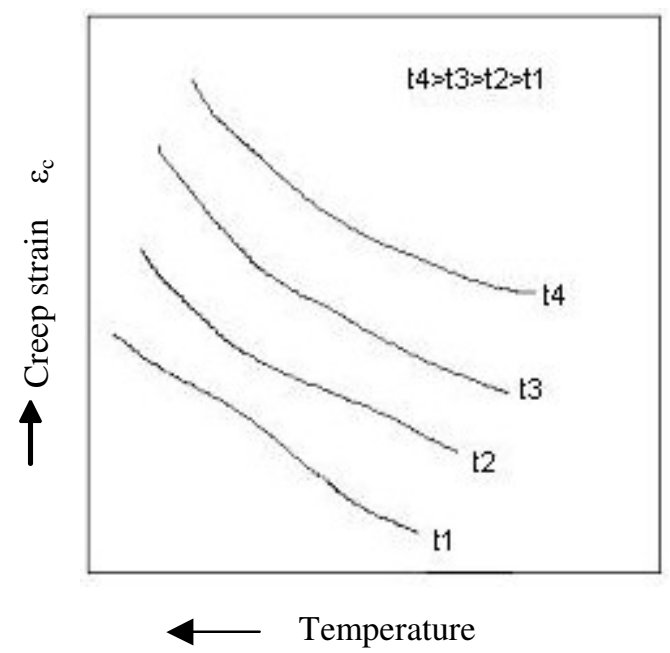

Figure 4.3 Creep Strain Dependence on Temperature 


\subsubsection{Interpretation of Figure 4.2 and Figure 4.3}

- $\mathrm{T}_{3}$, the higher operating temperature, might indicate oxy-fuel firing and $\mathrm{T}_{2}$ or $\mathrm{T}_{1}$, the lower operating temperatures, would indicate natural-gas firing.

- The glass melting furnace can be operated at higher temperatures by incorporating oxy-fuel environment. Figure 4.2 indicates the need for more creep resistant refractory materials that can withstand higher operating temperatures and more applied stress.

\subsection{High Density Infrared Treated Refractory Material Versus Untreated Refractory Material}

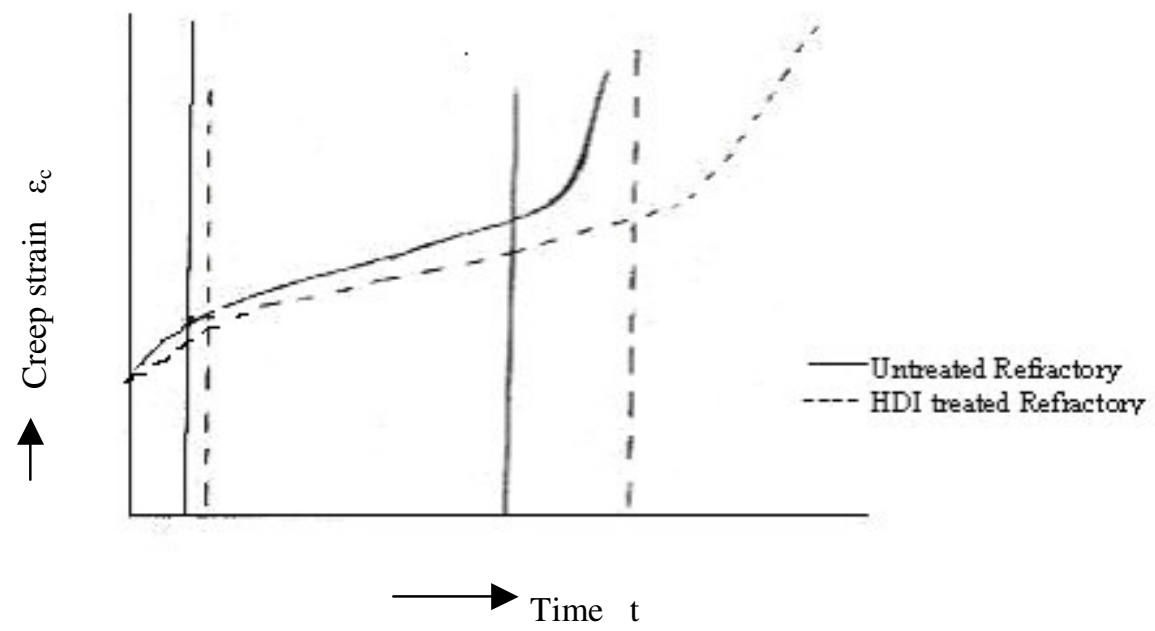

Figure 4.4. Comparative Creep Curve of HDI Treated Material and Untreated Material

Figures 4.4, 4.5 and 4.6 show the creep behavior of refractory material as a function of time, stress and temperature respectively, with surface coating, glass temperature and operating time as parameters respectively. 


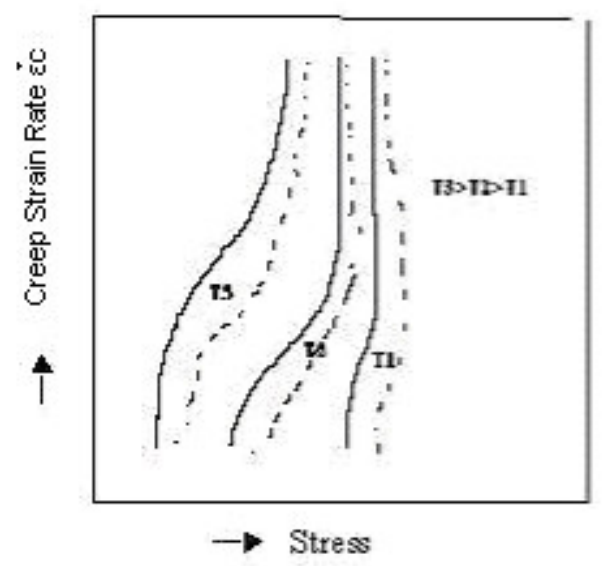

Figure 4.5 Comparative Stress Dependence Curves of HDI and Untreated Materials

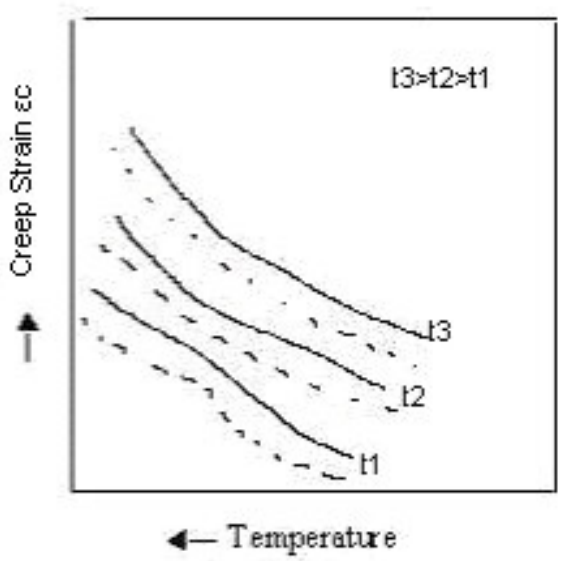

Figure 4.6 Comparative Temperature Dependence Curves of HDI and Untreated Materials

\subsubsection{Interpretation of Figure 4.4, Figure 4.5 and Figure 4.6}

- Figure 4.4 indicates the expected increased effectiveness of HDI surface treatment of refractory material (solid line). It illustrates the extended life of refractory material through HDI surface treatment.

- Figure 4.5 shows that more glass can be melted for the same creep strain rate of the refractory material. The HDI treated refractory material (dashed lines) can withstand more applied stress compared to that of untreated refractory material (solid lines) to reach the same creep strain rate.

- Figure 4.6 illustrates the possible effective usefulness of HDI treated refractory materials for oxy-fuel-fired furnace. The HDI treated refractory material (dashed lines) can withstand higher operating temperature for the same creep strain than untreated refractory material (solid lines).

\subsection{Validation of Creep Equation}

The mathematical creep model has material constants a, b and c as shown in Equation 4.1. These material constants for fused cast alumina are obtained by curve fitting procedure of the published experimental data. For the present analysis, the data has been collected from masters' thesis at Alfred University ${ }^{23}$. 


\subsubsection{Experimental Creep Data}

Table 4.2 Experimental Creep Data of Fused Cast Alumina

\begin{tabular}{|c|c|c|c|}
\hline Temperature $\left({ }^{\circ} \mathbf{F}\right)$ & Stress (psi) & Time (hrs) & $\begin{array}{l}\text { Experimental Creep } \\
\text { Strain }\left(\varepsilon_{c}\right)\end{array}$ \\
\hline \multirow{4}{*}{2600} & \multirow{4}{*}{50} & 5.0 & $1.00 \mathrm{e}-03$ \\
\hline & & 12.0 & $2.50 \mathrm{e}-03$ \\
\hline & & 24.0 & $3.50 \mathrm{e}-03$ \\
\hline & & 48.0 & $4.50 \mathrm{e}-03$ \\
\hline \multirow{4}{*}{2600} & \multirow{4}{*}{100} & 5.0 & $5.00 \mathrm{e}-03$ \\
\hline & & 12.0 & $8.00 \mathrm{e}-03$ \\
\hline & & 24.0 & $1.10 \mathrm{e}-02$ \\
\hline & & 48.0 & $1.30 \mathrm{e}-02$ \\
\hline \multirow{3}{*}{2650} & \multirow{3}{*}{50} & 7.5 & $2.00 \mathrm{e}-03$ \\
\hline & & 37.5 & $6.00 \mathrm{e}-03$ \\
\hline & & 63.0 & $7.00 \mathrm{e}-03$ \\
\hline \multirow{4}{*}{2650} & \multirow{4}{*}{150} & 4.0 & $5.00 \mathrm{e}-03$ \\
\hline & & 10.0 & $9.00 \mathrm{e}-03$ \\
\hline & & 24.0 & $1.30 \mathrm{e}-02$ \\
\hline & & 70.0 & $1.80 \mathrm{e}-02$ \\
\hline
\end{tabular}

\subsubsection{Curve Fit of Experimental Data}

The material constants obtained by curve fitting of experimental data are substituted into the mathematical model expressed by Equation 4.1 to predict the creep strain values. These values are plotted against time and compared against the experimental data creep curves for $2600^{\circ} \mathrm{F}$. The two plots for each pressure are in good agreement as shown in Figure 4.7.

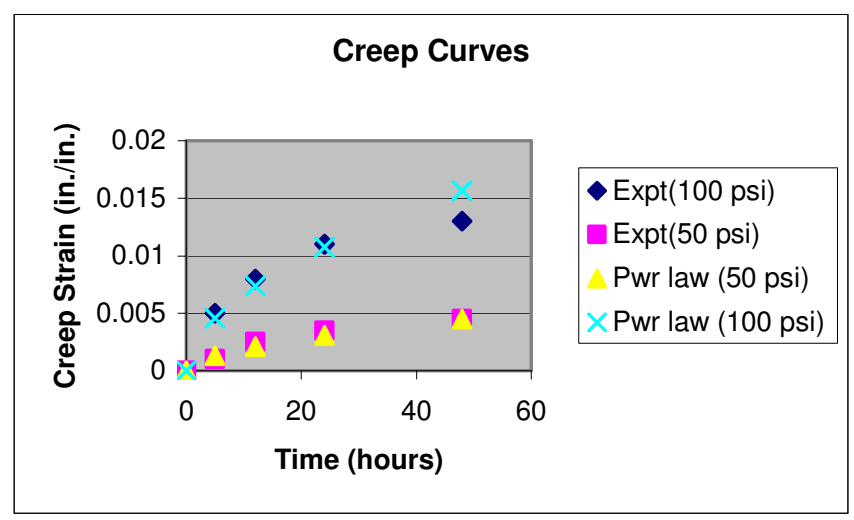

Figure 4.7 Comparative Experimental and Mathematical Creep Curves 


\section{CHAPTER 5. FINITE ELEMENT APPROACH FOR CREEP ANALYSIS}

\subsection{Introduction}

Finite element method (FEM) for creep analysis in this thesis involves primarily the implementation of creep mathematical model to study the creep resistance effectiveness of HDI treated refractory material. The present analysis involves a cylindrical plunger model that is used in the control of molten glass in the manufacture of jars and bottles. The finite element model of a plunger is an axisymmetric model with symmetric boundary conditions and loading. Two FEM models are studied. One model is an axisymmetric model of a substrate material, fused cast alumina, and the other model is an axisymmetric model of the fused cast alumina that has been HDI surface treated with Zirconia.

\subsection{Principles and Analysis Considerations}

In an axisymmetric model, the geometry and boundary conditions are assumed to be revolved $360^{\circ}$ about the vertical axis of the plunger. Plunger models are planar models in which the solver understands that the modeled half of the cross section is revolved $360^{\circ}$. By using a planar model instead of a full 3D solid model especially for nonlinear creep analysis solution, there is a significant gain in run time and cost saving.

The analysis of the plunger assumes that the plunger remains in the molten glass without oscillating. This assumption is based on the fact that the plunger does operate (oscillate) so fast that the thermal strains would remain almost the same should the plunger be considered oscillating or static at its operating position in the molten glass. The operating position in the analysis is when $3 / 4^{\text {th }}$ of the plunger is in the molten glass, which is assumed to be at $2100^{\circ} \mathrm{F}$, and the remaining portion of the plunger is at $170^{\circ} \mathrm{F}$, positioned above the molten glass level. 


\subsection{Procedure for Creep Analysis}

The FEA package considered in this thesis is ABAQUS. The ABAQUS program is implemented on a brick model by using the mathematical creep model with curve fitted values of material constants to reflect the experimental values. This procedure is considered as a means of validating the program and then, it is extended to study the HDI surface treatment of the Plunger model. The finite element analysis in this thesis involves primarily two steps, static analysis and visco analysis. The importance of these two steps is discussed as below.

\subsubsection{Static Analysis}

Since creep is a nonlinear problem, the sizes of element mesh in the model and time increment setting have a strong bearing on the convergence and accuracy of the solution $^{24}$. Initially, the loads are assumed to be applied so quickly that it involves purely elastic response, which is obtained by using the static analysis. Thus, using the known static solution and the creep data as a guide, the mesh refinement is designed.

\subsubsection{Visco Analysis}

The second step in the analysis involves creep response, which is obtained by using the visco analysis. This step is exclusively considered for creep response after allowing the structure to deform elastically so that the structure can be analyzed for elastic deformation followed by creep deformation. This procedure gives a broader understanding of the physical behavior of the structure both graphically and numerically because of the versatile finite element package. The convergence of this nonlinear mathematical creep problem can be assured by keeping the time interval, $\Delta \mathrm{t}_{\mathrm{i}}$, sufficiently small such that the variations of the stress tensor, $\Delta \sigma_{\mathrm{ij}}$, do not exceed two percent of $\sigma_{\mathrm{ij}}{ }^{26}$. 


\subsection{Reliability of Creep Analysis}

This section is about the validation of the ABAQUS program. The following information is about the finite element analysis of the brick model and the validation of creep analysis results.

\subsubsection{Finite Element Modeling of a Refractory Brick}

The specimen under consideration for validating the ABAQUS program is a fused cast alumina brick for which experimental data is collected. The specimen is 4.5 in. $x 1.5 \mathrm{in}$. $\mathrm{x} 1.5 \mathrm{in}$. with a square cross section. These dimensions are equivalent to $0.114 \mathrm{~m} \times 0.038$ $\mathrm{m} \times 0.038 \mathrm{~m}$ in SI units.

\begin{tabular}{|l|l|l|l|l|l|l|l|l|l|l|l|l|l|l|}
\hline 67 & 68 & 56 & 57 & 46 & 47 & 36 & 37 & 26 & 27 & 16 & 17 & 3 & 4 & 5 \\
\hline 76 & 69 & 58 & 59 & 48 & 49 & 38 & 39 & 28 & 29 & 18 & 19 & 2 & 1 & 6 \\
\hline 73 & 70 & 60 & 61 & 53 & 50 & 43 & 40 & 30 & 31 & 23 & 20 & 13 & 10 & 7 \\
\hline 75 & 72 & 65 & 64 & 55 & 52 & 45 & 42 & 35 & 34 & 25 & 22 & 15 & 12 & 9 \\
\hline
\end{tabular}

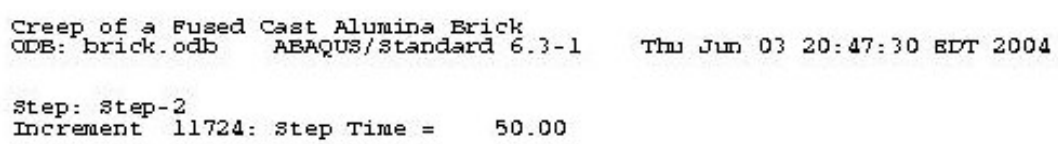

Figure 5.1 Finite Element Model of Standard Brick

Material Properties: Young's Modulus $(E)=28.0 \mathrm{e} 06$ psi

Poisson's Ratio $(\mu)=0.47$ 
Type of Element: Plane Stress Element, CPS4

Constants in FEA creep equation that is referred in Equation 4.1: $\mathrm{a}=6.74, \mathrm{~b}=0.54, \mathrm{c}=$ $1.80, \mathrm{Q}=71,500 \mathrm{cal} / \mathrm{mol}, \mathrm{R}=1.98 \mathrm{cal} / \mathrm{mol}-\mathrm{K}$.

\subsubsection{Finite Element Analysis and Validation}

The ABAQUS program was implemented for the finite element brick model. The load applied is $50 \mathrm{psi}$ at one end by holding the specimen at the other end. Refer to Appendix A. The creep analysis was carried out for a time period of 50 hours and the results obtained are compared to the results of curve fit of experimental data. Good agreement has been achieved between FEA model and curve fit data.

Figure 5.2 shows the creep strain distribution after a time period of 50 hours. The maximum strain value is about 4.92e-03 in magnitude as indicated by the blue color.

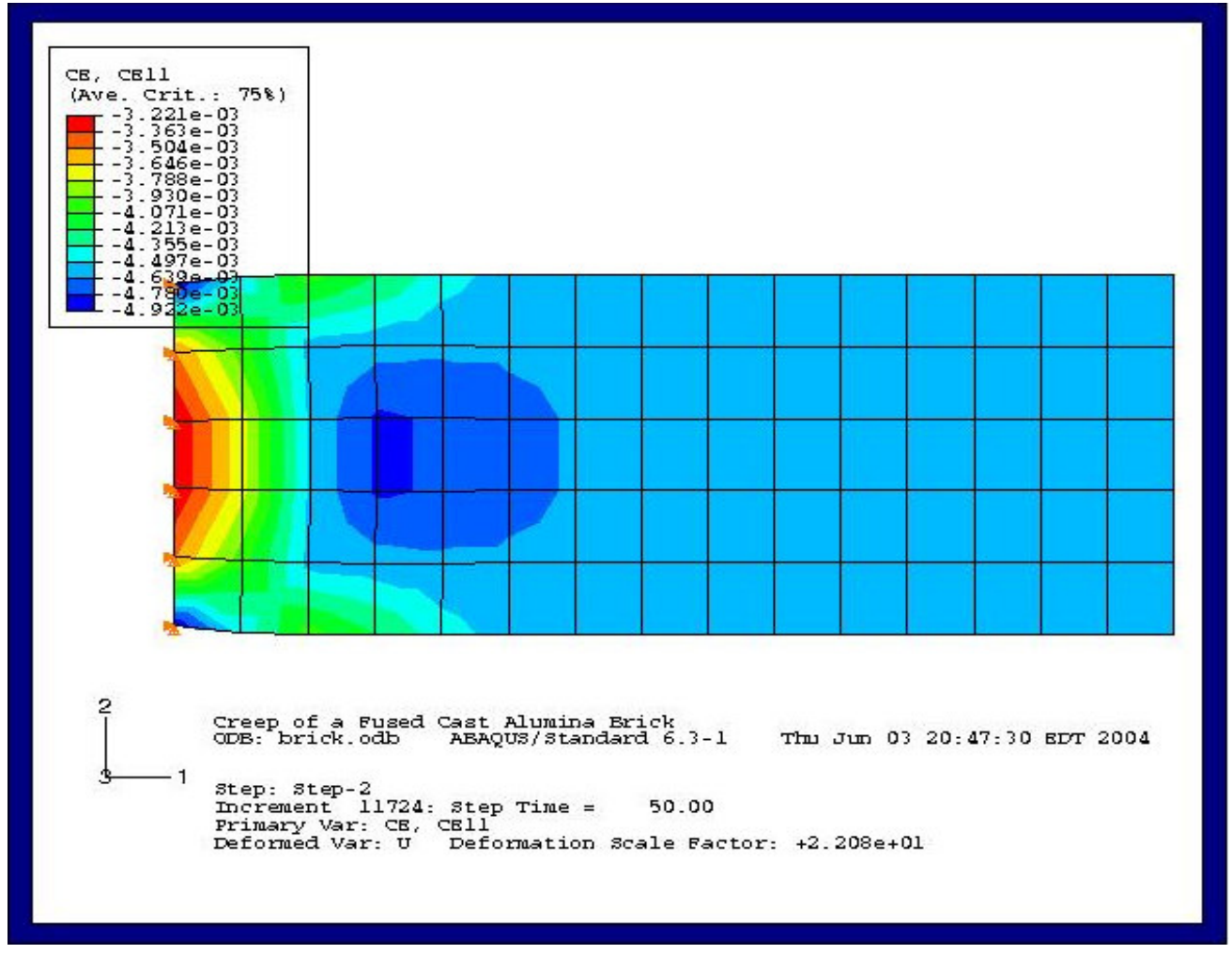

Figure 5.2 Creep Strain Distribution after 50 Hours 
The analysis results over the time period of 50 hours are tabulated in Table 5.1 and plotted against the curve fitted plot of experimental data in Figure 5.3.

Table 5.1 FEA Creep Strain Data

\begin{tabular}{|c|c|}
\hline Maximum Strain (in./in.) & Time (hrs) \\
\hline $1.85 \mathrm{e}-04$ & 0.125 \\
\hline $3.77 e-04$ & 0.463 \\
\hline $5.72 \mathrm{e}-04$ & 0.999 \\
\hline $7.64 \mathrm{e}-04$ & 1.7 \\
\hline $9.22 \mathrm{e}-04$ & 2.4 \\
\hline $1.1 \mathrm{e}-03$ & 3.33 \\
\hline $1.33 \mathrm{e}-03$ & 4.73 \\
\hline $1.53 \mathrm{e}-03$ & 6.13 \\
\hline $1.72 \mathrm{e}-03$ & 7.54 \\
\hline $1.88 \mathrm{e}-03$ & 8.94 \\
\hline $2.04 \mathrm{e}-03$ & 10.3 \\
\hline $2.18 \mathrm{e}-03$ & 11.7 \\
\hline $2.32 \mathrm{e}-03$ & 13.1 \\
\hline $2.58 \mathrm{e}-03$ & 15.9 \\
\hline $2.82 \mathrm{e}-03$ & 18.8 \\
\hline $3.25 \mathrm{e}-03$ & 24.4 \\
\hline $3.45 e-03$ & 27.2 \\
\hline $3.64 \mathrm{e}-03$ & 30 \\
\hline $3.82 \mathrm{e}-03$ & 32.8 \\
\hline $4.0 \mathrm{e}-03$ & 35.6 \\
\hline $4.16 \mathrm{e}-03$ & 38.4 \\
\hline $4.32 \mathrm{e}-03$ & 41.2 \\
\hline $4.48 \mathrm{e}-03$ & 44 \\
\hline $4.63 \mathrm{e}-03$ & 46.8 \\
\hline $4.78 \mathrm{e}-03$ & 49.6 \\
\hline $4.92 \mathrm{e}-03$ & 50 \\
\hline
\end{tabular}


Figure 5.3 shows validation of the ABAQUS program since the two curves show good agreement with each other.

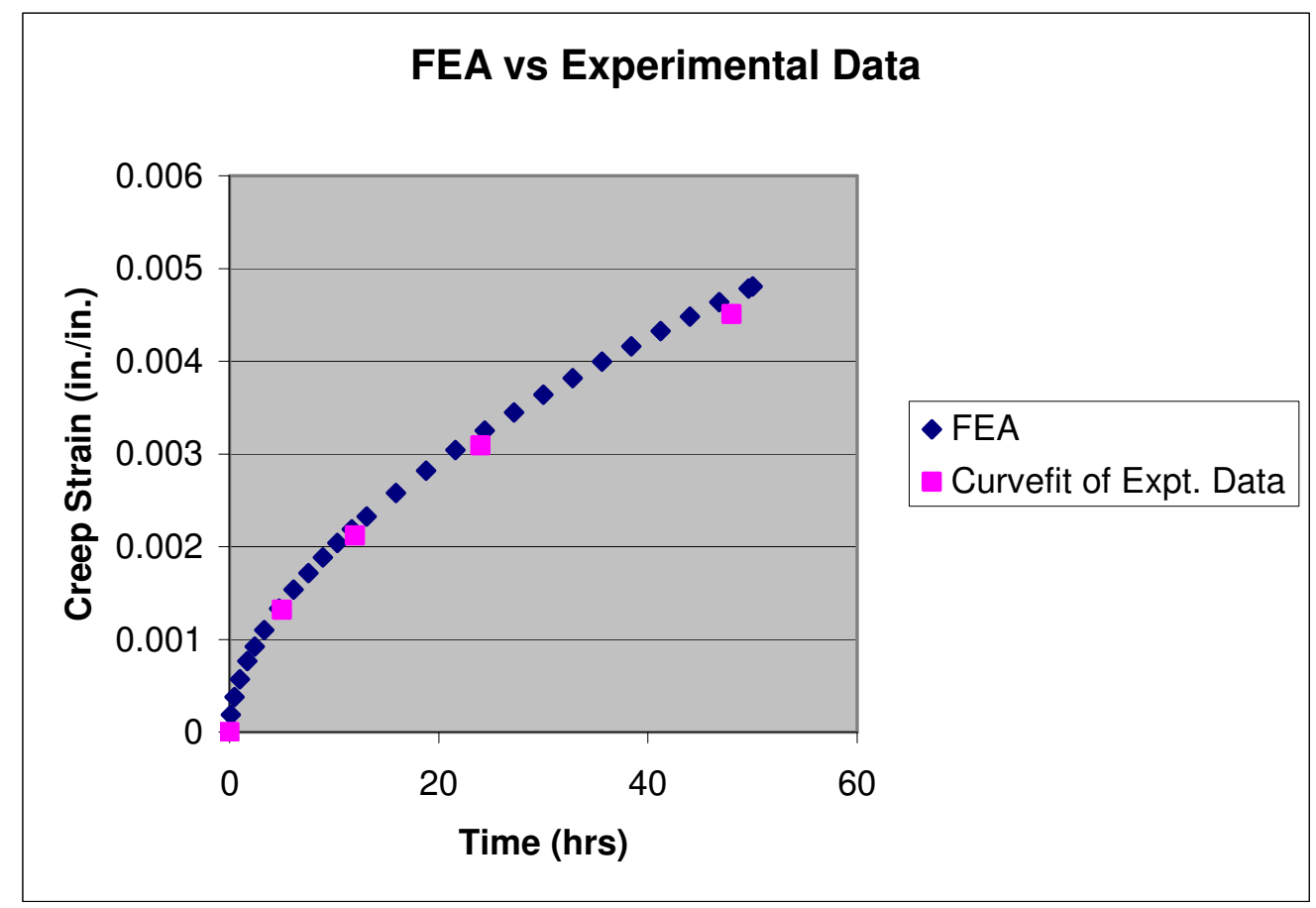

Figure 5.3 Finite Element Analysis Validation 


\section{CHAPTER 6. Refractory Material Without HDI Treatment}

\subsection{Introduction}

The refractory material considered for creep analysis is a fused cast alumina. This refractory material has dense crystal structure and little potential for glass contamination. Hence fused cast alumina is suitable for glass contact applications such as refiner, fore hearth, etc. Another material that is equally important for manufacture of expendables such as plungers, feeder tubes, spouts and orifice rings is Alumina-Zirconia-Silica (AZS). The reason for analyzing fused cast alumina is that the creep experimental data of fused cast alumina is collected from a masters' thesis at Alfred University ${ }^{23}$.

\subsection{Design Considerations for Untreated Refractory Material}

The finite element analysis of the untreated plunger is based on certain assumptions. The assumptions and as well as the steps involved to study the behavior of the plunger are as described below.

\subsubsection{Finite Element Model of Untreated Refractory Material}

The steps involved in implementing the finite element model of the untreated plunger model are explained as below.

\subsubsection{Geometry and Material Model}

The untreated plunger is a cylindrical model with assumed dimensions of $26 \mathrm{in}$. long and $3.74 \mathrm{in}$. diameter. These dimensions are taken from an online refractories catalog of Emhart Glass. See Table 6.1 for an online refractories catalog of Emhart Glass. The axisymmetric finite element model is shown in the Figure 6.1. 
Table 6.1 Online Catalog Showing Standard Plunger Dimensions

EMH/ARTGLASS Online Refractories Catalog

$\begin{array}{lll}\text { Orifice Rings } & \text { Spouts } & \text { Stirrers \& Rotor Segments } \\ \text { Plungers } & \text { Spout Assemblies } & \text { Spout Insulation \& Cements } \\ \text { Tubes } & \text { Metering Spout System } & \text { Forehearth Maintenance }\end{array}$

Plungers

Plungers - Ball Point

\begin{tabular}{|c|c|c|c|c|c|c|c|}
\hline & \multirow[b]{2}{*}{ Part \# } & \multicolumn{2}{|c|}{$x$} & \multicolumn{2}{|c|}{$Y$} & \multicolumn{2}{|c|}{$Z$} \\
\hline & & $\mathbb{N}$ & MM & IN & MM & IN & MM \\
\hline & $144-11794$ & 3 & 76 & $251 / 2$ & 648 & $23 / 4$ & 70 \\
\hline & $144-11795$ & $31 / 4$ & 83 & $251 / 2$ & 648 & $31 / 8$ & 79 \\
\hline & $144-11796$ & $31 / 2$ & 89 & $251 / 2$ & 648 & $31 / 8$ & 79 \\
\hline $9 y$ & $144-11797$ & $33 / 4$ & 95 & $251 / 2$ & 648 & $31 / 8$ & 79 \\
\hline & $144-780$ & $31 / 4$ & 83 & 26 & 660 & $31 / 8$ & 79 \\
\hline & $144-781$ & $31 / 2$ & 89 & 26 & 660 & $31 / 8$ & 79 \\
\hline & $144-3985$ & $33 / 4$ & 95 & 26 & 660 & $31 / 8$ & 79 \\
\hline & $81-4566$ & $31 / 4$ & 83 & 27 & 686 & $23 / 4$ & 70 \\
\hline
\end{tabular}




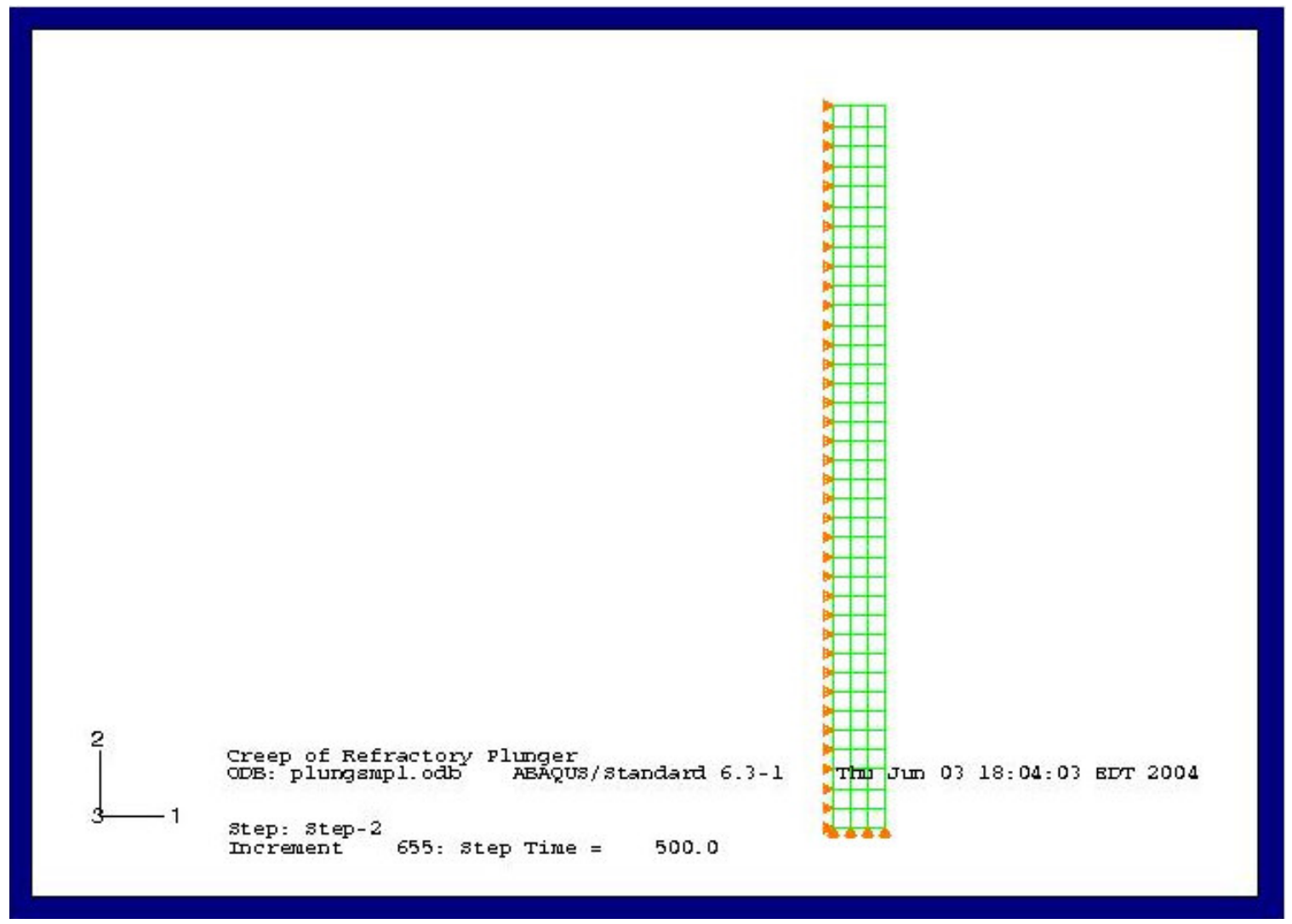

Figure 6.1 Finite Element Model of Untreated Plunger

The creep behavior is predicted by using the creep mathematical model referred in Equation 4.1. This model is implemented in the finite element program by making use of the creep subroutine program. See Appendix B. The following are the material properties of fused cast alumina. These material constants are used in the user creep subroutine program ${ }^{26}$.

Material Properties of Alumina: Young's Modulus $(E)=28.0 \mathrm{e} 6$

$$
\text { Poisson's Ratio }(\mu)=0.47
$$

Type of Element: Axisymmetric Element, CAX4

Constants in FEA creep equation that is referred in Equation 4.1: $\mathrm{a}=6.74, \mathrm{~b}=0.54, \mathrm{c}=$ $1.80, \mathrm{Q}=71500 \mathrm{cal} / \mathrm{mol}, \mathrm{R}=1.98 \mathrm{cal} / \mathrm{mol}-\mathrm{K}$. 


\subsubsection{Boundary Conditions}

In order to save the computational time only half of the model is considered. Axisymmetric boundary conditions are applied to represent the other half of the model. The plunger model is also assumed to have a constraint in the Y-direction while it reaches nearer to the orifice plate in the process of pushing the molten glass.

Plunger is subjected to a temperature of $2100{ }^{\circ} \mathrm{F}$ over $3 / 4^{\text {th }}$ of its length and the remaining portion is subjected to an assumed temperature of $170{ }^{\circ} \mathrm{F}$ as per the assumption described in Section 5.2. Axial load on the plunger is assumed to be about 30 lb. The pressures exerted by the molten glass are calculated based on an assumption of steady oscillation of a plane below a viscous fluid ${ }^{25}$. The normal and shear stresses exerted on the plunger are calculated as follows.

1. Normal Stress at Wall: Normal stress on the plunger is calculated based on the assumption that the plunger is immersed in the molten glass through $3 / 4^{\text {th }}$ of its length. The profile of the normal pressure load is as shown in Figure 6.2.

The formula ${ }^{25}$ for normal stress is,

$$
\sigma_{w}=\rho g h
$$

where $\rho$ is mass density of glass.

$\mathrm{g}$ is acceleration due to gravity.

$\mathrm{h}$ is height of the molten glass measured from the melt line.

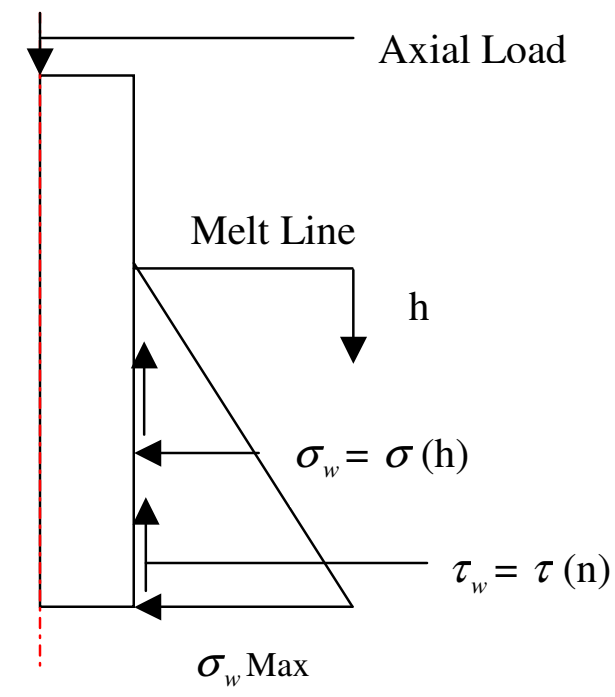

Figure 6.2 Loading Profile in a Plunger

2. Shear Stress at wall: Shear stress on the plunger is due to the traction force exerted by the molten glass. 
The formula ${ }^{25}$ used to calculate the shear stress is

$\tau_{w}=U_{0} \sqrt{\rho \omega \mu} \sin \left(\omega t-\frac{\pi}{4}\right)$

where $U_{0}$ is Initial Velocity

$\omega$ is plate frequency, $\omega=2 \pi \mathrm{n}$

$\mathrm{n}$ is number of oscillations of the plunger per second (Assume $\mathrm{n}=5$ ).

$\mu$ is coefficient of viscosity, $\mu$ of glass at about $2100^{\circ} \mathrm{F}$ is $10^{3}$ Poise. See Figures 6.3 and 6.4 for viscosity variation with temperature.

The approximate calculation of the shear stress at the wall of the plunger is about 6.36 psi.

Table 6.2 Critical Range of Key Parameters of a Coated Refractory Plunger

\begin{tabular}{|l|c|c|}
\hline Critical Parameters & Symbol (Units) & Range Assumed \\
\hline $\begin{array}{l}\text { Creep of a } \\
\text { Refractory Material }\end{array}$ & $\varepsilon_{\mathrm{c}}$ (in./in.) & - ------------ \\
\hline \multicolumn{1}{|c|}{ Time } & $\mathrm{t}$ (hours) & $0-500$ \\
\hline $\begin{array}{l}\text { Applied Stress by } \\
\text { Molten Glass }\end{array}$ & Normal Stress (psi) & $1.76-3.5$ \\
\hline $\begin{array}{l}\text { Temperature } \\
\text { experienced by the } \\
\text { Plunger }\end{array}$ & $\mathrm{T}(\mathrm{F})$ & $6.36-10$ \\
\hline $\begin{array}{l}\text { Thickness of HDI } \\
\text { coated material }\end{array}$ & $\mathrm{t}_{\mathrm{c}}(\mu \mathrm{m})$ & $2010-2200$ \\
\hline
\end{tabular}




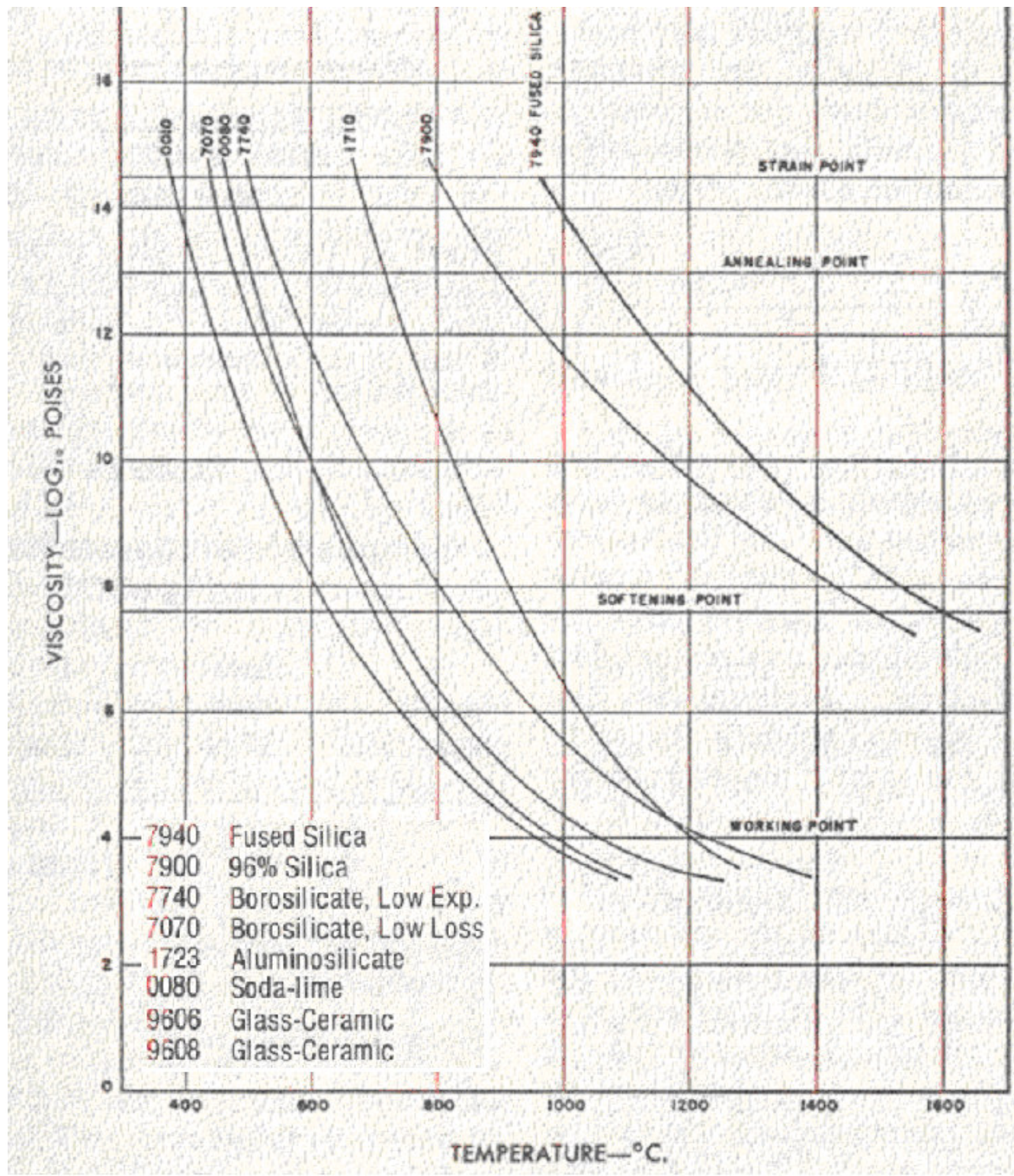

Figure 6.3 Viscosity Variation with Temperature 


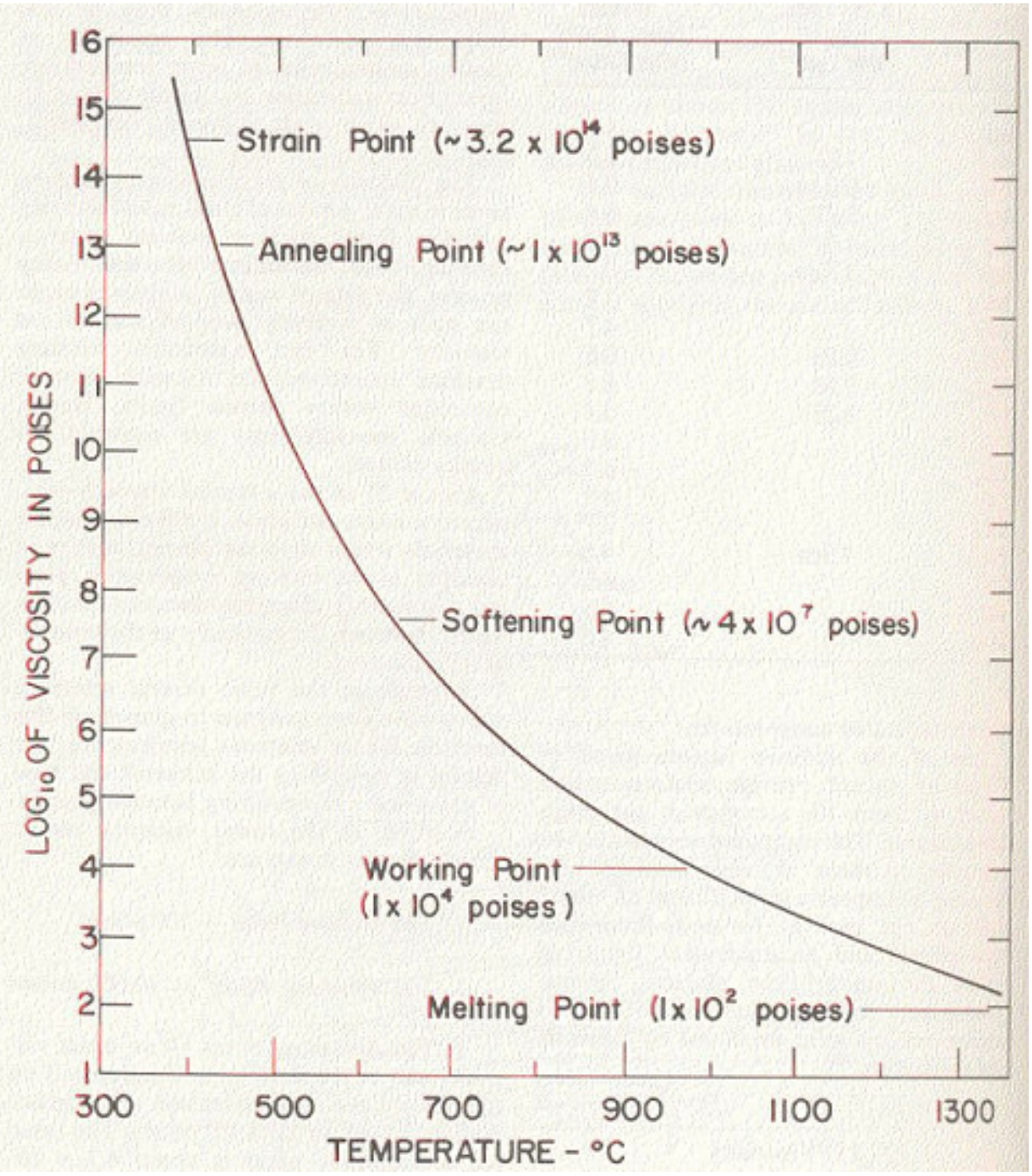

Figure 6.4 Viscosity Variation with Temperature of Soda-Lime Glass

\subsubsection{Creep Curve Behavior}

Creep behavior of untreated fused cast alumina plunger is analyzed for a period of 500 hours. Figure 6.5 shows the creep strain contour of the untreated plunger after a period of 500 hours. 


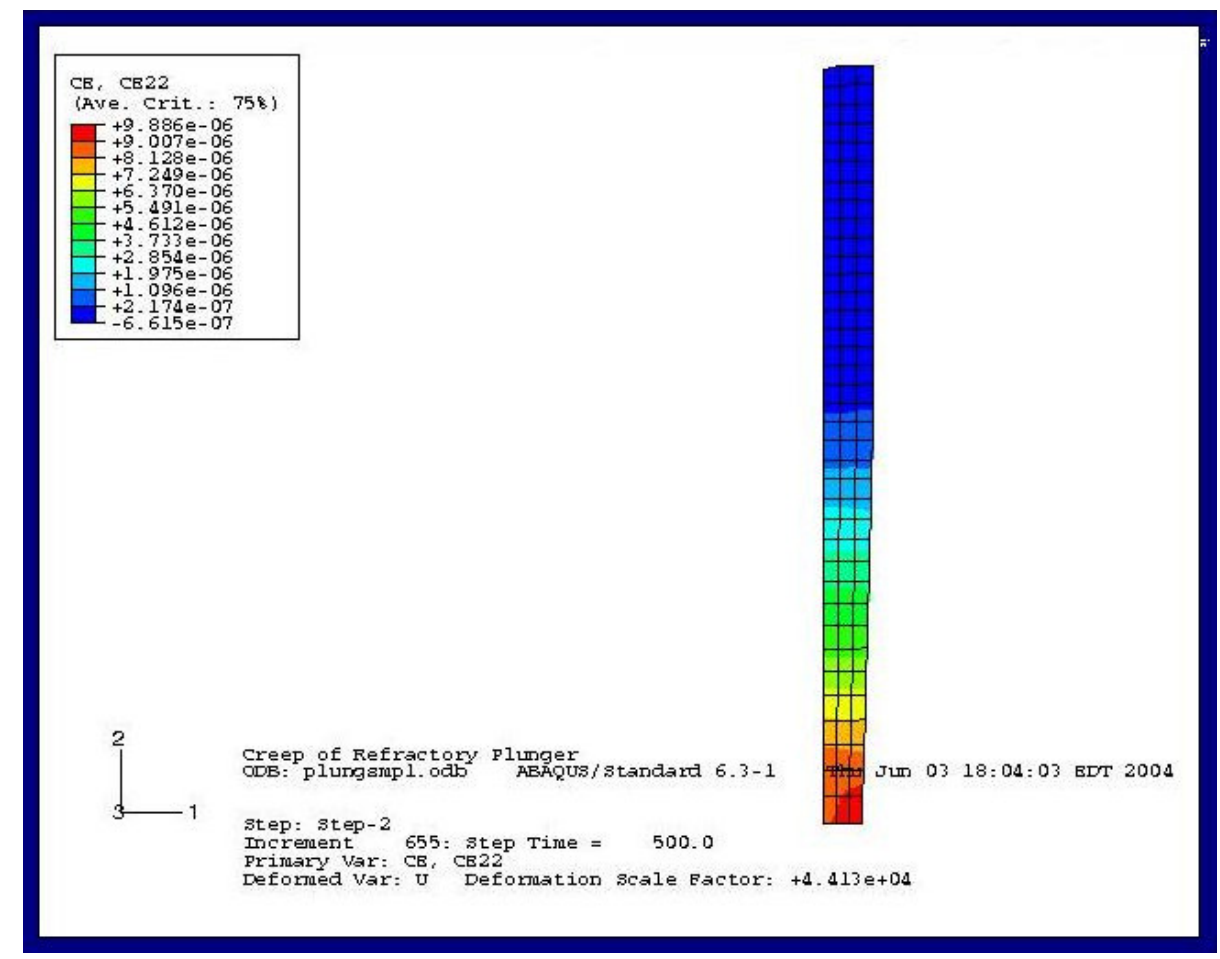

Figure 6.5 Creep Strain Contour after 500 Hours

The strain contour indicates that the maximum strain occurs at the bottom right corner of the plunger under assumed boundary conditions as specified in the Section 6.2.1.2.

Table 6.3 illustrates the creep strain values obtained over a period of 500 hours, which is the life time the refractory material is in use in the glass melting furnace. The average glass temperature is assumed to be $2060^{\circ} \mathrm{F}$.

Table 6.3 FEA Creep Strain Data

\begin{tabular}{|c||c|}
\hline Time (hrs) & $\begin{array}{c}\text { Maximum Strain } \\
\text { (At Bottom Right Corner) }\end{array}$ \\
\hline 0.01 & $1.58 \mathrm{e}-08$ \\
\hline 0.03 & $3.68 \mathrm{e}-08$ \\
\hline 0.09 & $7.49 \mathrm{e}-08$ \\
\hline 0.17 & $1.09 \mathrm{e}-07$ \\
\hline 0.33 & $1.60 \mathrm{e}-07$ \\
\hline 0.65 & $2.33 \mathrm{e}-07$ \\
\hline \hline
\end{tabular}




\begin{tabular}{|c|c|}
\hline 1.93 & $4.28 \mathrm{e}-07$ \\
\hline 2.01 & $4.39 \mathrm{e}-07$ \\
\hline 2.25 & $4.70 \mathrm{e}-07$ \\
\hline 2.49 & $5.00 \mathrm{e}-07$ \\
\hline 2.73 & $5.28 \mathrm{e}-07$ \\
\hline 2.89 & $5.47 \mathrm{e}-07$ \\
\hline 3.37 & $5.99 \mathrm{e}-07$ \\
\hline 3.85 & $6.48 \mathrm{e}-07$ \\
\hline 5.53 & $8.00 \mathrm{e}-07$ \\
\hline 6.81 & $9.03 \mathrm{e}-07$ \\
\hline 7.93 & $9.85 \mathrm{e}-07$ \\
\hline 9.21 & $1.07 \mathrm{e}-06$ \\
\hline 10.3 & $1.15 \mathrm{e}-06$ \\
\hline 11.6 & $1.23 \mathrm{e}-06$ \\
\hline 12.7 & $1.29 \mathrm{e}-06$ \\
\hline 14.0 & $1.36 \mathrm{e}-06$ \\
\hline 15.1 & $1.42 \mathrm{e}-06$ \\
\hline 16.4 & $1.49 \mathrm{e}-06$ \\
\hline 17.3 & $1.54 \mathrm{e}-06$ \\
\hline 18.5 & $1.59 \mathrm{e}-06$ \\
\hline 20.9 & $1.71 \mathrm{e}-06$ \\
\hline 25.7 & $1.92 \mathrm{e}-06$ \\
\hline 30.5 & $2.11 \mathrm{e}-06$ \\
\hline 35.3 & $2.29 \mathrm{e}-06$ \\
\hline 40.1 & $2.46 \mathrm{e}-06$ \\
\hline 44.9 & $2.62 \mathrm{e}-06$ \\
\hline 50.0 & $2.78 \mathrm{e}-06$ \\
\hline 55.8 & $2.95 \mathrm{e}-06$ \\
\hline 61.5 & $3.12 \mathrm{e}-06$ \\
\hline 68.9 & $3.32 \mathrm{e}-06$ \\
\hline 74.6 & $3.47 \mathrm{e}-06$ \\
\hline 80.4 & $3.62 \mathrm{e}-06$ \\
\hline 86.2 & $3.76 \mathrm{e}-06$ \\
\hline 93.2 & $3.93 \mathrm{e}-06$ \\
\hline 107.6 & $4.25 \mathrm{e}-06$ \\
\hline
\end{tabular}




\begin{tabular}{|c|c|}
\hline 126.8 & $4.65 \mathrm{e}-06$ \\
\hline 146.6 & $5.04 \mathrm{e}-06$ \\
\hline 167.1 & $5.42 \mathrm{e}-06$ \\
\hline 185.0 & $5.73 e-06$ \\
\hline 204.2 & $6.05 \mathrm{e}-06$ \\
\hline 223.4 & $6.36 \mathrm{e}-06$ \\
\hline 242.6 & $6.65 \mathrm{e}-06$ \\
\hline 263.1 & $6.95 e-06$ \\
\hline 282.3 & $7.23 e-06$ \\
\hline 301.5 & $7.49 \mathrm{e} 06$ \\
\hline 320.7 & $7.75 \mathrm{e}-06$ \\
\hline 339.9 & $8.00 \mathrm{e}-06$ \\
\hline 359.1 & $8.25 e-06$ \\
\hline 378.3 & $8.49 \mathrm{e}-06$ \\
\hline 398.2 & $8.73 e-06$ \\
\hline 417.4 & $8.95 e-06$ \\
\hline 436.6 & $9.18 \mathrm{e}-06$ \\
\hline 491.6 & $9.80 \mathrm{e}-06$ \\
\hline 500.0 & $9.89 \mathrm{e}-06$ \\
\hline
\end{tabular}

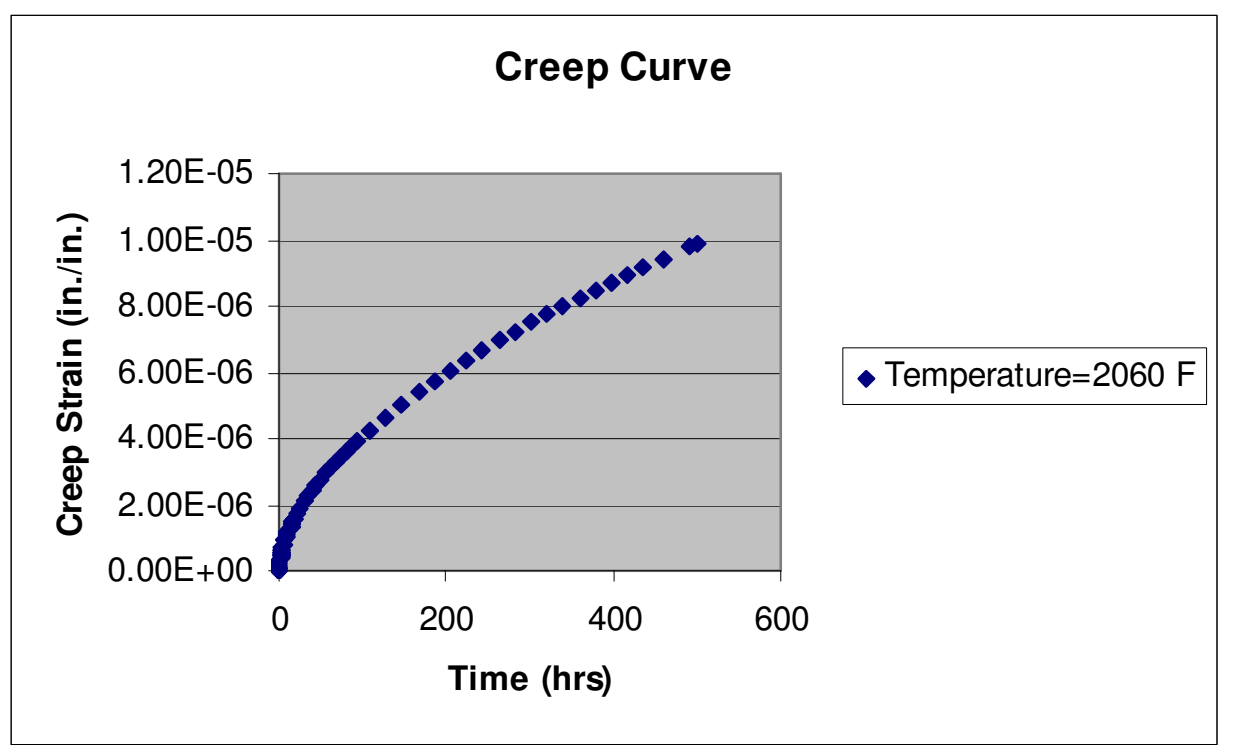

Figure 6.6 Creep Curve of Untreated Plunger 


\subsubsection{Creep Strain Dependence on Stress}

Stress dependence of creep strain in the untreated plunger model is studied by the variation of applied normal stress and shear stress due to the molten glass at a constant temperature. The varied normal stress and the shear stress at the wall by the molten glass are taken as 1.76 psi, 2 psi, 2.75 psi, 3.5 psi and 6.5 psi, 7 psi, 8.5 psi, 10 psi respectively. Figures 6.7, 6.8, 6.9 and 6.10 show the creep strain contours with varied stresses after 500 hours. The average glass temperature is assumed to be $2060^{\circ} \mathrm{F}$

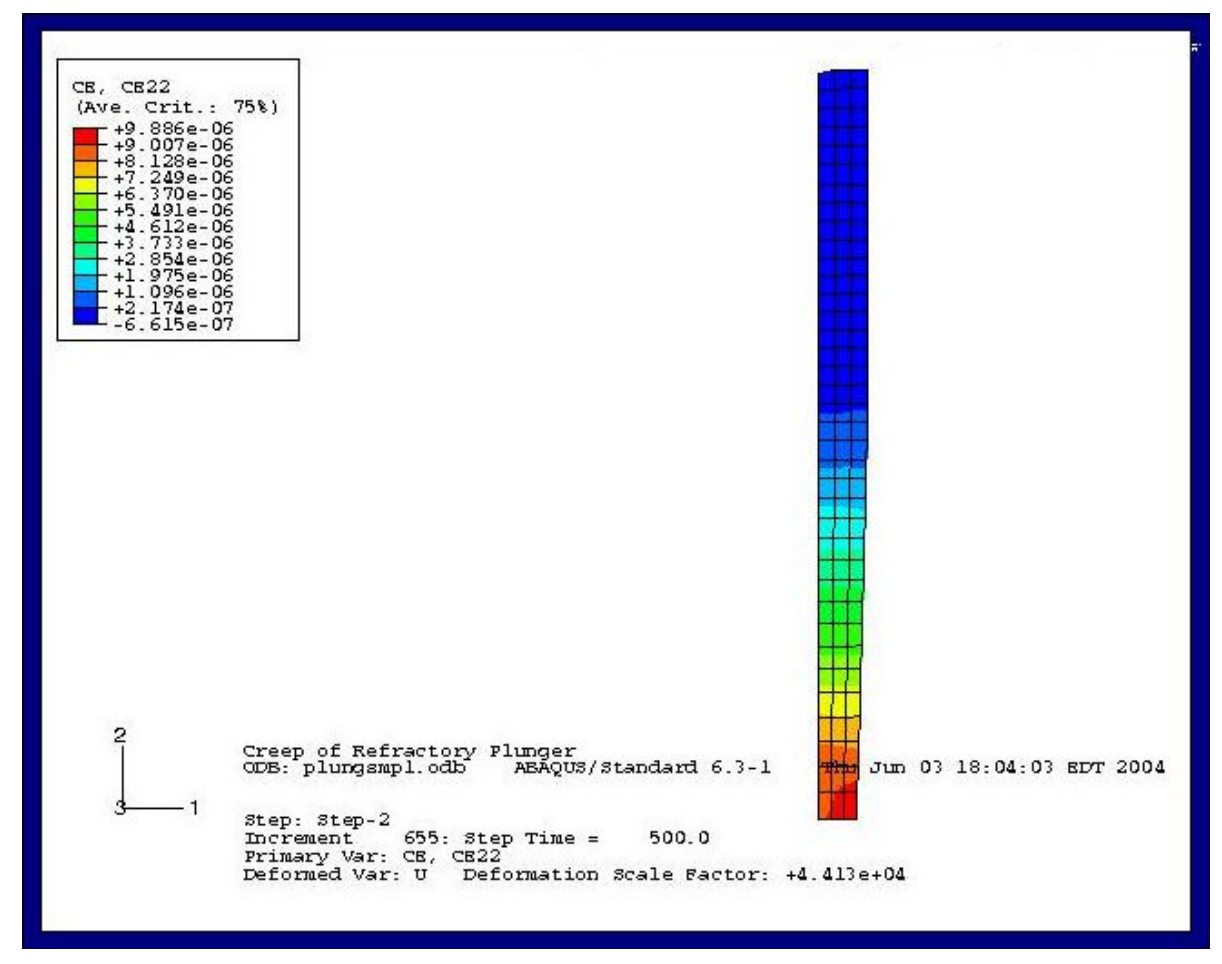

Figure 6.7 Creep Strain Contour for Applied Stresses of $\sigma_{w}=6.5 \mathrm{psi}$ and $\tau_{w}=1.76 \mathrm{psi}$ at $2060^{\circ} \mathrm{F}$ 


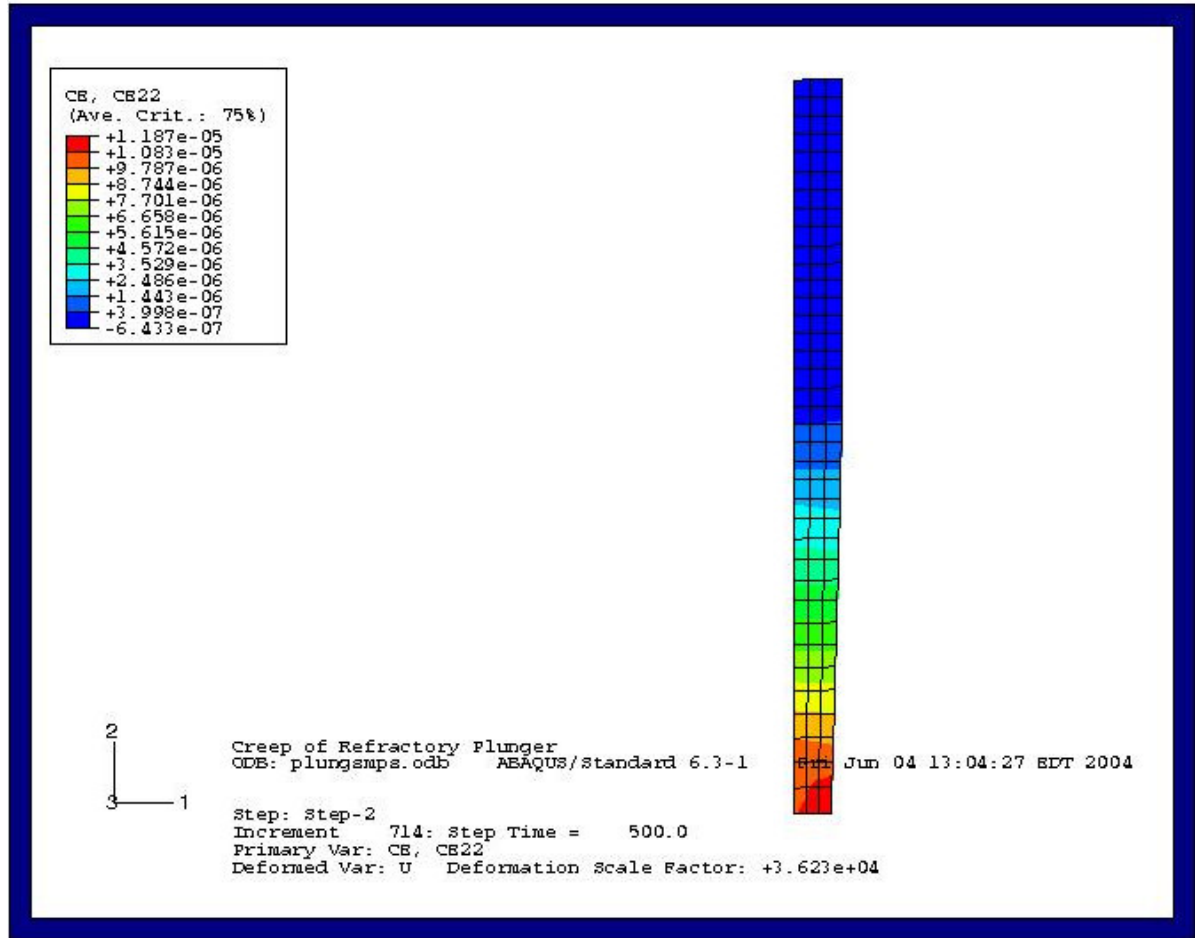

Figure 6.8 Creep Strain Contour for Applied Stresses of $\sigma_{w}=7 \mathrm{psi}$ and $\tau_{w}=2$ psi at $2060^{\circ} \mathrm{F}$

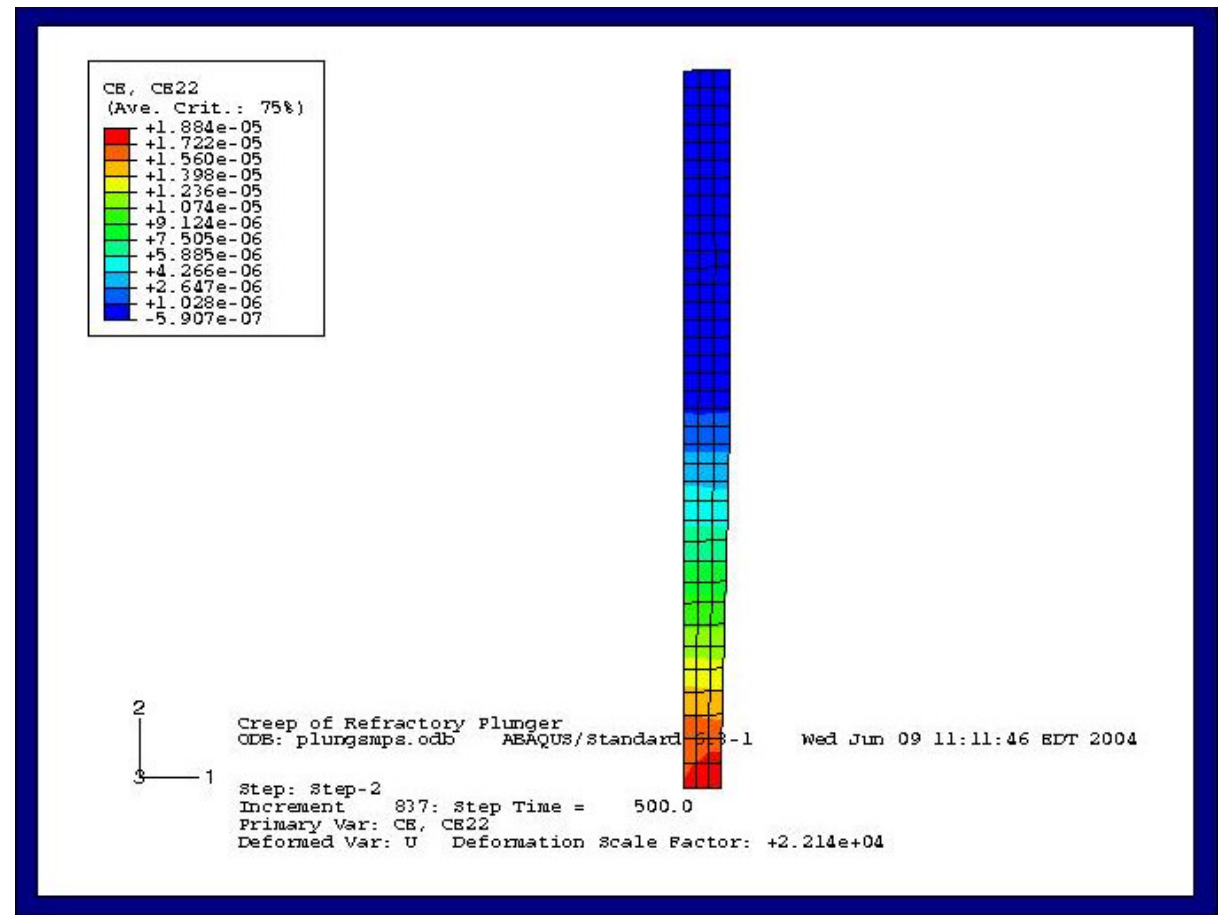

Figure 6.9 Creep Strain Contour for Applied Stresses of $\sigma_{w}=8.5 \mathrm{psi}$ and $\tau_{w}=2.75 \mathrm{psi}$ at $2060{ }^{\circ} \mathrm{F}$ 


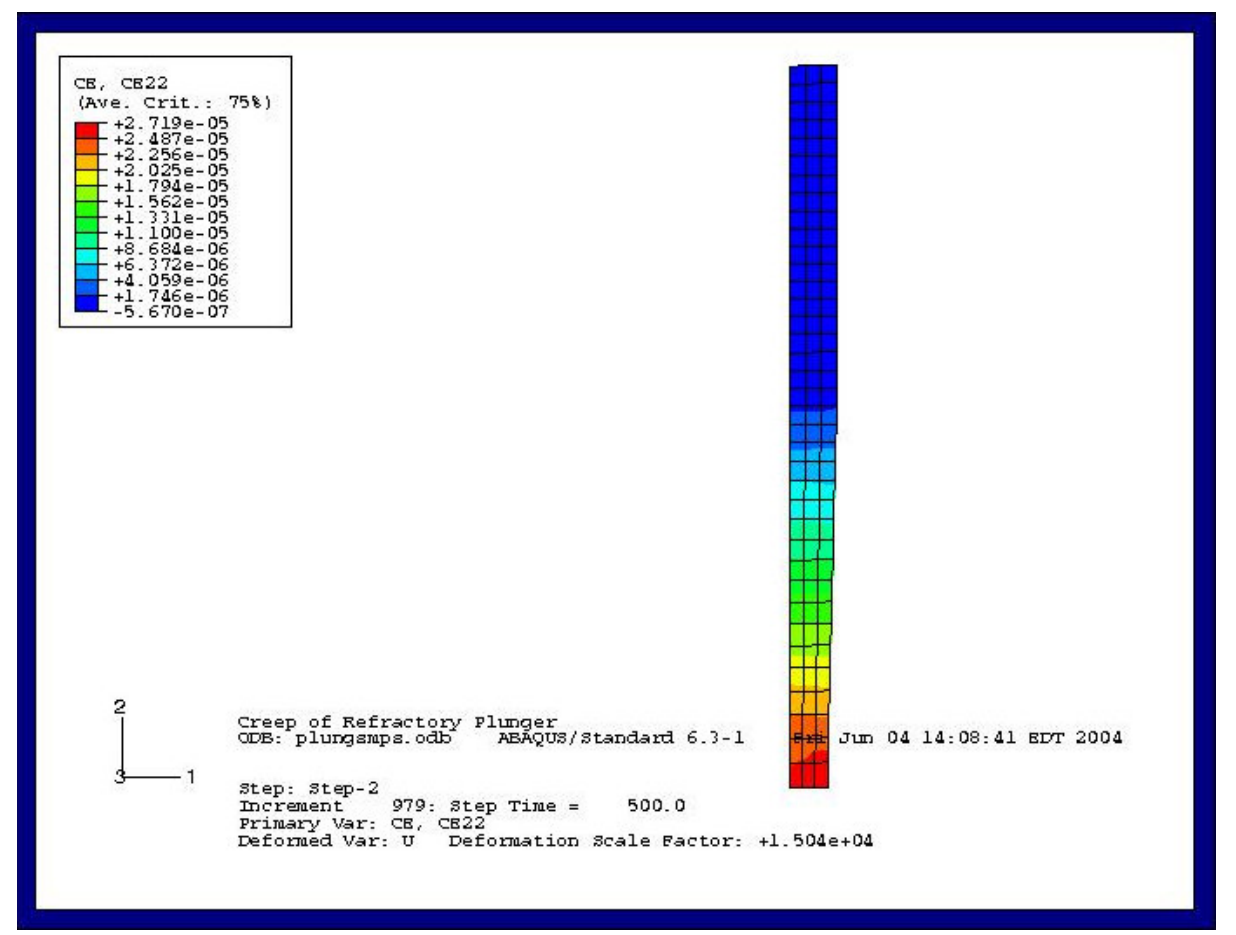

Figure 6.10 Creep Strain Contour for Applied Stresses of $\sigma_{w}=10 \mathrm{psi}$ and $\tau_{w}=3.5$ psi at $2060{ }^{\circ} \mathrm{F}$

\subsubsection{Creep Strain Dependence on Normal Stress}

Table 6.4 illustrates the creep strain values obtained for varied normal stress at a glass temperature of $2060^{\circ} \mathrm{F}$ over a time period of 500 hours.

Table 6.4 Creep Strain Data with Variation of Normal Stress $\left(\sigma_{w}\right)$ at $2060^{\circ} \mathbf{F}$

\begin{tabular}{|c|c|}
\hline Normal Stress (psi) & Creep Strain \\
\hline 1.76 & $9.88 \mathrm{e}-06$ \\
\hline 2.00 & $1.19 \mathrm{e}-05$ \\
\hline 2.75 & $1.89 \mathrm{e}-05$ \\
\hline 3.50 & $2.72 \mathrm{e}-05$ \\
\hline
\end{tabular}

Table 6.5 illustrates the creep strain values obtained for varied normal stress at a glass temperature of $2010^{\circ} \mathrm{F}$ over a time period of 500 hours. 
Table 6.5 Creep Strain Data with Variation of Normal Stress $\left(\sigma_{w}\right)$ at $2010{ }^{\circ} \mathbf{F}$

\begin{tabular}{|c|c|}
\hline Normal Stress (psi) & Creep Strain \\
\hline 1.76 & $5.60 \mathrm{e}-06$ \\
\hline 2.00 & $6.72 \mathrm{e}-06$ \\
\hline 2.75 & $1.07 \mathrm{e}-05$ \\
\hline 3.50 & $1.54 \mathrm{e}-05$ \\
\hline
\end{tabular}

Figure 6.11 shows the Creep Strain Dependence on Normal Stress at two glass temperatures $2060^{\circ} \mathrm{F}$ and $2010^{\circ} \mathrm{F}$ respectively after a time period of 500 hours.

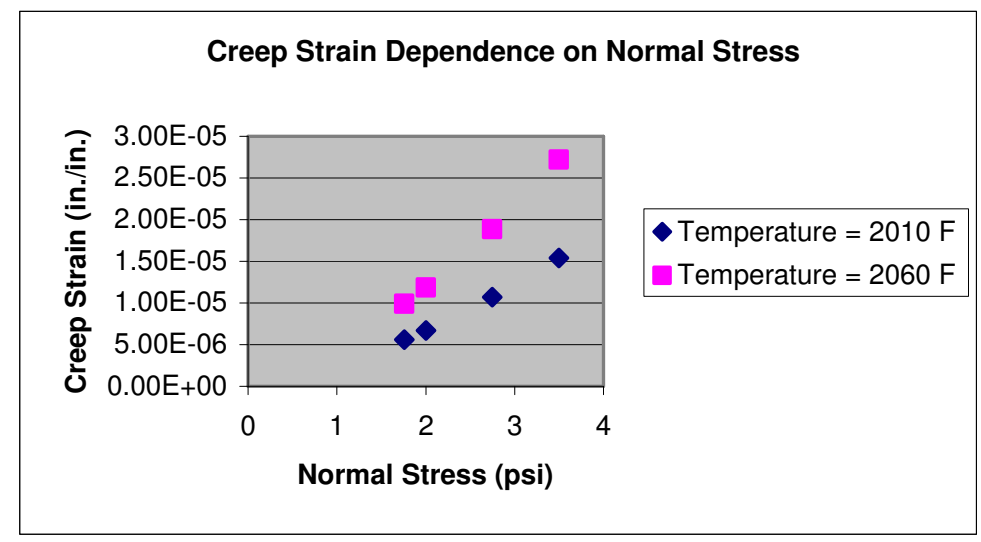

Figure 6.11 Creep Strain Dependence on Normal Stress

\subsubsection{Creep Strain Dependence on Shear Stress}

Table 6.6 illustrates the creep strain values obtained for varied shear stress at a glass temperature of $2060^{\circ} \mathrm{F}$ over a time period of 500 hours.

Table 6.6 Creep Strain Data with Variation of Shear Stress $\left(\tau_{w}\right)$ at $2060^{\circ} \mathbf{F}$

\begin{tabular}{|c|c|}
\hline Shear Stress (psi) & Creep Strain \\
\hline 6.50 & $9.89 \mathrm{e}-06$ \\
\hline 7.00 & $1.19 \mathrm{e}-05$ \\
\hline 8.50 & $1.89 \mathrm{e}-05$ \\
\hline 10.00 & $2.72 \mathrm{e}-05$ \\
\hline
\end{tabular}


Table 6.7 illustrates the creep strain values obtained for varied shear stress at a glass temperature of $2010^{\circ} \mathrm{F}$ over a time period of 500 hours.

Table 6.7 Creep Strain Data with Variation of Shear Stress $\left(\tau_{w}\right)$ at $2010{ }^{\circ} \mathbf{F}$

\begin{tabular}{|c|c|}
\hline Shear Stress (psi) & Creep Strain \\
\hline 6.50 & $5.60 \mathrm{e}-06$ \\
\hline 7.00 & $6.72 \mathrm{e}-06$ \\
\hline 8.50 & $1.07 \mathrm{e}-05$ \\
\hline 10.00 & $1.54 \mathrm{e}-05$ \\
\hline
\end{tabular}

Figure 6.12 shows the creep strain dependence on shear stress at two glass temperatures $2060^{\circ} \mathrm{F}$ and $2010^{\circ} \mathrm{F}$ respectively after a time period of 500 hours.

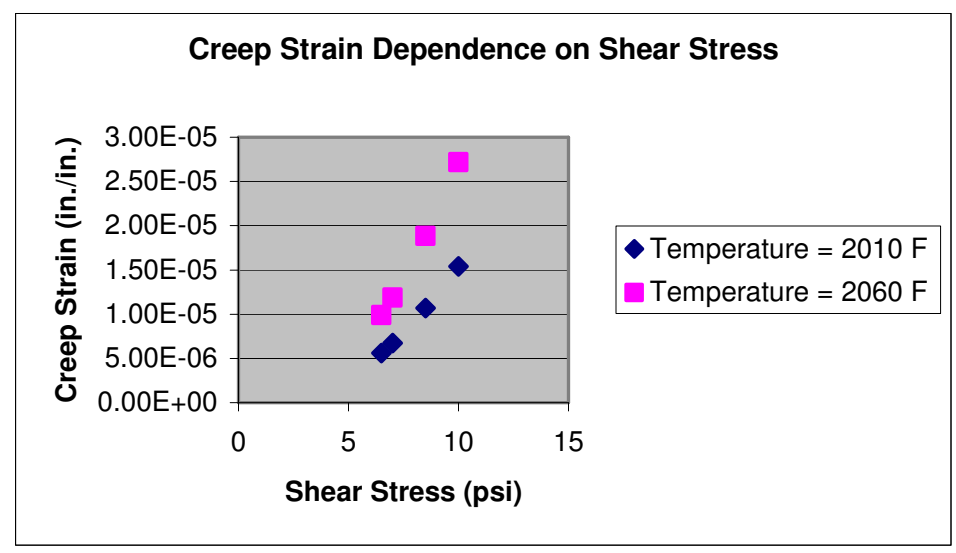

Figure 6.12 Creep Strain Dependence on Shear Stress

\subsubsection{Creep Strain Dependence on Temperature}

Creep Strain Dependence on Temperature in the untreated plunger model is studied by the variation of temperature at constant applied stresses over a specific period of time. For this analysis three different temperatures of $2010^{\circ} \mathrm{F}, 2060^{\circ} \mathrm{F}$ and $2200{ }^{\circ} \mathrm{F}$ are considered. Figures $6.13,6.14$ and 6.15 show the creep strain contours with varied temperatures. 


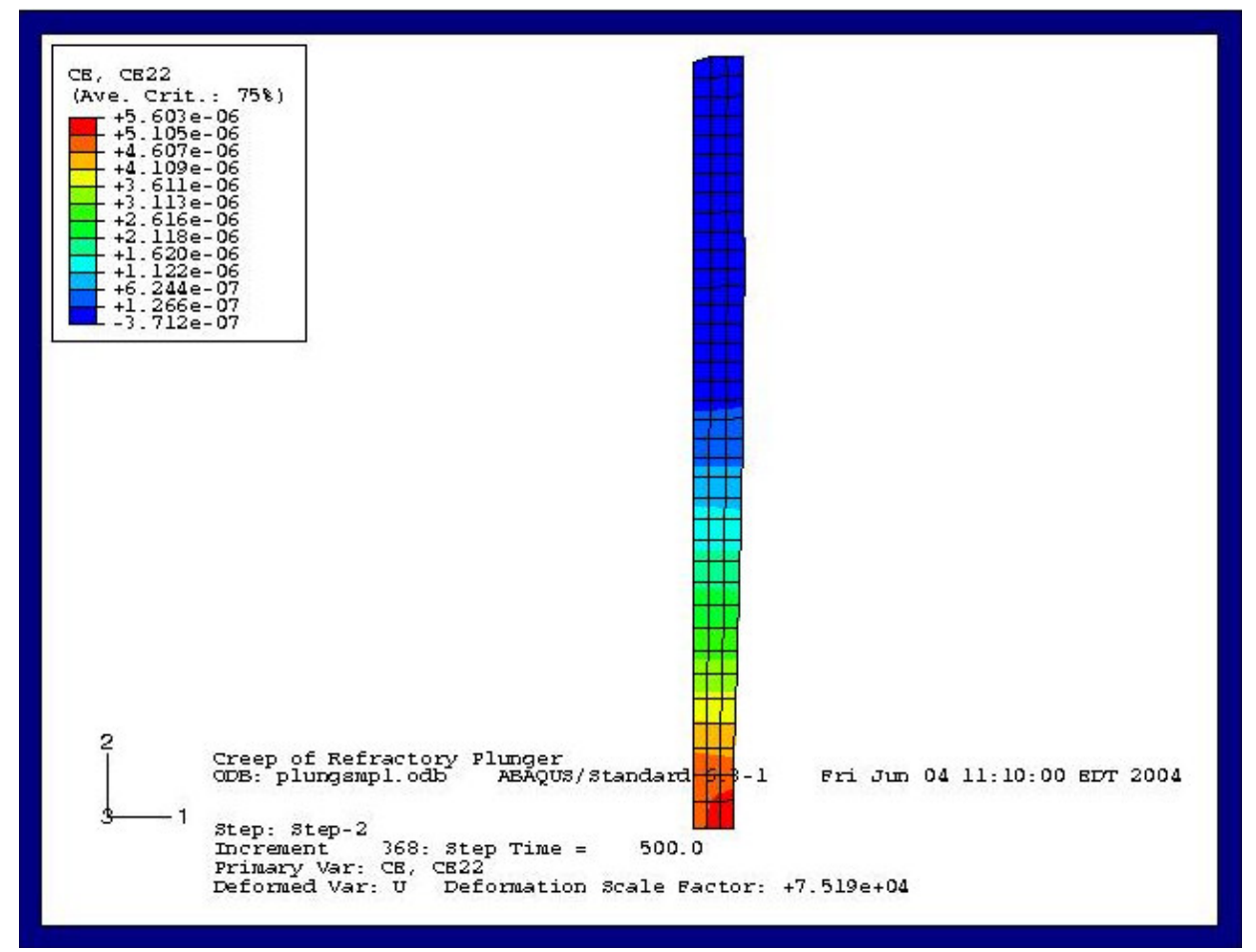

Figure 6.13 Creep Strain Contour at $2010{ }^{\circ} \mathrm{F}$ after 500 Hours

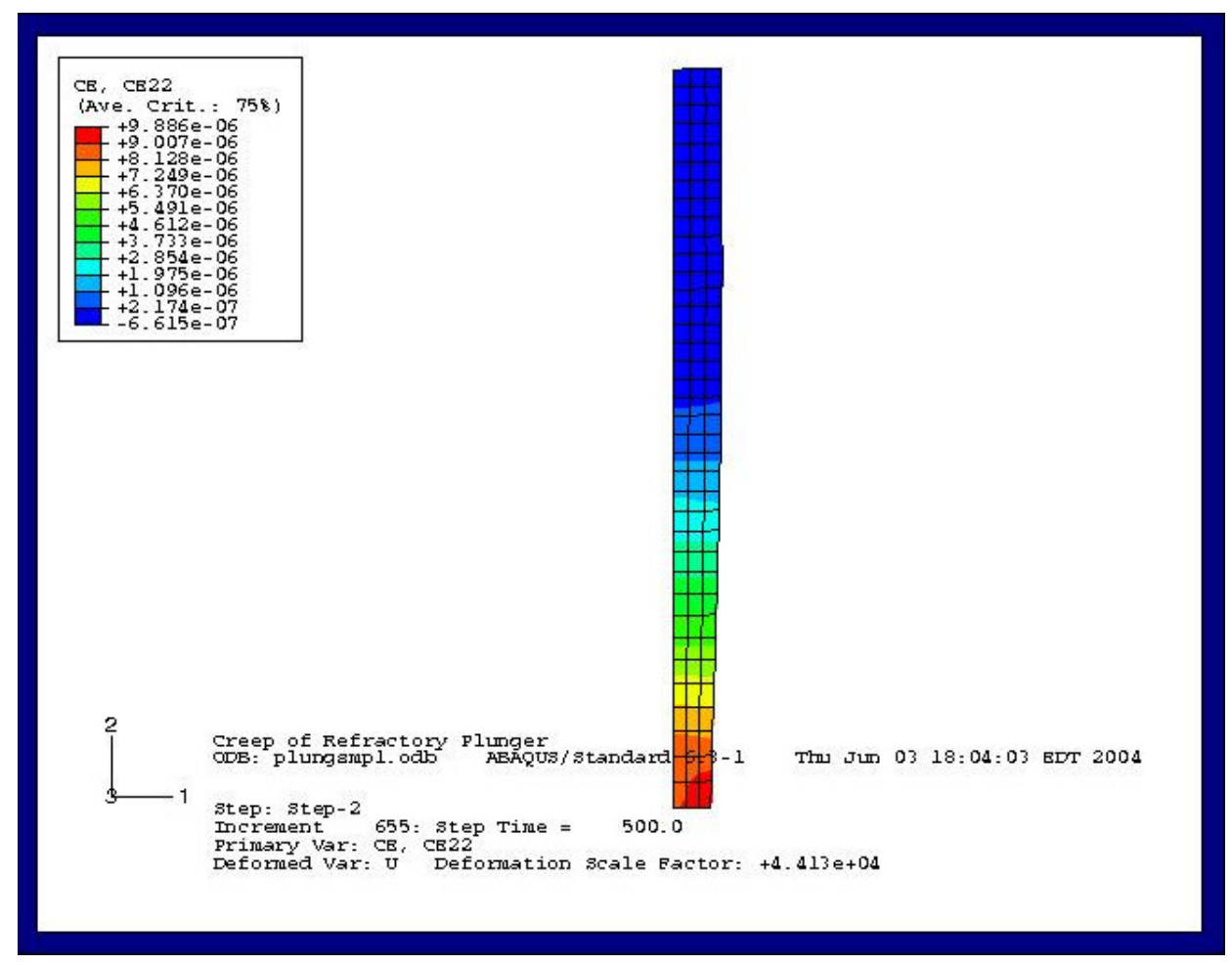

Figure 6.14 Creep Strain Contour at $2060^{\circ} \mathrm{F}$ after 500 Hours 


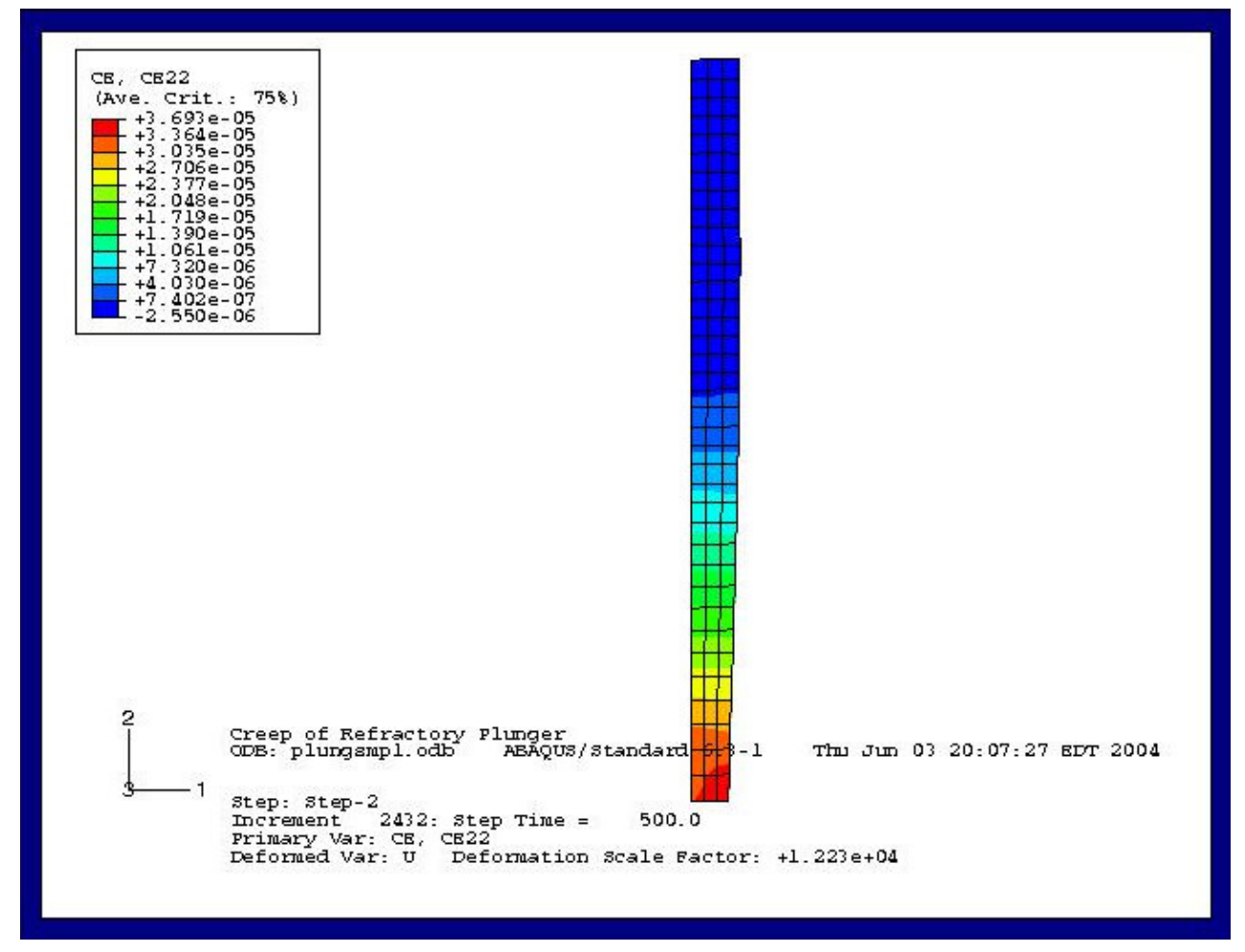

Figure 6.15 Creep Strain Contour at $2200{ }^{\circ} \mathrm{F}$ after 500 Hours

Table 6.8 illustrates the creep strain values obtained for varied temperatures for the applied stresses of $\sigma_{w}=6.5$ psi and $\tau_{w}=1.76$ psi after a time period of 50 hours.

Table 6.8 Creep Strain Data after 50 Hours

\begin{tabular}{|c|c|}
\hline Temperature $\left({ }^{\circ} \mathrm{F}\right)$ & Creep Strain \\
\hline 2010 & $1.58 \mathrm{e}-06$ \\
\hline 2060 & $2.78 \mathrm{e}-06$ \\
\hline 2200 & $1.05 \mathrm{e}-05$ \\
\hline
\end{tabular}

Table 6.9 illustrates the creep strain values obtained for varied temperatures for the applied stresses of $\sigma_{w}=6.5 \mathrm{psi}$ and $\tau_{w}=1.76$ psi after a time period of 250 hours.

Table 6.9 Creep Strain Data after 250 Hours

\begin{tabular}{|c|c|}
\hline Temperature $\left({ }^{\circ} \mathrm{F}\right)$ & Creep Strain \\
\hline 2010 & $3.82 \mathrm{e}-06$ \\
\hline 2060 & $6.75 \mathrm{e}-06$ \\
\hline 2200 & $2.53 \mathrm{e}-05$ \\
\hline
\end{tabular}


Table 6.10 illustrates the creep strain values obtained for varied temperatures for the applied stresses of $\sigma_{w}=6.5 \mathrm{psi}$ and $\tau_{w}=1.76 \mathrm{psi}$ after a time period of 500 hours.

Table 6.10 Creep Strain Data after 500 Hours

\begin{tabular}{|c|c|}
\hline Temperature $\left({ }^{\circ} \mathrm{F}\right)$ & Creep Strain \\
\hline 2010 & $5.60 \mathrm{e}-06$ \\
\hline 2060 & $9.89 \mathrm{e}-06$ \\
\hline 2200 & $3.70 \mathrm{e}-05$ \\
\hline
\end{tabular}

Figure 6.16 shows the Creep Strain Dependence on Temperature after time periods of 50 hours, 250 hours and 500 hours for the applied stresses of $\sigma_{w}=6.5$ psi and $\tau_{w}=1.76$ psi.

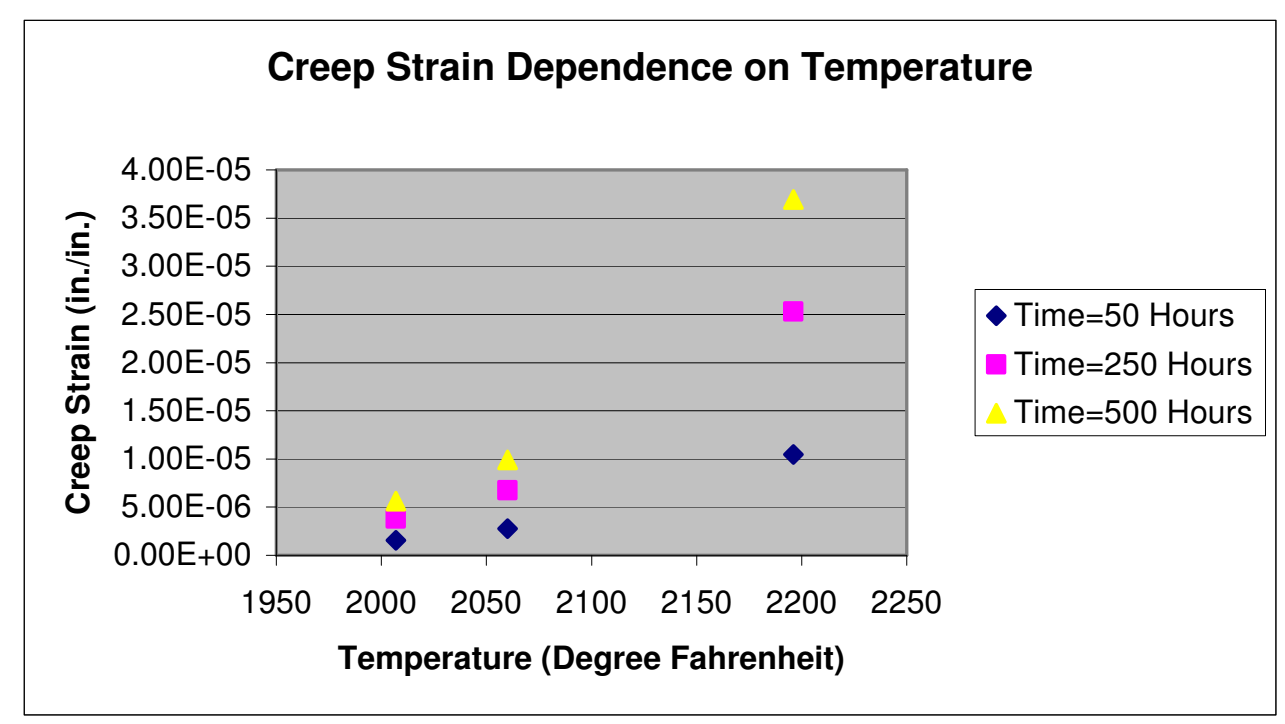

Figure 6.16 Creep Strain Dependence on Temperature 


\section{CHAPTER 7. Refractory Material with HDI Treatment}

\subsection{Introduction}

The HDI treated refractory material in this thesis is a composite material that consists of a substrate material (fused cast alumina) and a coating material (Zirconia). This refractory material is supposed to be a better creep resistant material than that of an untreated refractory material because the coating material will have higher strength at elevated temperatures compared to that of a substrate material. ABAQUS program has been implemented to study the creep behavior of HDI treated refractory material.

\subsection{Design Considerations for Untreated Refractory Material}

The finite element analysis of the HDI treated plunger is based on certain assumptions. The assumptions and the steps involved to study the behavior of the HDI treated plunger are described below.

\subsubsection{Finite Element Model of HDI Treated Refractory Material}

The steps involved in implementing the finite element model of the HDI treated plunger model are explained as below.

\subsubsection{Geometry and Material Model}

The HDI treated refractory material has a coating material of thickness about $200 \mu \mathrm{m}$. This coating thickness is relatively very low compared to that of the diameter of the substrate material. The diameter of the substrate material is 3.74 in. as indicated earlier in Section 6.2.1.1. The axisymmetric finite element model of the HDI treated refractory material is as shown in the Figure 7.1. Figure 7.2 shows the magnified view of the mesh. 


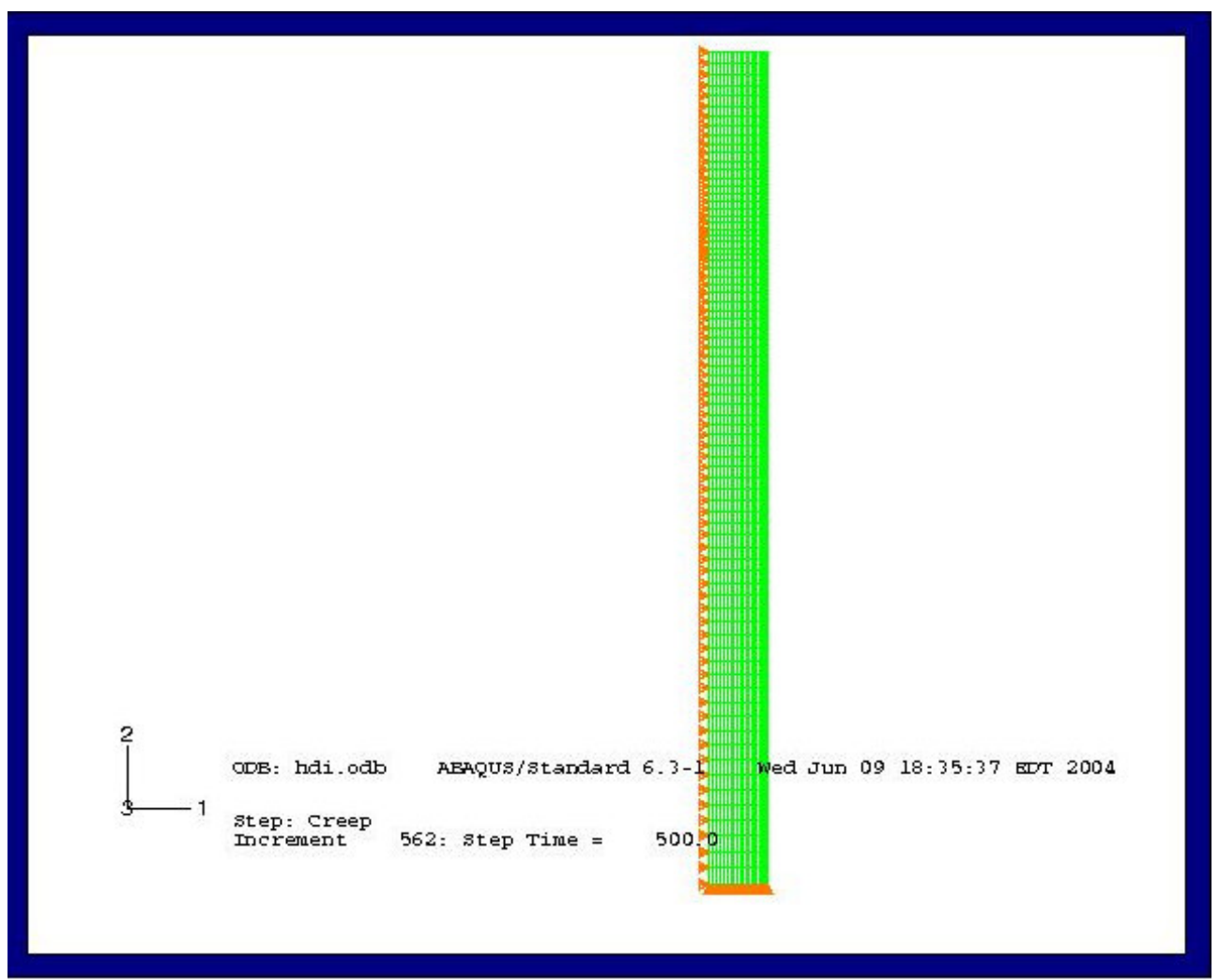

Figure 7.1 Finite Element Model of HDI Treated Plunger

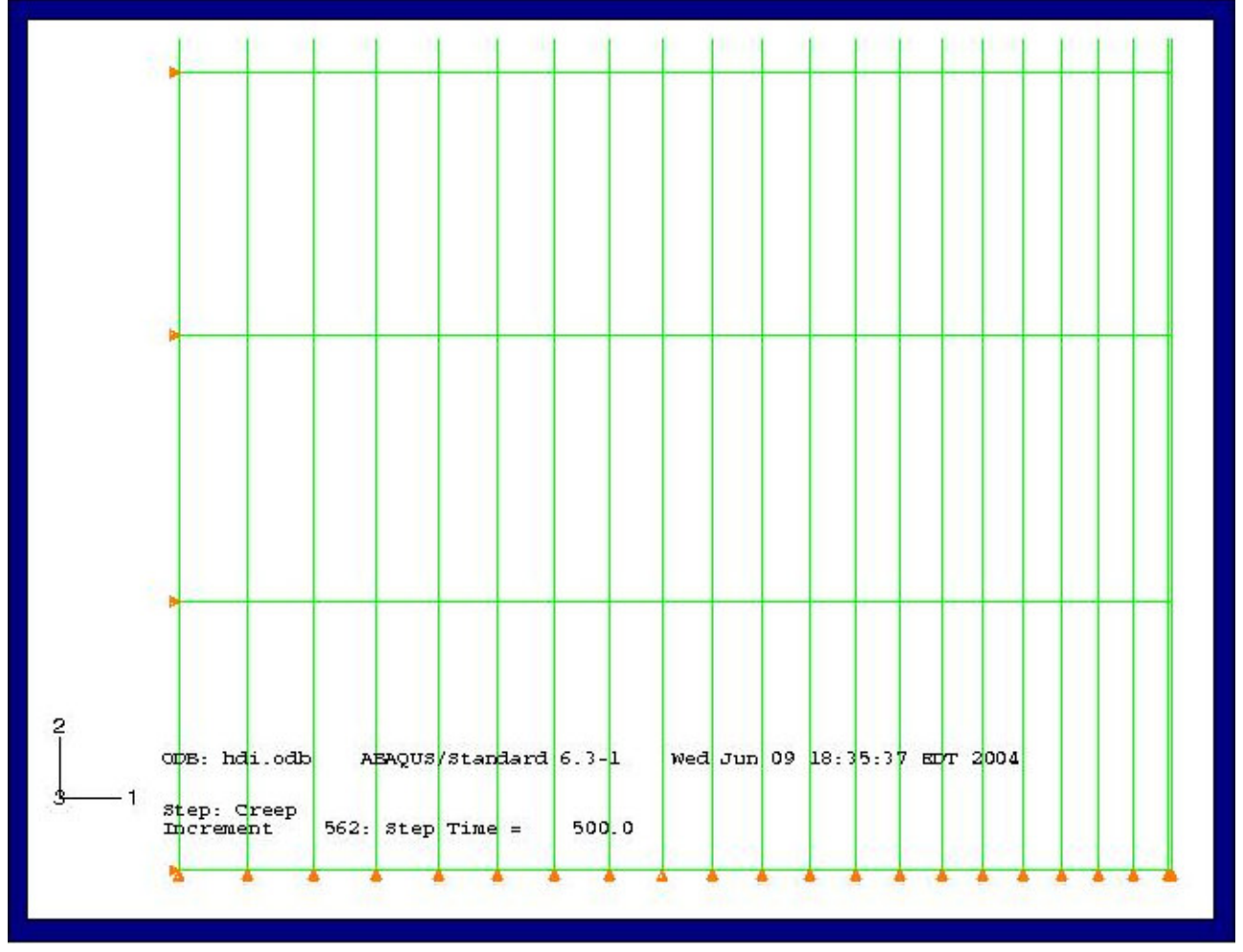

Figure 7.2 Magnified View of Finite Element Model 
The creep behavior of the HDI treated refractory material is predicted by using two different sets of material constants a1, b1, c1 and a2, b2, c2 associated with the mathematical creep models.

$$
\begin{aligned}
& \mathcal{E}_{c 1}=e^{a 1} t^{b 1} \sigma^{c 1} \exp (-Q / R T) \\
& \varepsilon_{c 2}=e^{a 2} t^{b 2} \sigma^{c 2} \exp (-Q / R T)
\end{aligned}
$$

Equation 7.1 is used to model the creep behavior of substrate material and Equation 7.2 is used to model the creep behavior of coating material, which are incorporated using the creep subroutine program. The material properties of fused cast alumina are same as indicated in the Section 6.2.1.1. The assumed material properties of coating material at a temperature, $2100^{\circ} \mathrm{F}$ are as given below.

Material Properties of Coating Material: Young's Modulus $(E)=30 \mathrm{e} 6 \mathrm{psi}$

$$
\text { Poisson's Ratio }(\mu)=0.45
$$

Type of Element: Axisymmetric Element, CAX4

Material Constants in Equation 7.1: $\mathrm{a} 1=6.74, \mathrm{~b} 1=0.54, \mathrm{c} 1=1.80, \mathrm{Q}=71500 \mathrm{cal} / \mathrm{mol}$, $\mathrm{R}=1.98 \mathrm{cal} / \mathrm{mol}-\mathrm{K}$.

Material Constants in Equation 7.2: $\mathrm{a} 2=6.6, \mathrm{~b} 2=0.45, \mathrm{c} 1=1.7, \mathrm{Q}=71500 \mathrm{cal} / \mathrm{mol}, \mathrm{R}$ $=1.98 \mathrm{cal} / \mathrm{mol}-\mathrm{K}$.

\subsubsection{Boundary Conditions}

The boundary conditions for the HDI treated refractory material are same as mentioned in the Section 6.2.1.2. The interface between the fused cast alumina and the coating material, zirconia, is assumed to be perfectly bonded. This boundary condition has been taken care of by the nature of the 2D axisymmetric model that is implemented. 


\subsubsection{Creep Curve Behavior}

Creep behavior of HDI treated fused cast alumina plunger with Zirconia coating is analyzed for a period of 500 hours. Refer to Appendix C. Figure 7.3 shows the creep strain contour of the HDI treated plunger after a period of 500 hours.

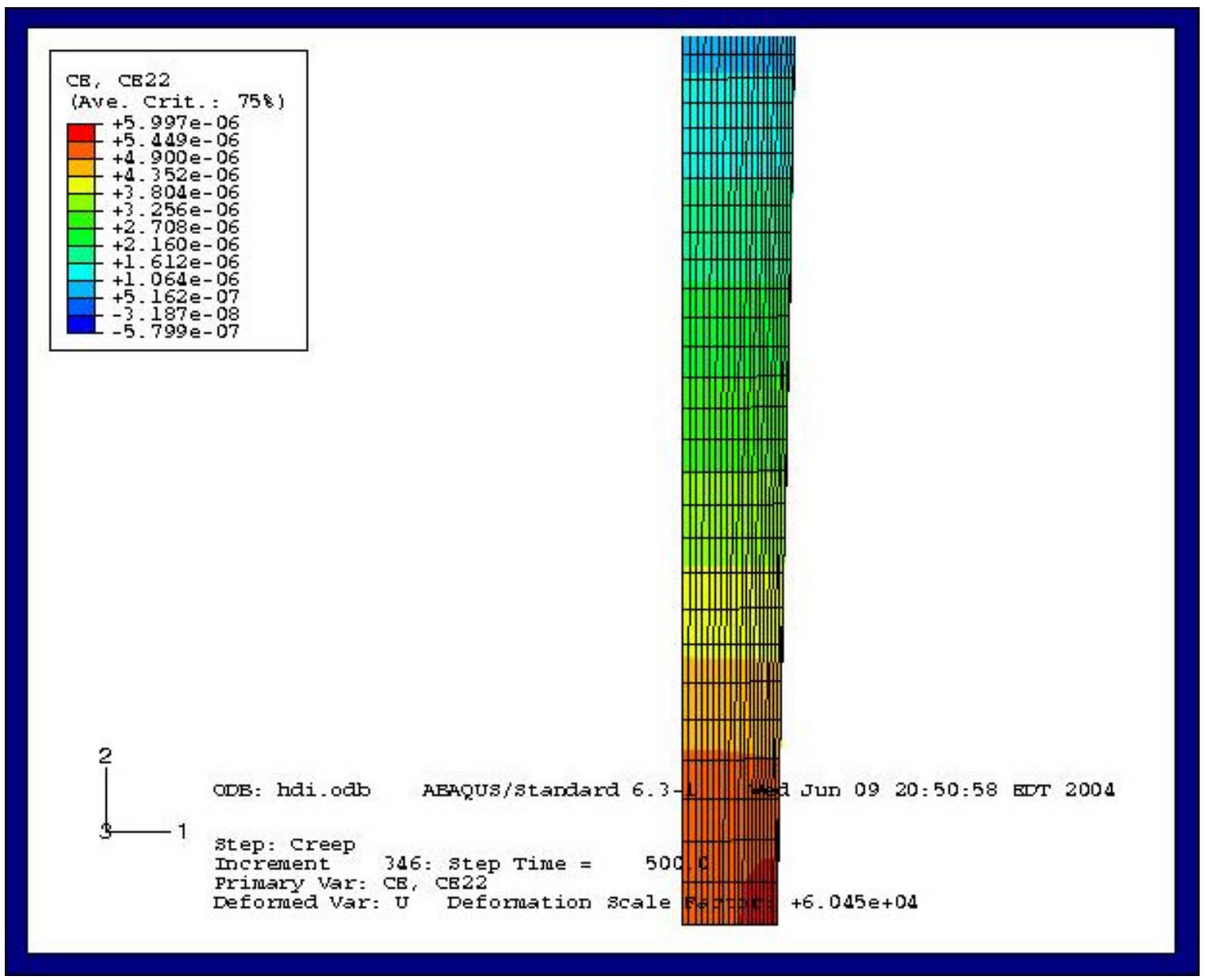

Figure 7.3 Creep Strain Contour after 500 Hours 
Table 7.1 illustrates the creep strain values obtained over a period of 500 hours, which is the time the HDI treated refractory material is in use in the glass melting furnace.

Table 7.1 FEA Creep Strain Data

\begin{tabular}{|c|c|}
\hline Time (hrs) & "Maximum Strain \\
\hline 0.17 & $1.01 \mathrm{e}-07$ \\
\hline 2.37 & $3.89 e-07$ \\
\hline 3.81 & $5.01 \mathrm{e}-07$ \\
\hline 5.25 & $5.92 \mathrm{e}-07$ \\
\hline 11.25 & $8.78 \mathrm{e}-07$ \\
\hline 17.73 & $1.11 \mathrm{e}-06$ \\
\hline 29.25 & $1.43 e-06$ \\
\hline 40.77 & $1.69 \mathrm{e}-06$ \\
\hline 52.29 & $1.92 \mathrm{e}-06$ \\
\hline 63.81 & $2.12 \mathrm{e}-06$ \\
\hline 83.97 & $2.44 \mathrm{e}-06$ \\
\hline 107.00 & $2.76 \mathrm{e}-06$ \\
\hline 130.00 & $3.04 \mathrm{e}-06$ \\
\hline 153.00 & $3.30 \mathrm{e}-06$ \\
\hline 176.00 & $3.55 e-06$ \\
\hline 199.20 & $3.77 \mathrm{e}-06$ \\
\hline 222.20 & $3.99 \mathrm{e}-06$ \\
\hline 245.20 & $4.19 \mathrm{e}-06$ \\
\hline 268.30 & $4.38 \mathrm{e}-06$ \\
\hline 314.40 & $4.75 \mathrm{e}-06$ \\
\hline 360.40 & $5.09 \mathrm{e}-06$ \\
\hline 406.50 & $5.40 \mathrm{e}-06$ \\
\hline 437.20 & $5.61 \mathrm{e}-06$ \\
\hline 469.90 & $5.81 \mathrm{e}-06$ \\
\hline 500.00 & $6.00 e-06$ \\
\hline
\end{tabular}




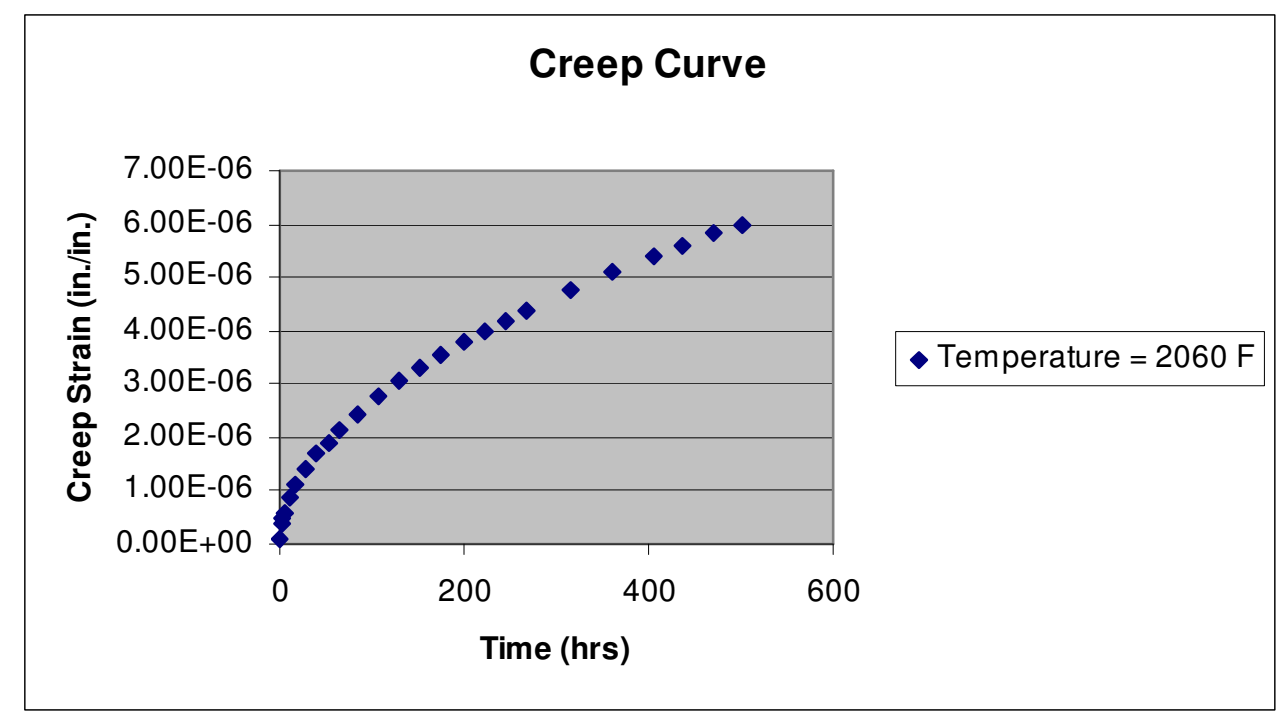

Figure 7.4 Creep Curve of HDI Treated Plunger

\subsubsection{Creep Strain Dependence on Stress}

Stress dependence of creep strain in the HDI treated plunger model is also studied by the variation of applied normal stress and shear stress due to the molten glass at a constant temperature. The varied normal pressure and the shear stress at the wall by the molten glass are taken as $1.76 \mathrm{psi}, 2 \mathrm{psi}, 2.75 \mathrm{psi}, 3.5 \mathrm{psi}$ and $6.5 \mathrm{psi}, 7 \mathrm{psi}, 8.5 \mathrm{psi}, 10 \mathrm{psi}$ respectively. Figures 7.5, 7.6, 7.7 and 7.8 show the creep strain contours with varied stresses after 500 hours. 


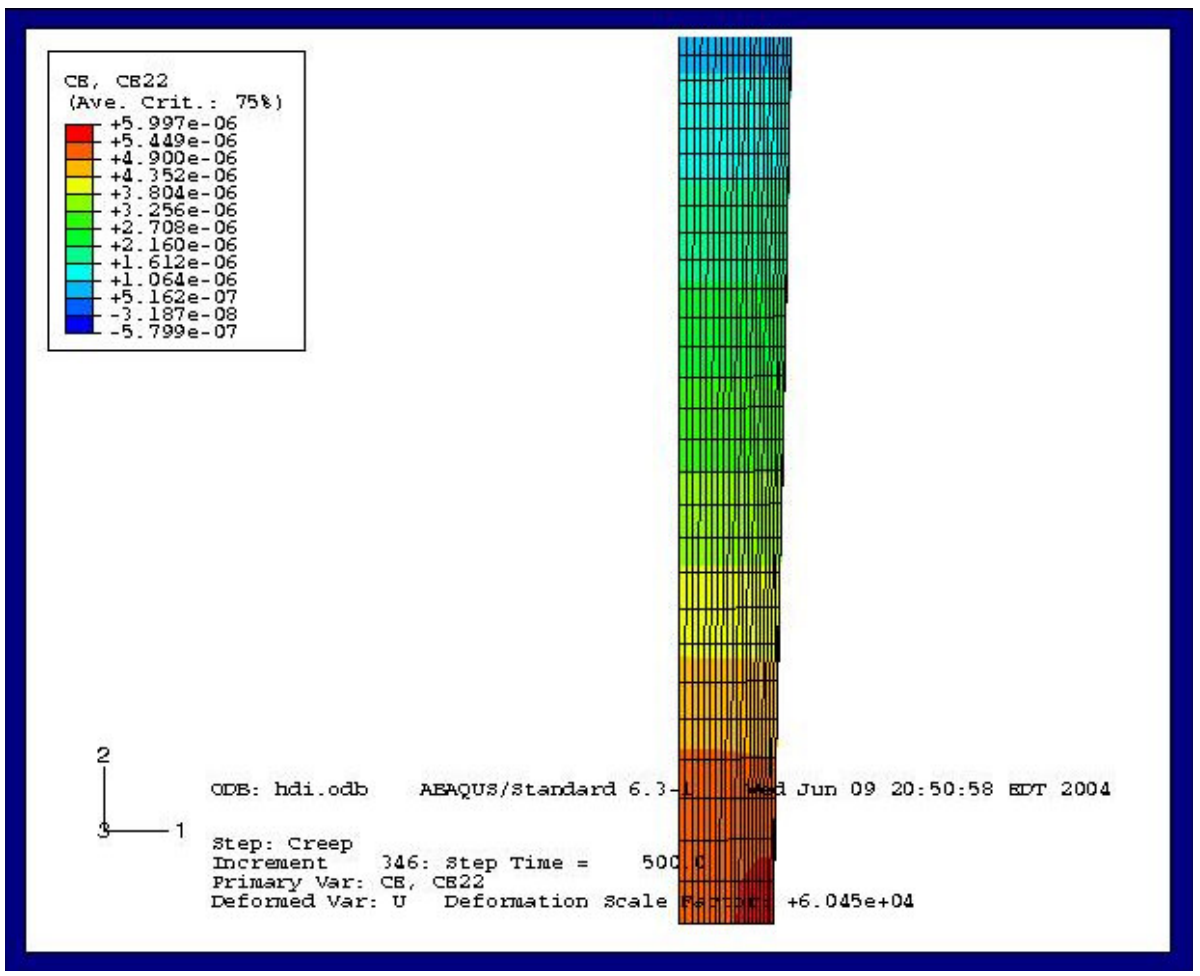

Figure 7.5 Creep Strain Contour for Applied Stresses of $\sigma_{w}=6.5$ psi and $\tau_{w}=1.76$ psi at $2060{ }^{\circ} \mathbf{F}$

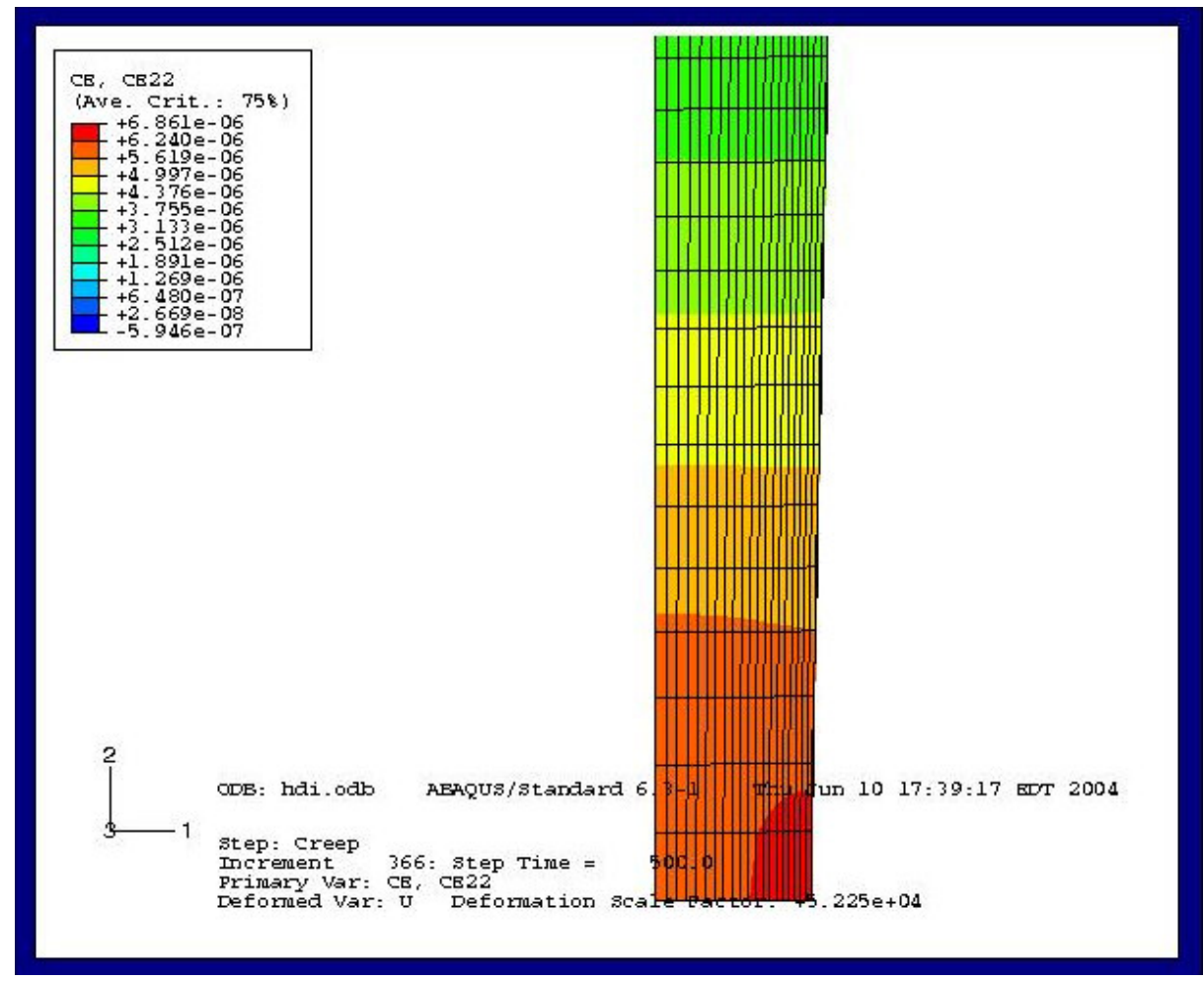

Figure 7.6 Creep Strain Contour for Applied Stresses of $\sigma_{w}=7 \mathrm{psi}$ and $\tau_{w}=2$ psi at $2060{ }^{\circ} \mathrm{F}$ 


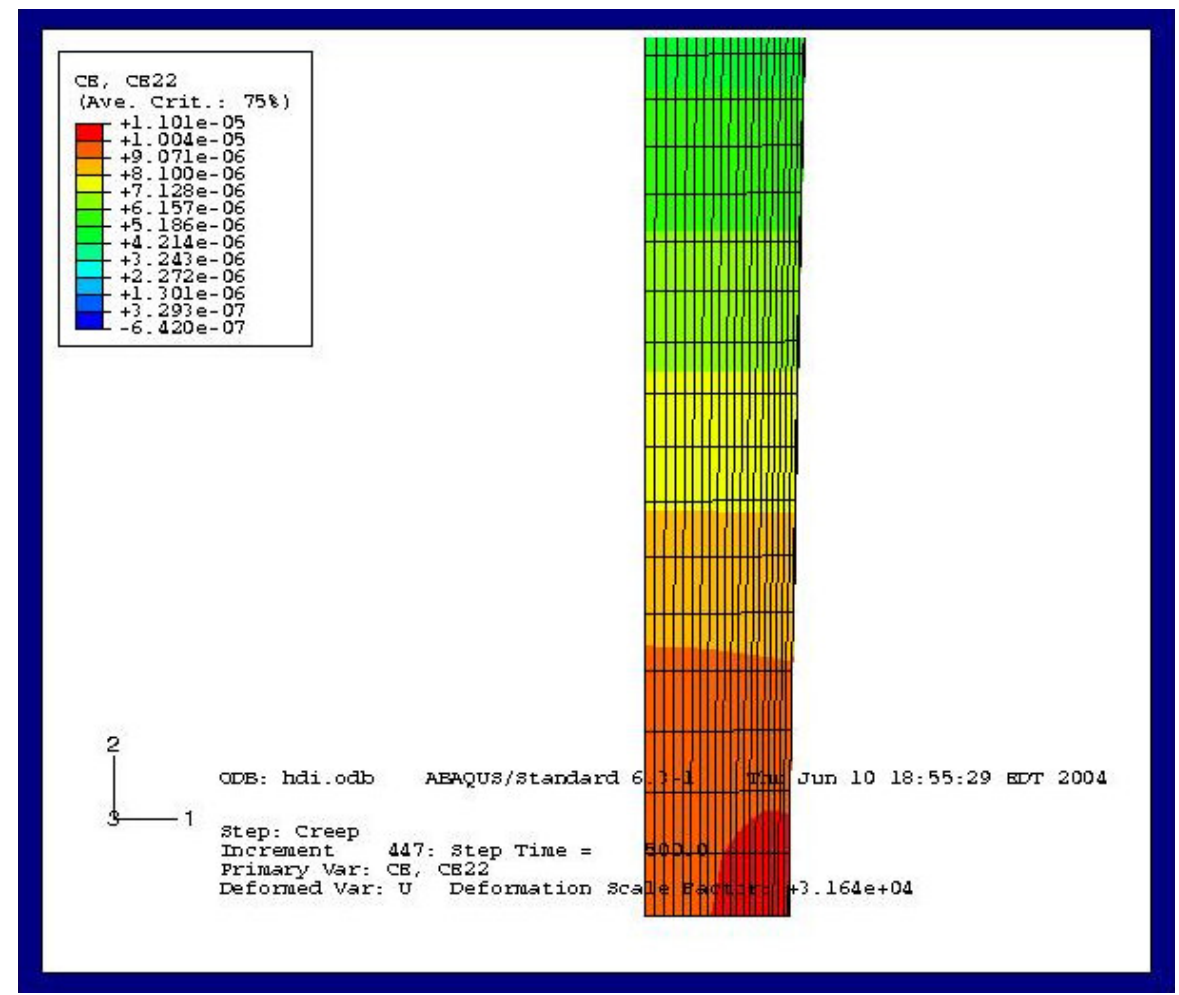

Figure 7.7 Creep Strain Contour for Applied Stresses of $\sigma_{w}=8.5$ psi and $\tau_{w}=2.75$ psi at $2060^{\circ} \mathrm{F}$

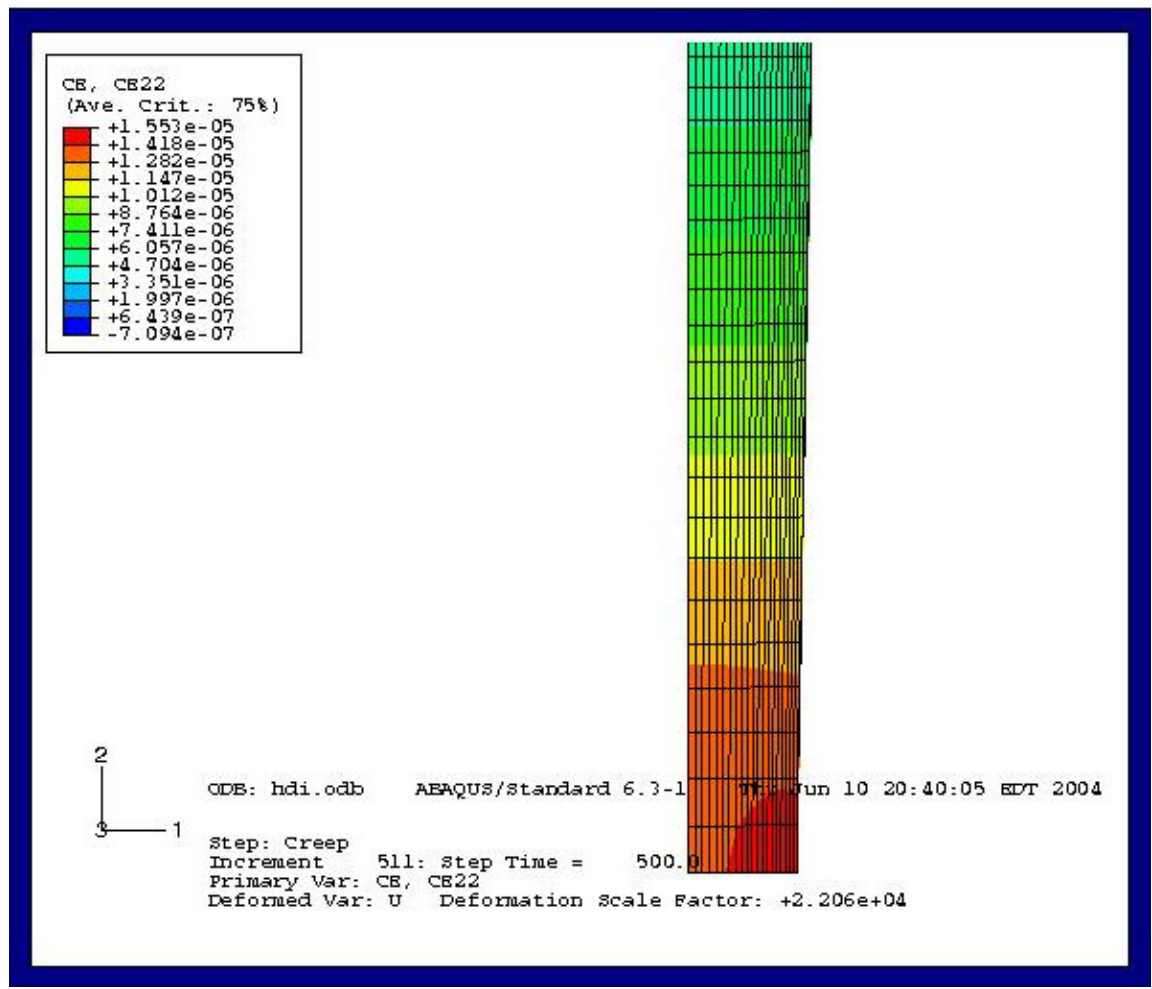

Figure 7.8 Creep Strain Contour for Applied Stresses of $\sigma_{w}=10 \mathrm{psi}$ and $\tau_{w}=3.5 \mathrm{psi}$ at $2060{ }^{\circ} \mathrm{F}$ 


\subsubsection{Creep Strain Dependence on Normal Stress}

Table 7.2 illustrates the creep strain values obtained for varied normal stress at a temperature of $2060^{\circ} \mathrm{F}$ over a time period of 500 hours.

Table 7.2 Creep Strain Data with Variation of Normal Stress $\left(\sigma_{w}\right)$ at $2060{ }^{\circ} \mathbf{F}$

\begin{tabular}{|c|c|}
\hline Normal Stress (psi) & Creep Strain \\
\hline 1.76 & $6.00 \mathrm{e}-06$ \\
\hline 2.00 & $6.86 \mathrm{e}-06$ \\
\hline 2.75 & $1.10 \mathrm{e}-05$ \\
\hline 3.50 & $1.55 \mathrm{e}-05$ \\
\hline
\end{tabular}

Table 7.3 illustrates the creep strain values obtained for varied normal stress at a temperature of $2010^{\circ} \mathrm{F}$ over a time period of 500 hours.

Table 7.3 Creep Strain Data with Variation of Normal Stress $\left(\sigma_{w}\right)$ at $2010{ }^{\circ} \mathbf{F}$

\begin{tabular}{|c|c|}
\hline Normal Stress (psi) & Creep Strain \\
\hline 1.76 & $3.40 \mathrm{e}-06$ \\
\hline 2.00 & $4.03 \mathrm{e}-06$ \\
\hline 2.75 & $6.25 \mathrm{e}-06$ \\
\hline 3.50 & $8.80 \mathrm{e}-06$ \\
\hline
\end{tabular}

Figure 7.9 shows the creep strain dependence on normal stress at two temperatures $2060^{\circ} \mathrm{F}$ and $2010^{\circ} \mathrm{F}$ respectively after a time period of 500 hours.

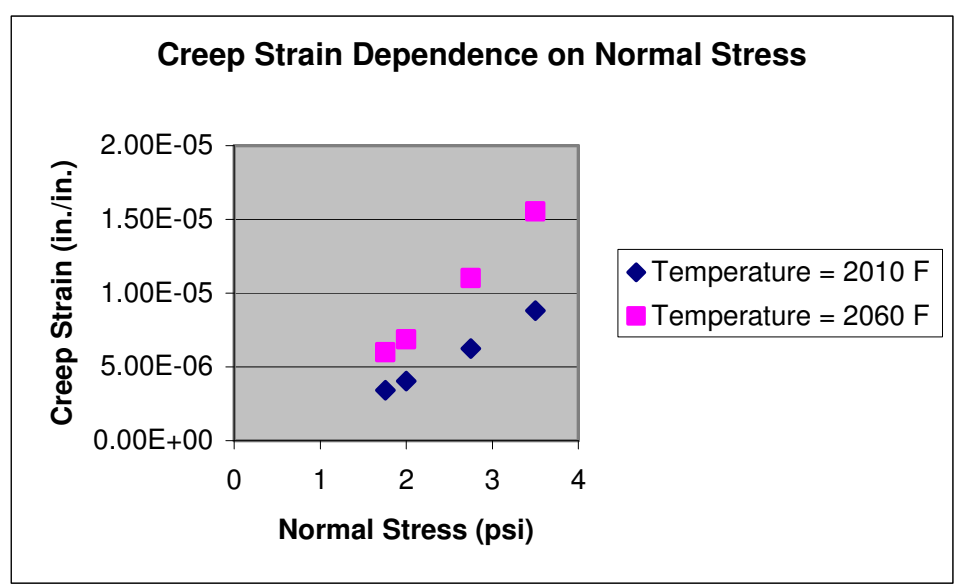

Figure 7.9 Creep Strain Dependence on Normal Stress 


\subsubsection{Creep Strain Dependence on Shear Stress}

Table 7.4 illustrates the creep strain values obtained for varied shear stress at a temperature of $2060^{\circ} \mathrm{F}$ over a time period of 500 hours.

Table 7.4 Creep Strain Data with Variation of Shear Stress $\left(\tau_{w}\right)$ at $2060{ }^{\circ} \mathbf{F}$

\begin{tabular}{|c|c|}
\hline Shear Stress (psi) & Creep Strain \\
\hline 6.50 & $6.00 \mathrm{e}-06$ \\
\hline 7.00 & $6.86 \mathrm{e}-06$ \\
\hline 8.50 & $1.10 \mathrm{e}-05$ \\
\hline 10.00 & $1.55 \mathrm{e}-05$ \\
\hline
\end{tabular}

Table 7.5 illustrates the creep strain values obtained for varied shear stress at a temperature of $2010^{\circ} \mathrm{F}$ over a time period of 500 hours.

Table 7.5 Creep Strain Data with Variation of Shear Stress $\left(\tau_{w}\right)$ at $2010^{\circ} \mathbf{F}$

\begin{tabular}{|c|c|}
\hline Shear Stress (psi) & Creep Strain \\
\hline 6.50 & $3.40 \mathrm{e}-06$ \\
\hline 7.00 & $4.03 \mathrm{e}-06$ \\
\hline 8.50 & $6.25 \mathrm{e}-06$ \\
\hline 10.00 & $8.80 \mathrm{e}-06$ \\
\hline
\end{tabular}

Figure 7.10 shows the creep strain dependence on shear stress at two temperatures $2060^{\circ} \mathrm{F}$ and $2010^{\circ} \mathrm{F}$ respectively after a time period of 500 hours.

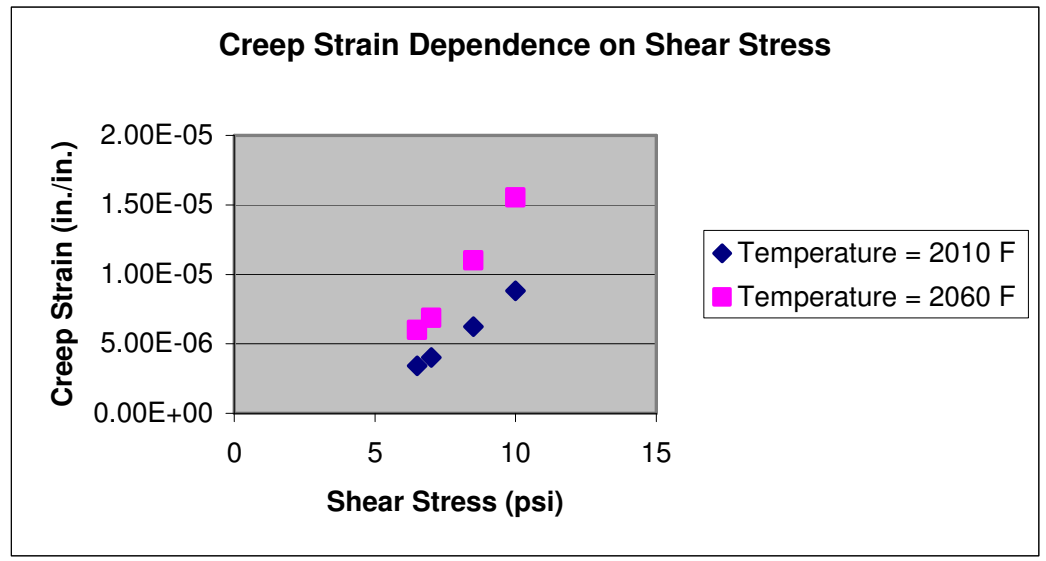

Figure 7.10 Creep Strain Dependence on Shear Stress 


\subsubsection{Creep Strain Dependence on Temperature}

Temperature dependence of creep strain in the untreated plunger model is studied by the variation of temperature at a constant applied stress over a specific period of time. For the present analysis three different temperatures of $2010^{\circ} \mathrm{F}, 2060^{\circ} \mathrm{F}$ and $2200^{\circ} \mathrm{F}$ are considered. Figures 7.11, 7.12 and 7.13 show the creep strain contours with varied temperatures.

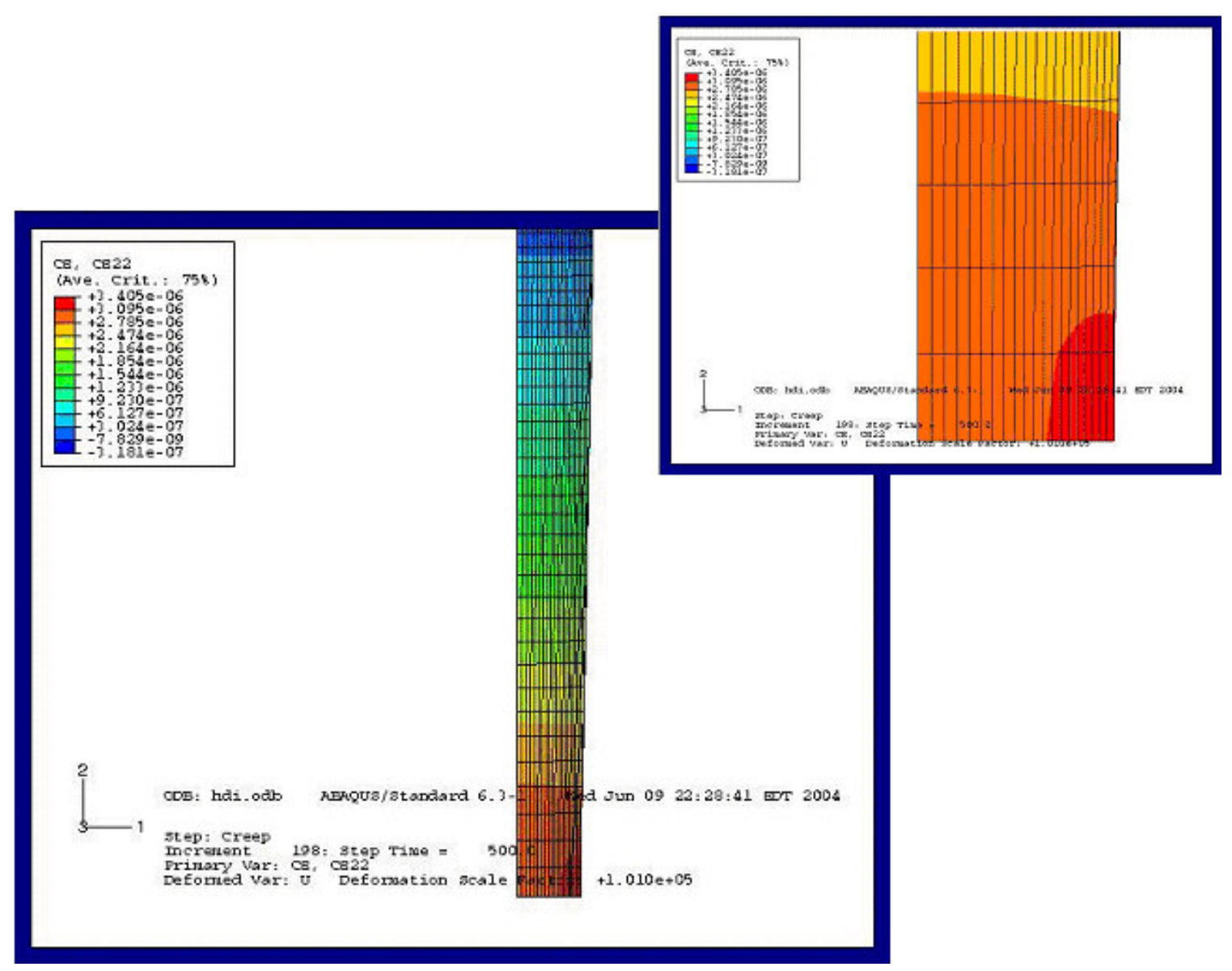

Figure 7.11 Creep Strain Contour at $2010{ }^{\circ} \mathrm{F}$ after 500 Hours 


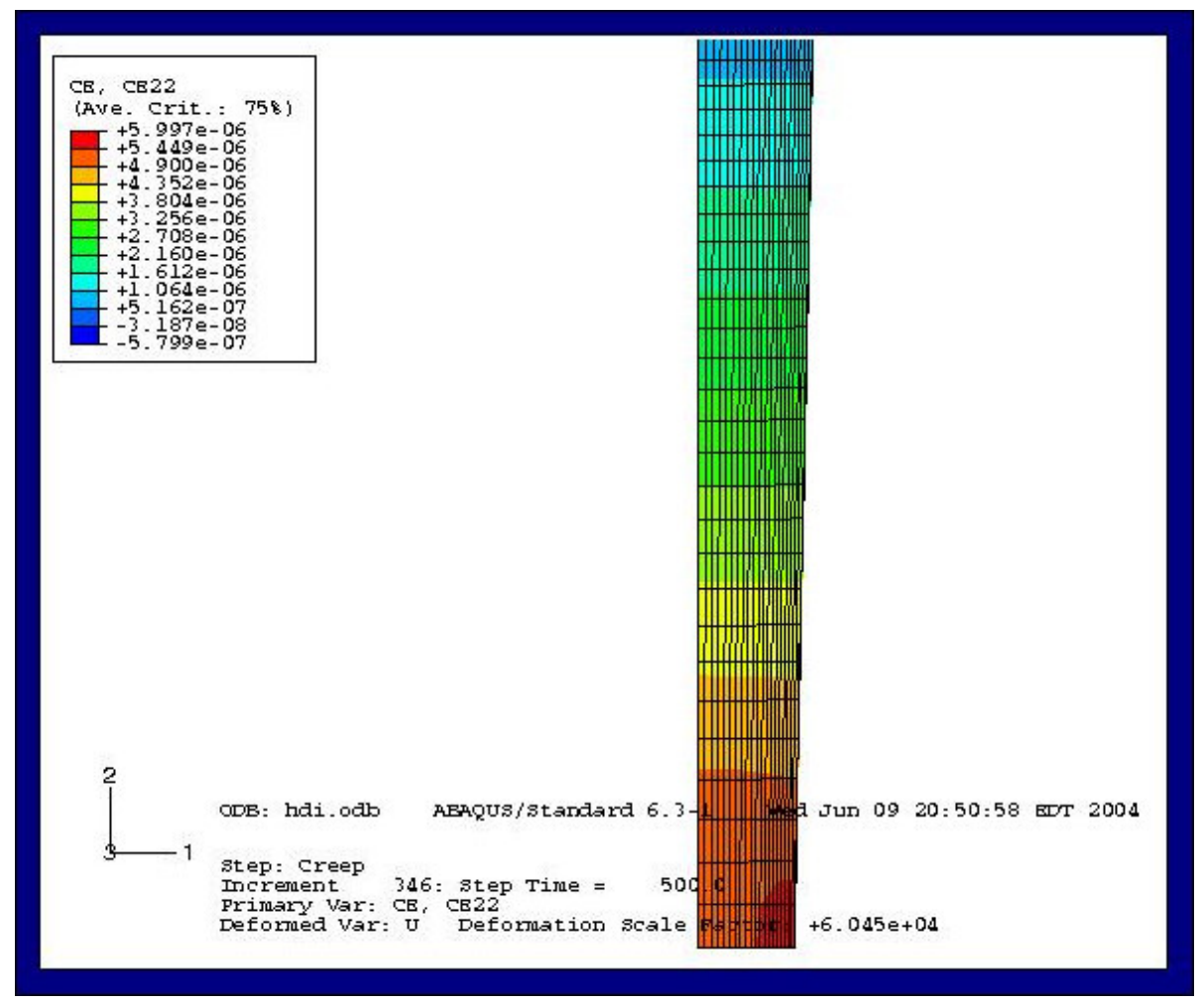

Figure 7.12 Creep Strain Contour at $2060^{\circ} \mathrm{F}$ after 500 Hours

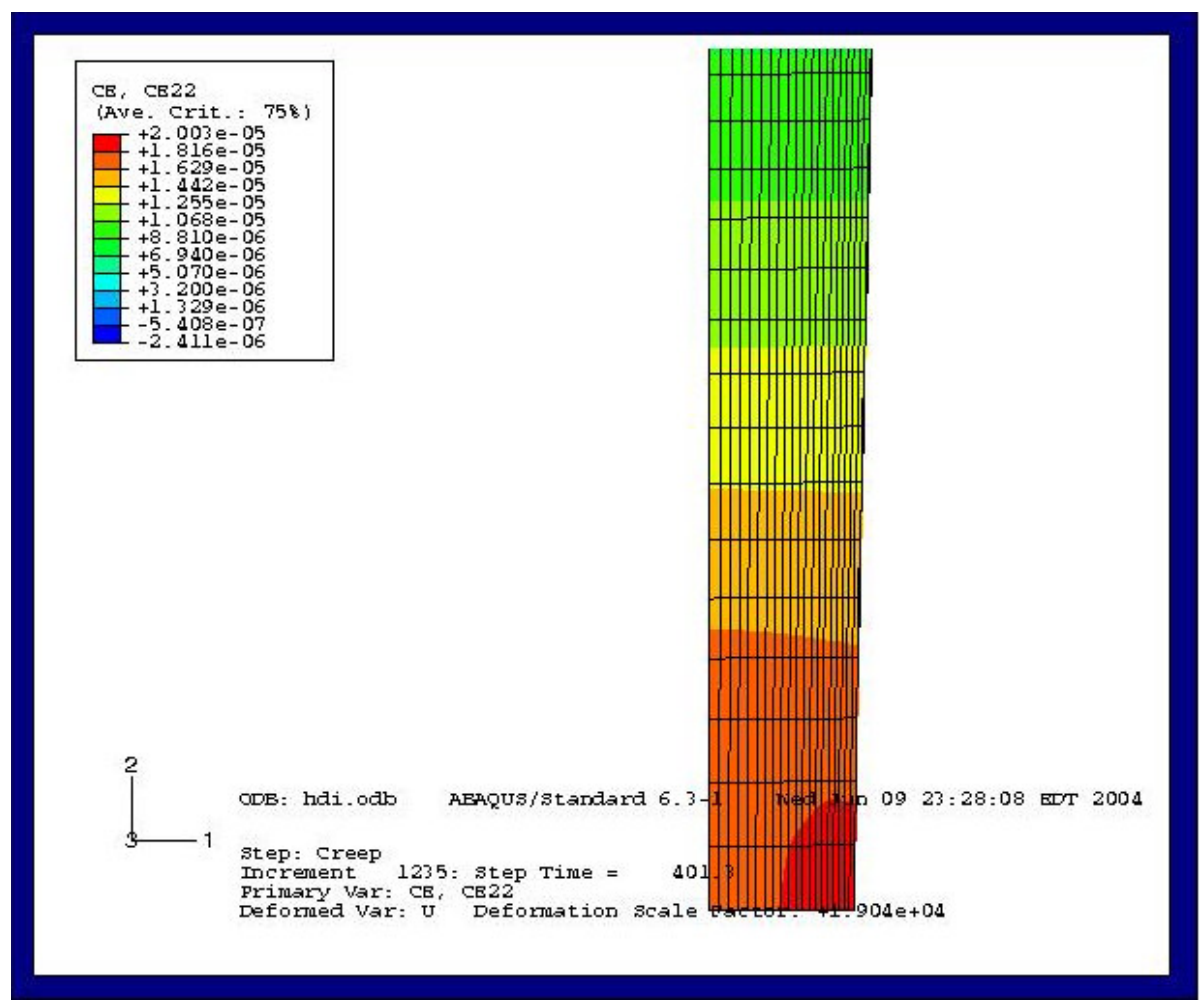

Figure 7.13 Creep Strain Contour at $2200{ }^{\circ} \mathrm{F}$ after 500 Hours 
Table 7.6 illustrates the creep strain values obtained for varied temperatures for the applied stresses of $\sigma_{w}=6.5 \mathrm{psi}$ and $\tau_{w}=1.76 \mathrm{psi}$ after a time period of 50 hours.

Table 7.6 Creep Strain Data after 50 Hours

\begin{tabular}{|c|c|}
\hline Temperature $\left({ }^{\circ} \mathrm{F}\right)$ & Creep Strain \\
\hline 2010 & $1.07 \mathrm{e}-06$ \\
\hline 2060 & $1.87 \mathrm{e}-06$ \\
\hline 2200 & $7.00 \mathrm{e}-06$ \\
\hline
\end{tabular}

Table 7.7 illustrates the creep strain values obtained for varied temperatures for the applied stresses of $\sigma_{w}=6.5 \mathrm{psi}$ and $\tau_{w}=1.76 \mathrm{psi}$ after a time period of 250 hours.

Table 7.7 Creep Strain Data after 250 Hours

\begin{tabular}{|c|c|}
\hline Temperature $\left({ }^{\circ} \mathrm{F}\right)$ & Creep Strain \\
\hline 2010 & $2.40 \mathrm{e}-06$ \\
\hline 2060 & $4.23 \mathrm{e}-06$ \\
\hline 2200 & $1.58 \mathrm{e}-05$ \\
\hline
\end{tabular}

Table 7.8 illustrates the creep strain values obtained for varied temperatures for the applied stresses of $\sigma_{w}=6.5 \mathrm{psi}$ and $\tau_{w}=1.76 \mathrm{psi}$ after a time period of 500 hours.

Table 7.8 Creep Strain Data after 500 Hours

\begin{tabular}{|c|c|}
\hline Temperature $\left({ }^{\circ} \mathrm{F}\right)$ & Creep Strain \\
\hline 2010 & $3.40 \mathrm{e}-06$ \\
\hline 2060 & $6.00 \mathrm{e}-06$ \\
\hline 2200 & $2.20 \mathrm{e}-05$ \\
\hline
\end{tabular}


Figure 7.14 shows the creep strain dependence on temperature after time periods of 50 hours, 250 hours and 500 hours respectively for an applied stress of $\sigma_{w}=6.5 \mathrm{psi}$ and $\tau_{w}=$ 1.76 psi.

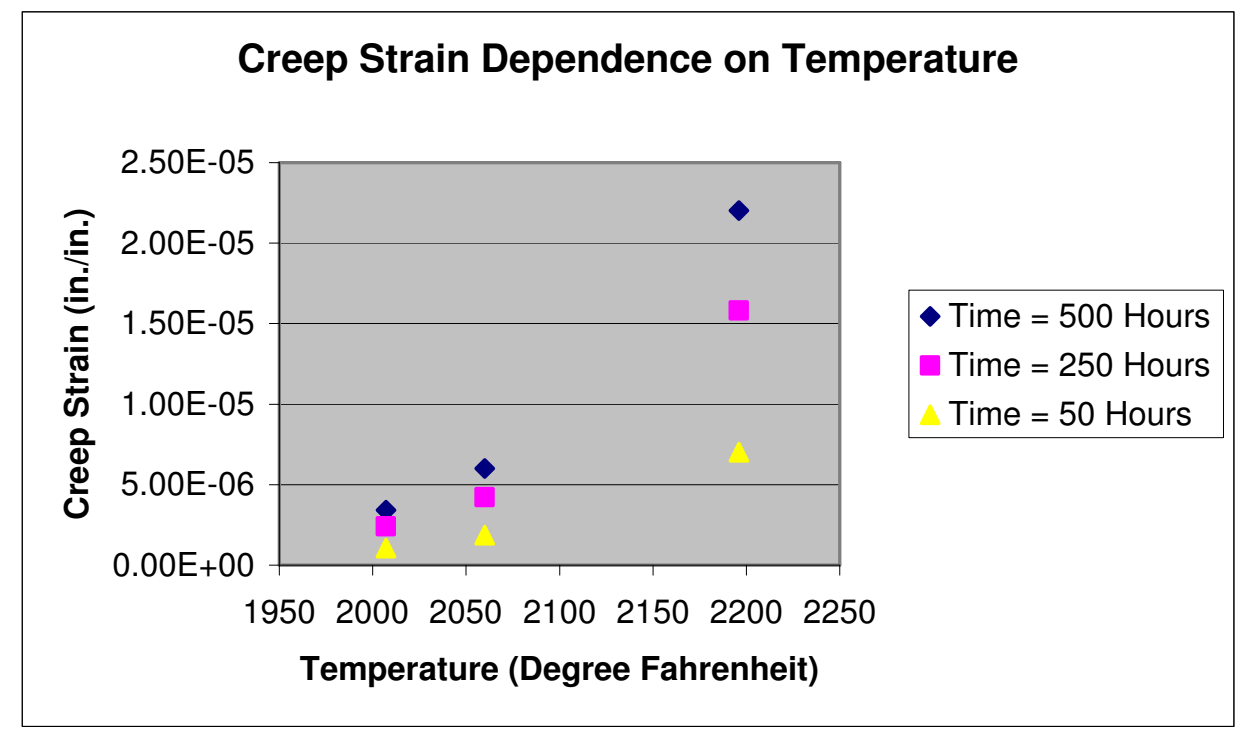

Figure 7.14 Creep Strain Dependence on Temperature 


\section{CHAPTER 8. Results and Discussion}

\subsection{Results Comparison}

The results obtained in Chapters 6 and 7 are compared as below to show the effectiveness of HDI surface treatment of ceramic refractory materials for glass furnace. All results are based on assumed values for the coating material. Refer Section 7.2.1.1.

\subsubsection{Creep Curves Comparison}

The creep strain vs time curves are plotted for both untreated and HDI treated refractory materials. The creep strains for both the refractory materials are obtained with finite element numerical simulation program using ABAQUS over a time period of 500 hours. The creep curve of HDI treated refractory material shows the effectiveness of HDI treatment to extend the useful life of refractory material.

\subsubsection{Extension of Useful Life of Refractory Material}

Figure 8.1 illustrates that the HDI treated refractory material creeps about $6.00 \mathrm{e}-06$ in./in. over a time period of 500 hours. On the other hand, the untreated refractory material creeps about the same over a time period of 200 hours. This result indicates that the useful life of the refractory material has been extended by 300 hours with HDI treatment. 


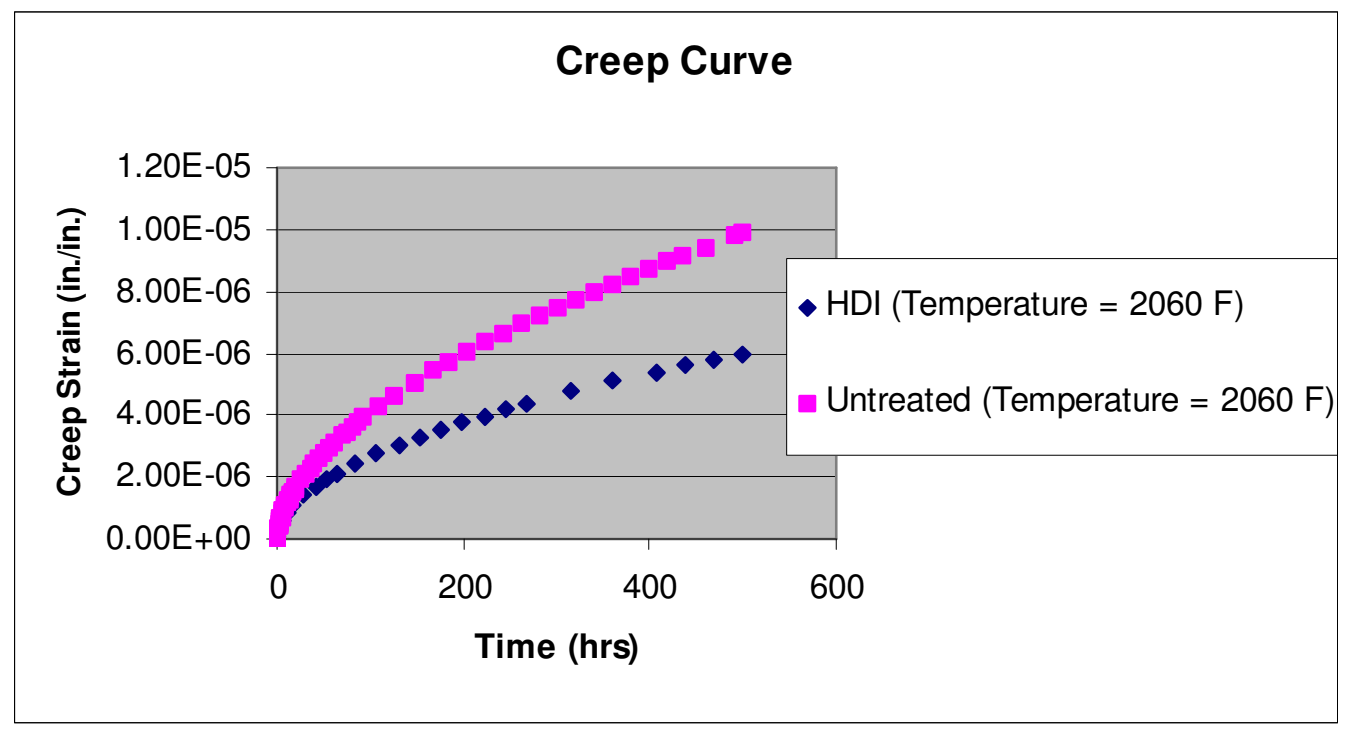

Figure 8.1 Creep Curves Comparison of HDI and Untreated Refractory Materials

\subsubsection{Stress Dependence Curves Comparison}

A comparison of the stress dependence curves is made to study the possibility of increasing the amount of glass to be melted and also the possibility of increasing the productivity of glassware manufacturing.

\subsubsection{Normal Stress Dependence Curves Comparison}

Normal stress directly corresponds to the amount of glass present as the normal stress experienced by the plunger increases with the height of the molten glass level. The normal stress comparison curves of untreated and HDI treated refractory materials reveal the importance of HDI treatment in increasing the amount of glass that can be melted.

\subsection{More Glass Output}

If a creep strain of 1.5e-05 in./in. is taken as a reference in Figure 8.2, the HDI treated refractory material operating at $2060{ }^{\circ} \mathrm{F}$ can withstand a normal stress of 3.5 psi. On the other hand, the untreated refractory material can only withstand a normal stress of about 2.3 psi. This illustration gives a good understanding that the HDI treatment can improve 
the output efficiency of a glass melting furnace because the normal stress directly relates the height of the molten glass present in a molten glass feeder.

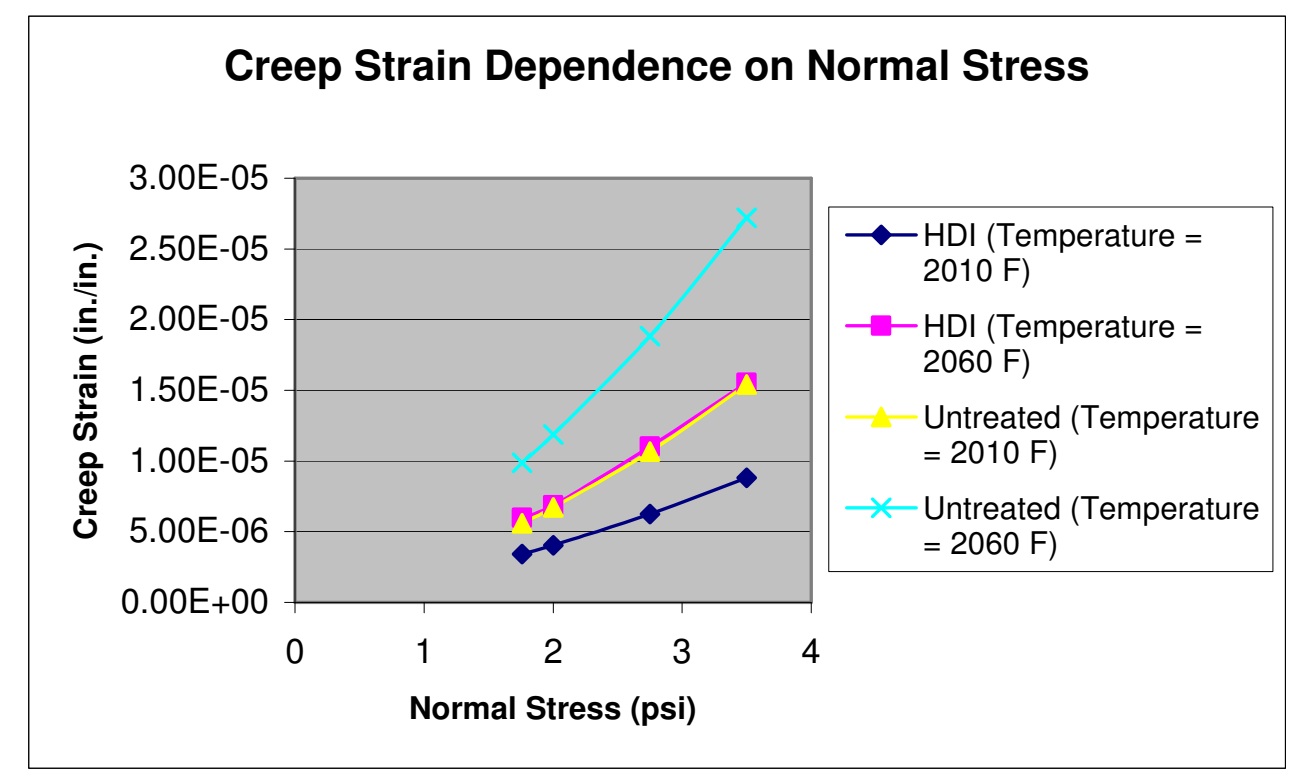

Figure 8.2 Creep Strain Dependence on Normal Stress of HDI and Untreated Refractory Materials

\subsubsection{Shear Stress Dependence Curves Comparison}

Shear stress dependence of creep strain suggests the possibility of increasing the operational speed of the plunger as the number of oscillations per second of the plunger is directly proportional to the shear stress on the wall of the plunger.

\subsection{Increased Productivity}

Figure 8.3 illustrates that the HDI treated refractory material can be used to withstand the higher shear stresses experienced by a plunger when it is operated at higher speeds because the shear stress is directly proportional to the number of oscillations per second of the plunger. This illustration indicates the increased productivity of glassware manufacturing. 


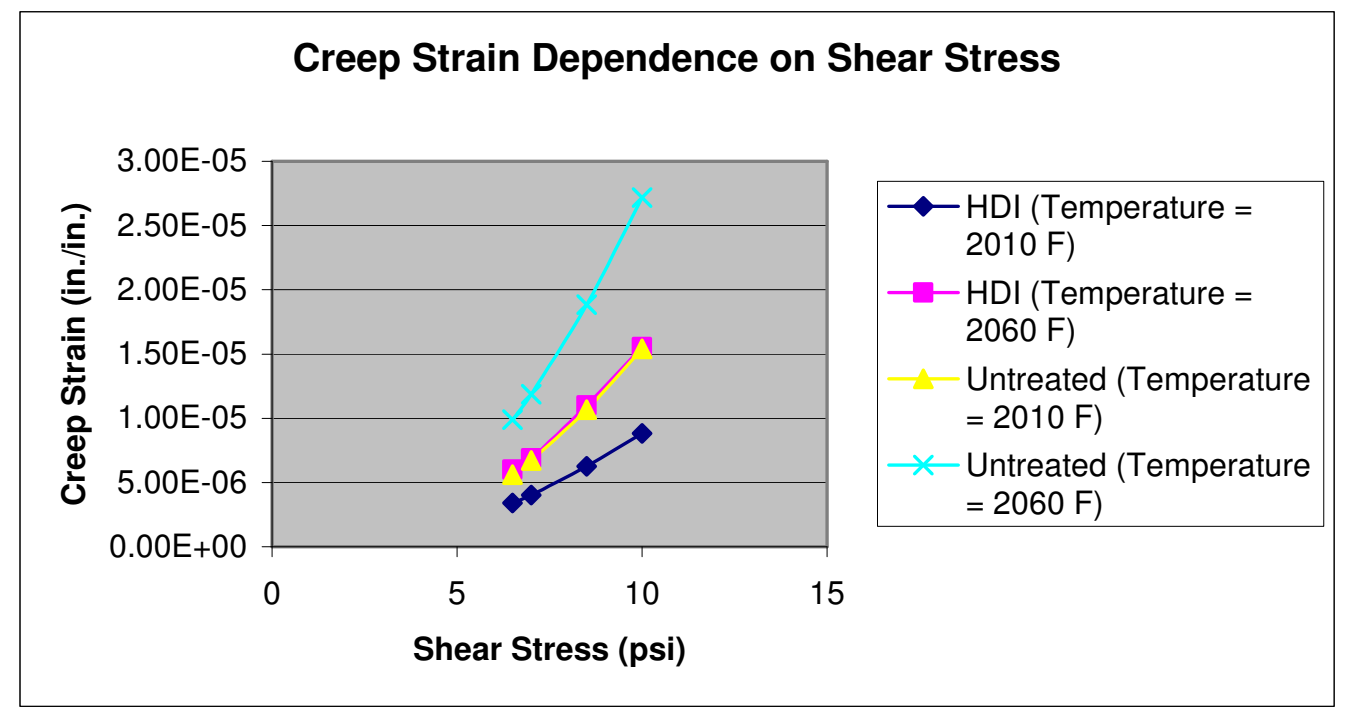

Figure 8.3 Creep Strain Dependence on Shear Stress of HDI and Untreated Refractory Materials

\subsubsection{Temperature Dependence Curves Comparison}

Study of temperature dependence of creep strain suggests the effective utilization of HDI treated refractory material for a glass melting furnace that contains an oxy-fuel environment, which can operate at higher temperatures.

\subsubsection{Enhanced Refractory Material for Oxy-Fuel Furnace}

Figure 8.4 illustrates that the HDI treated refractory material operating at a temperature of $2200{ }^{\circ} \mathrm{F}$ creeps about 2.25 e-05 in./in. over a time period of 500 hours. On the other hand, the untreated refractory material operated over 500 hours creeps the same at a temperature of about $2120{ }^{\circ} \mathrm{F}$. Also, the coincidence of normal stress dependence curves and as well as the shear stress dependence curves of HDI and Untreated refractory materials operating at $2060{ }^{\circ} \mathrm{F}$ and $2010{ }^{\circ} \mathrm{F}$ respectively gives a good reasoning for the effective utilization of HDI treated refractory materials at elevated temperatures, which would be an oxy-fuel environment. 


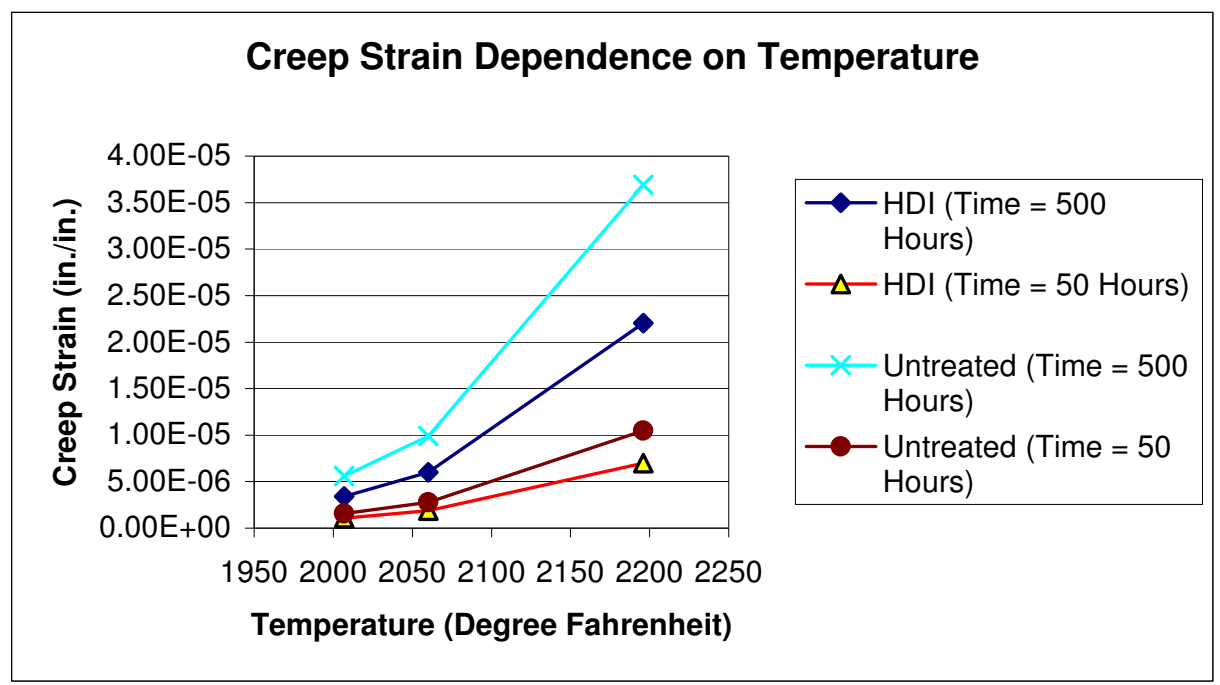

Figure 8.4 Creep Strain Dependence on Temperature of HDI and Untreated Refractory Materials 


\section{CHAPTER 9. CONTRIBUTIONS AND FUTURE RESEARCH}

\subsection{Contributions}

The goal of this thesis was to determine the effectiveness of HDI treatment to extend the useful life of refractory material. Numerical simulation studies were conducted to document the improved creep resistance of the treated refractory material. The main result of this thesis was to identify the importance of HDI surface treatment of refractory materials to the glass industry and, in particular, to project its effective use for enhancing an oxy-fuel furnace. The contributions are based on the assumed material constants for the surface coated material as given in Section 7.2.1.1.

The six key contributions of this thesis are:

1. Identified the critical range for the key parameters that control the creep strain in fused cast alumina material. See Table 6.2. These parameters include the time the refractory material is in use in the glass melting furnace, the operating temperature of the glass melting furnace, the state of stress in the refractory plunger material that includes the normal stress and the shear stress due to the molten glass, and the thickness of HDI coated material in the refractory material of interest.

2. Developed creep curves for both the untreated fused cast alumina material and the HDI treated alumina material using numerical results obtained using the finite element program, ABAQUS. These results, which are shown in Chapters 6 and 7, should aid furnace engineers better predict and maintain structural integrity of glass melting furnace.

3. Determined the effectiveness of HDI treatment on the fused cast alumina refractory material in terms of its improved creep resistance by calculating that 
the relative effectiveness of HDI treated alumina material compared to untreated alumina material was $150 \%$. See Figure 8.1.

4. Determined that $65 \%$ more glass can be melted using HDI treated refractory material by studying the creep strain dependence on normal stress. See Figure 8.2.

5. Determined that the creep strain dependence on shear stress of the plunger enabled $70 \%$ increased productivity of glassware manufacturing using HDI treated refractory material. See Figure 8.3.

6. Studied the creep strain dependence on glass melting temperature and determined a $40 \%$ improved effective utilization when HDI treated refractory material is used for a glass melting furnace that contains an oxy-fuel environment. See Figure 8.4.

\subsection{Future Research}

1. Alumina-Zirconia-Silica (AZS) refractory materials are widely used in the glass industry and hence experimental creep data might become available for HDI treated AZS materials.

2. Finite element analysis can be performed to optimize the critical parameters, such as temperature, applied stress and coating material thickness, that control the useful life of the enhanced refractory material.

3. Secondary creep analysis of HDI treated refractory materials can be performed using FEA with the help of experimental data to predict the failure.

4. Refractory bricks in the critical failure regions of an oxy-fuel-fired furnace environment can be analyzed. 


\section{REFERENCES}

1. Strategic Plan, Industrial Technologies Program, US Department of Energy, Office of Energy Efficiency and Renewable Energy, Washington, DC., August 2003, pp. 1-13.

URL: $\underline{w w w}$.eere.energy.gov/industry

2. Charles A. Sorrell, Development of Advanced Refractories for the Glass Manufacturing Industry, Project Fact Sheet, US Department of Energy, Office of Industrial Technologies, Energy Efficiency and Renewable Energy, Washington, DC., February 1999, pp. 1-2.

URL: http://www.ms.ornl.gov/programs/energyeff/aim/factsheets/glass.pdf

3. Science and Technology Highlights, Oak Ridge National Laboratory (ORNL) Energy Efficiency and Renewable Energy Program, No. 3, 2002, p 4.

4. Charles A.Sorrell and Mike Soboroff, High Density Infrared Surface Treatment of Refractories, Project Fact Sheet, US Department of Energy, Office of Industrial Technologies, Energy Efficiency and Renewable, Energy, Washington, DC., January 2002, pp. 4-5.

URL: http://www.ornl.gov/sci/eere/PDFs/sci_tech_hilights/No3_02.pdf

5. William Headrick, Robert Moore, James Hemrick and Mattison Ferber, Characterization and Modeling of Glass Tank Refractories at University of Missouri-Rolla (UMR) and Oak Ridge National Laboratory (ORNL), Refractory Applications and News, Volume 8, Number 4, July/August 2003, pp. 13-15. URL: http://www.ranews.info/feat_art/2003/faja03.pdf

6. James G. Hemrick, Robert E. Moore, Andrew A. Wereszczak and Mattison K. Ferber, Creep Behavior and Physical Characterization of Fusion-Cast Alumina Refractories, Refractory Applications and News, Volume 6, Number 3, August 2001, pp. 8-9. 
7. Glass-Industry of the Future, Energy and Environmental Profile of the U.S. Glass Industry, US Department of Energy, Office of Industrial Technologies Energy Efficiency and Renewable Energy, Washington, DC. April 2002, pp. 1-32.

8. Douglas W. Freitag, Glass Industry, Chapter 6, pp. 6.1-6.13.

9. T. N. Tiegs, J. O. Kiggans, F. C. Montgomery, D. C. Harper and C. A. Blue, M. Velez, M. Karakus and R. E. Moore, Surface Modification of Ceramics by High Density Infrared Heating, Ceram. Eng. Sci. Proc., 24[4], 2003.

10. T. N. Tiegs, F. C. Montgomery, D. C. Harper and C. A. Blue, Surface Treatment of AZS Refractories Using High Density Infrared Heating, Unpublished Results, 2004.

11. American Ceramic Society Bulletin, Volume 83, Number 1, Jan 2004, pp. 8-30.

12. American Ceramic Society Bulletin, Volume 83, Number 4, April 2004, pp. 4-5, 14, 27-36.

13. Ceramic Industry, Business News Publishing Company (BNP), Volume 151, Issue No. 11, October 2001, p 38.

14. David W. Richerson, Modern Ceramic Engineering, Marcel Dekker, Inc., 1982.

15. John B. Wachtman, Mechanical Properties of Ceramics, John Wiley \& Sons, Inc., 1996.

16. Carniglia, Stephen C., Handbook of Industrial Refractories Technology, William Andrew Pub., 1992.

17. F. V. Tooley, The Handbook of Glass Manufacture, Ashlee Publishing, NY, 1984. Vol. $1 \& 2$. 
18. Tze-jer Chuang, et al., Analysis of Creep in a Si-SiC C-Ring by Finite Element Method, Journal of Engineering Materials and Technology, Volume. 114, July 1992, pp. 311-316.

19. R. Volkl, B. Fischer, D. Gohlke, FEM-Modeling Of The Creep Behaviour Of Platinum Alloys For The Glass Industry, $23^{\text {rd }}$ International Precious Metals Conference, Acapulco, Mexico. June 20-23, 1999, pp. 1-6.

20. Zarina Masood, et al., A Modified Approach for Life Assessment of High Temperature Power Plant Components, Department of Aerospace Engineering, University Putra Malaysia, pp. 23-28.

21. C. D. Pomeroy, Creep of Ceramic Materials, A Journal of Strain Analysis Monograph from Creep of Engineering Materials, Mechanical Engineering Publications Limited, London. 1978, pp. 67-83, 85-97.

22. Charles A. Schacht, Refractory Linings, Thermo mechanical Design and Applications, Marcel Dekker, Inc., 1995, pp. 173-197.

23. Xiaopeng Chen, Computer Modeling and Simulation of Primary Creep Behavior in Glass Tank Refractories, MS Thesis, Alfred University, Alfred, NY, 1998.

24. Vince Adams and Abraham Askenazi, Building Better Products with Finite Element Analysis, OnWord Press, 1999.

25. Frank M. White, Viscous Fluid Flow, Mc Graw-Hill, Inc., 1974.

26. Abaqus/Standard User's Manual, Version 6.3, Volumes 1, 2 and 3.

27. Abaqus/CAE User's Manual, Version 6.3. 


\section{Appendix A. Input File and Creep Subroutine of Brick Model}

\section{A.1 ABAQUS Input File of Brick Model}

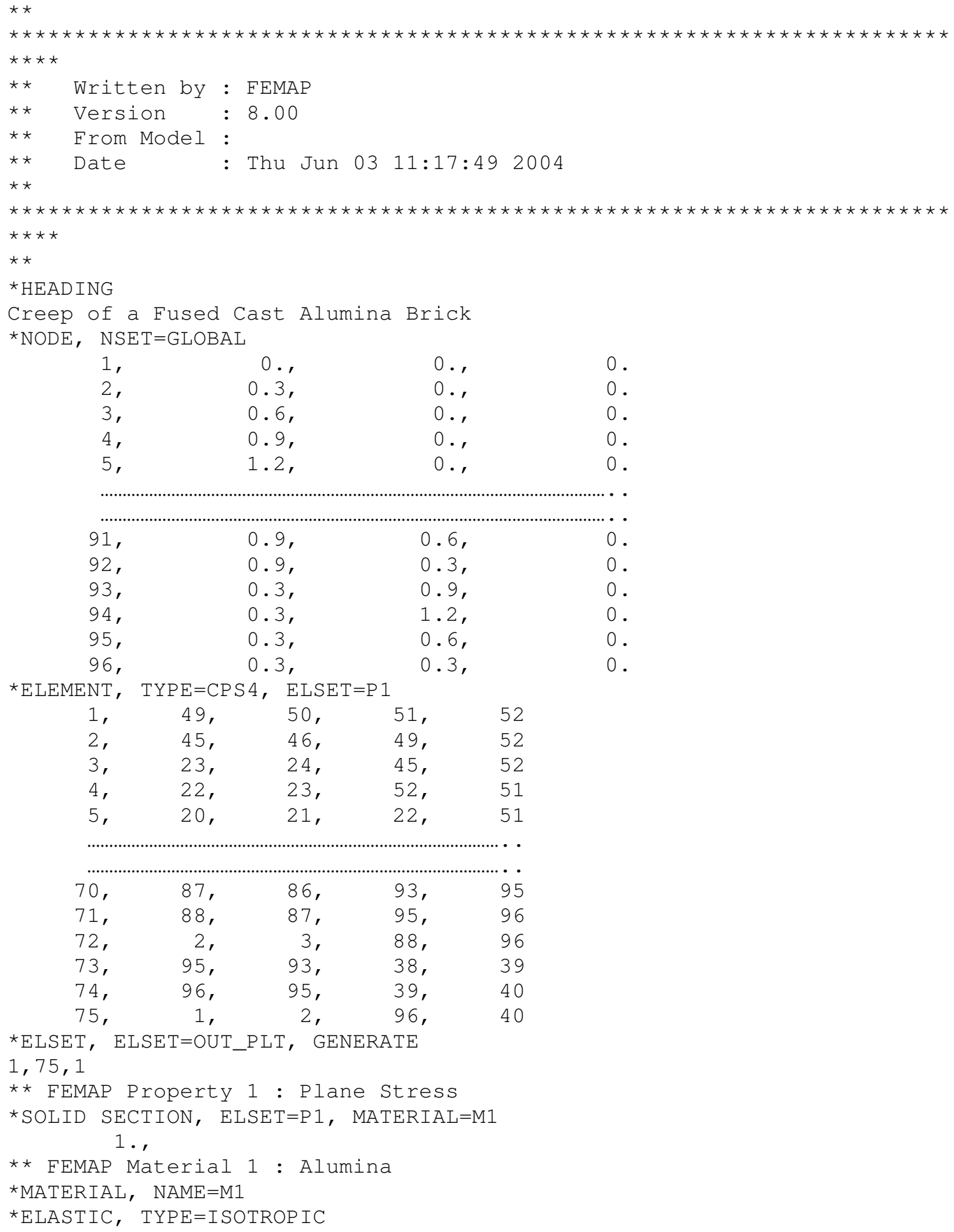




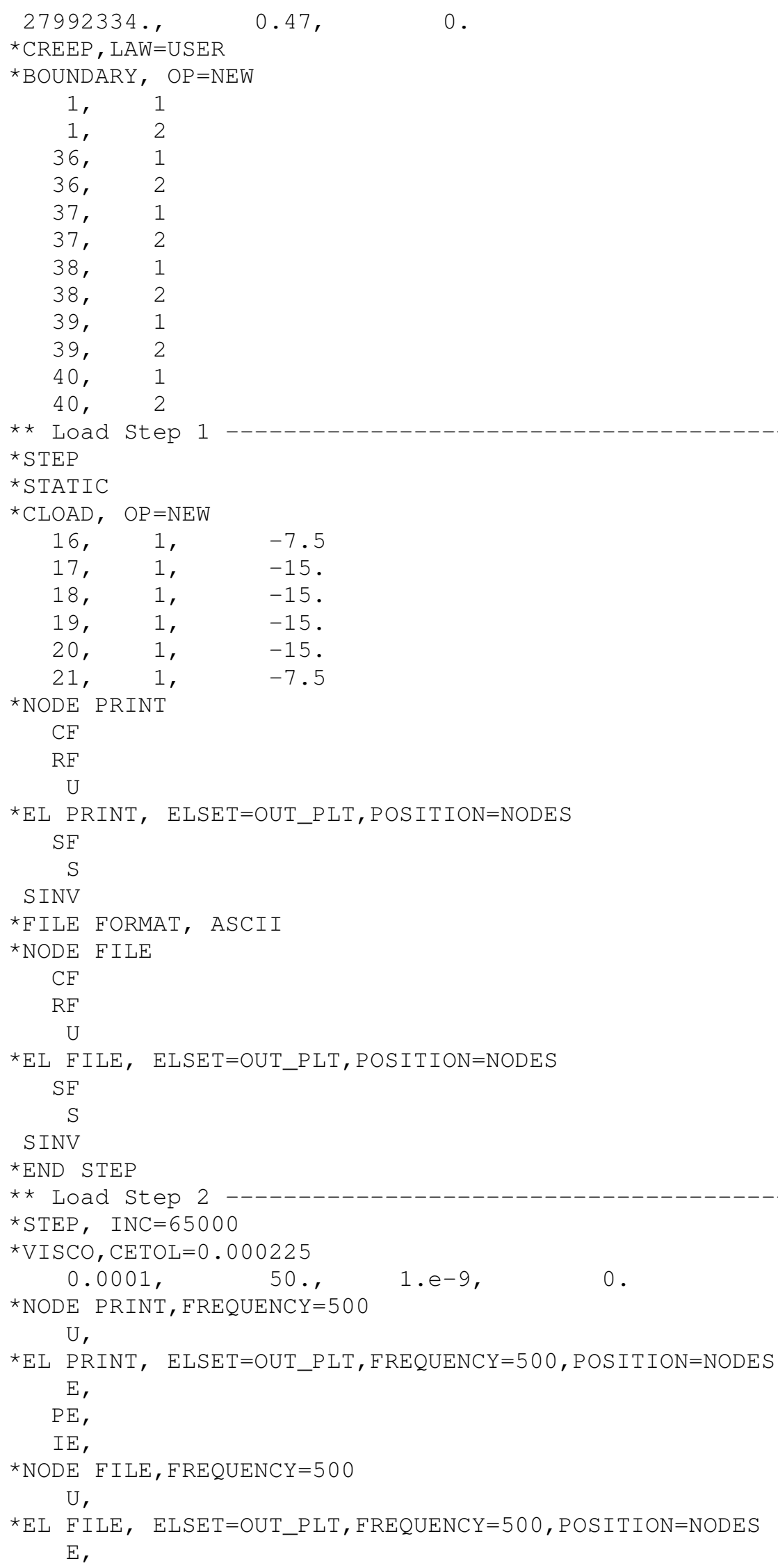




$$
\begin{gathered}
\text { PE, } \\
\text { IE, } \\
\text { *END STEP }
\end{gathered}
$$

\section{A.2 User Creep Subroutine Program for Brick Model}

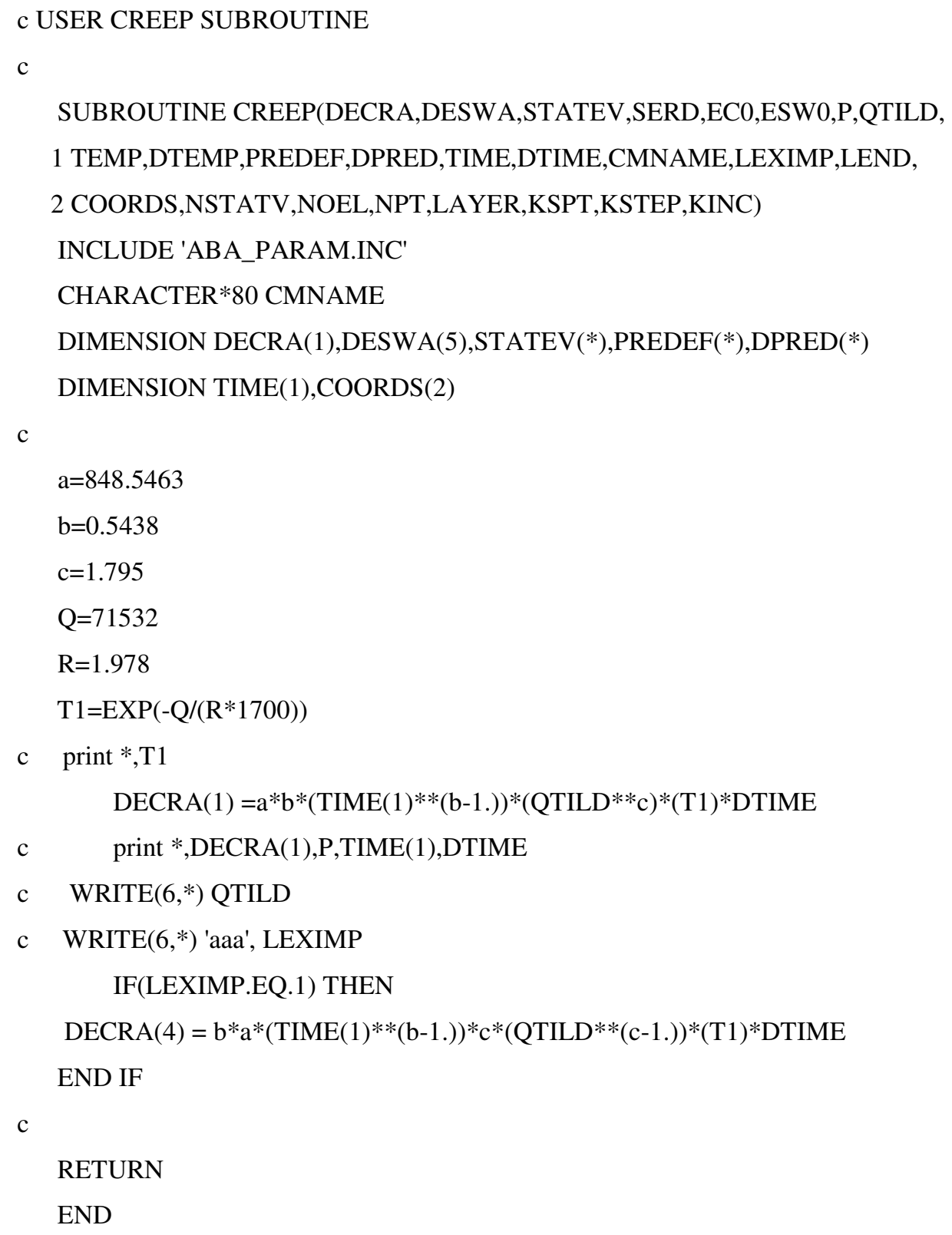




\section{Appendix B. Input File and Creep Subroutine of Untreated Plunger Model}

\section{B.1 ABAQUS Input File of Untreated Plunger Model}

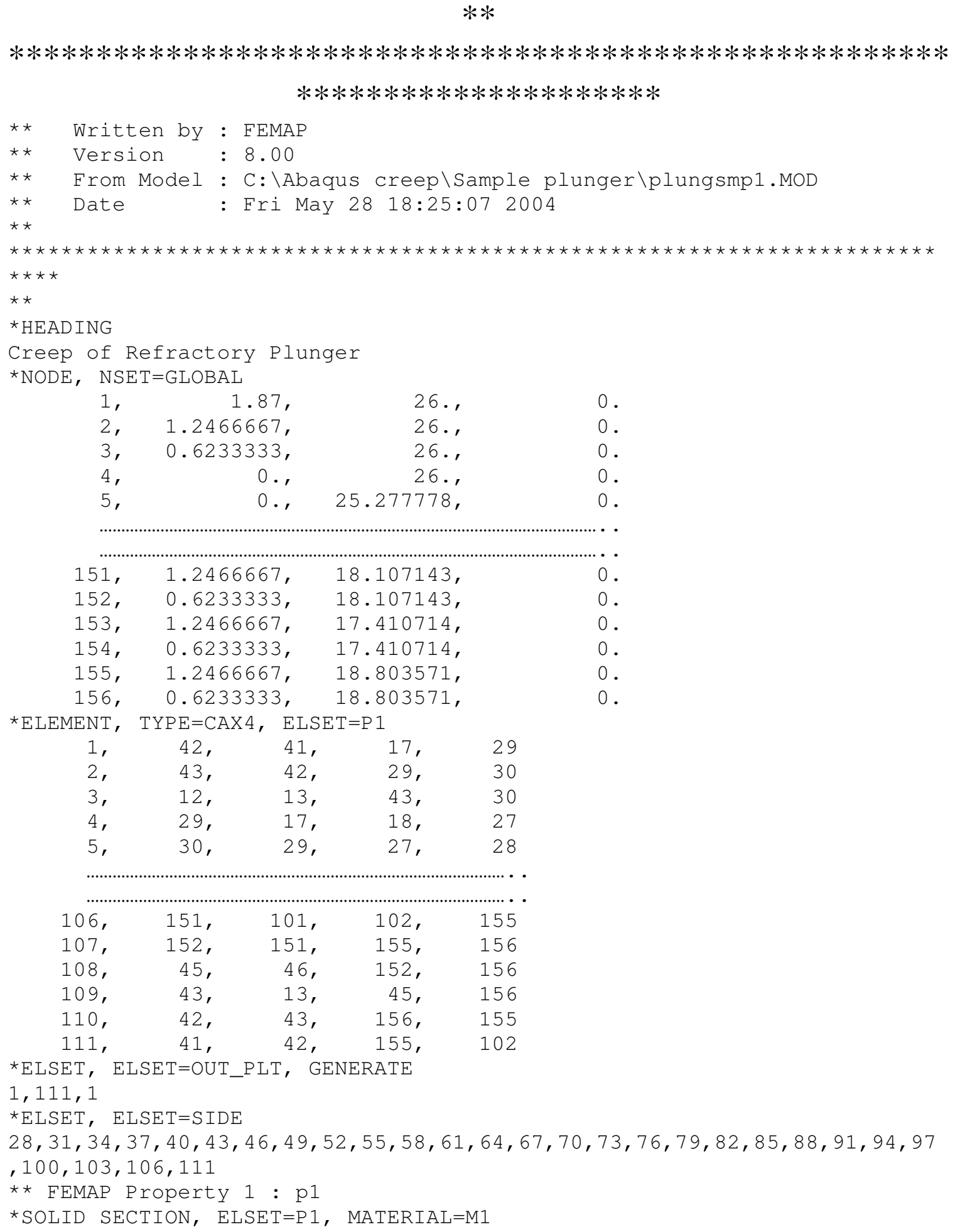


$1 .$,

** FEMAP Material 1 : Alumina

*MATERIAL, NAME $=\mathrm{M} 1$

*ELASTIC, TYPE=ISOTROPIC

27992334., $0.47, \quad 0$.

*CREEP, LAW=USER

*BOUNDARY, OP $=\mathrm{NEW}$

$4, \quad 1$

5,1

6,1

$7, \quad 1$

$8, \quad 1$

$9, \quad 1$

$10, \quad 1$

$11, \quad 1$

$12, \quad 1$

13,1

$45, \quad 1$

$46, \quad 1$

$47, \quad 1$

$48, \quad 1$

$49, \quad 1$

$50, \quad 1$

$51, \quad 1$

$52, \quad 1$

53,1

$54, \quad 1$

$55, \quad 1$

$56, \quad 1$

57,1

$58, \quad 1$

$59, \quad 1$

$60, \quad 1$

$61, \quad 1$

$62, \quad 1$

63,1

64,1

$65, \quad 1$

$66, \quad 1$

67,1

$68, \quad 1$

$69, \quad 1$

$70, \quad 1$

$71, \quad 1$

$72, \quad 1$

$72, \quad 2$

$73, \quad 2$

$74, \quad 2$

$75, \quad 2$

** Load Step 1

$\star \mathrm{STEP}$

L1

* STATIC

* CLOAD, OP=NEW

$4, \quad 2, \quad-30$.

$75, \quad 2, \quad 2.26339$

$76, \quad 2,4.52679$ 


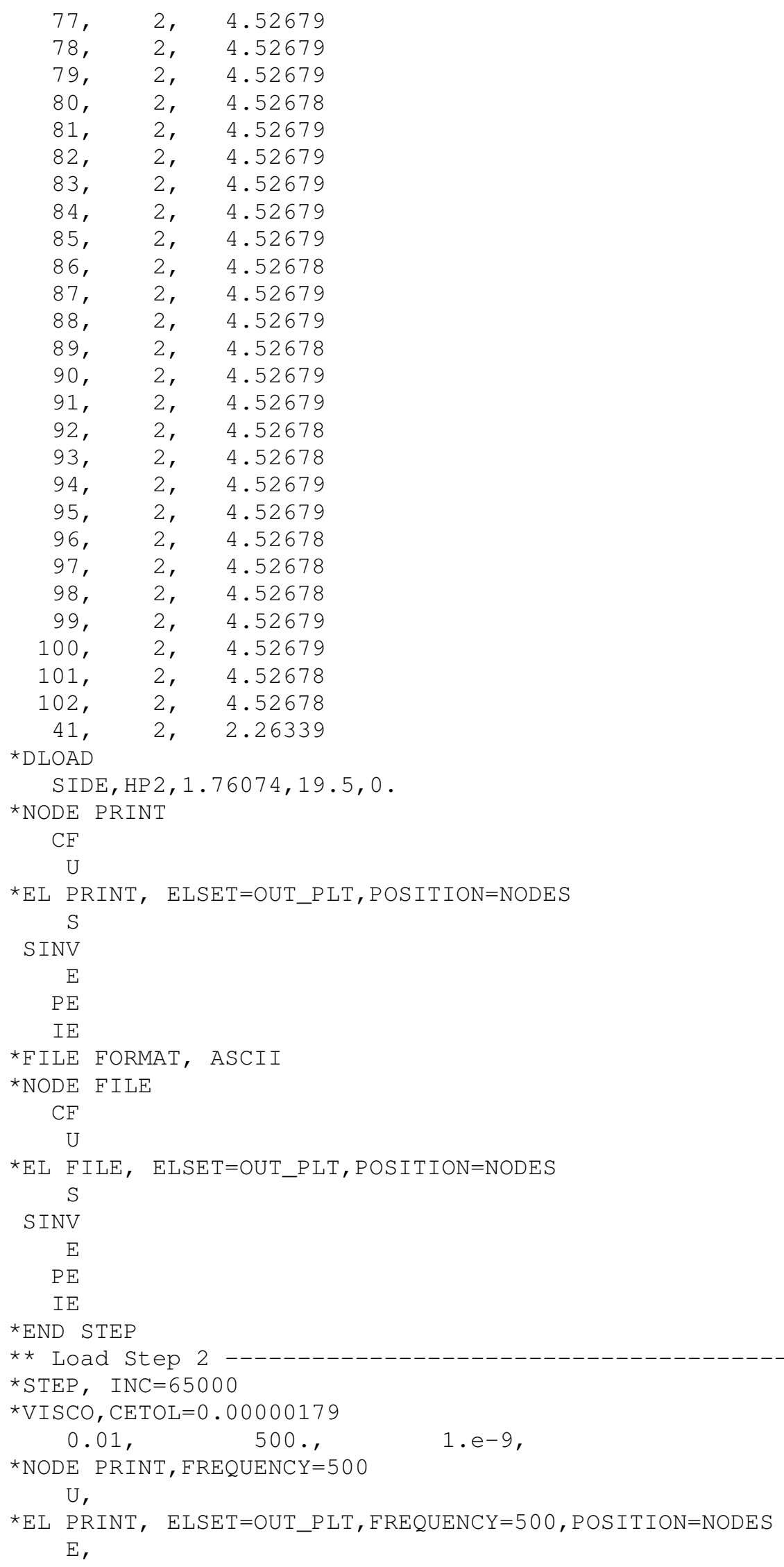




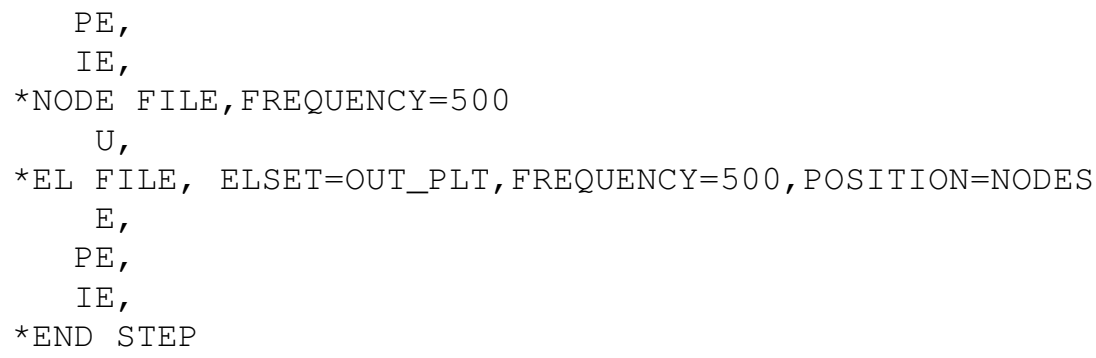

\section{B.2 User Creep Subroutine Program for Untreated Plunger Model}

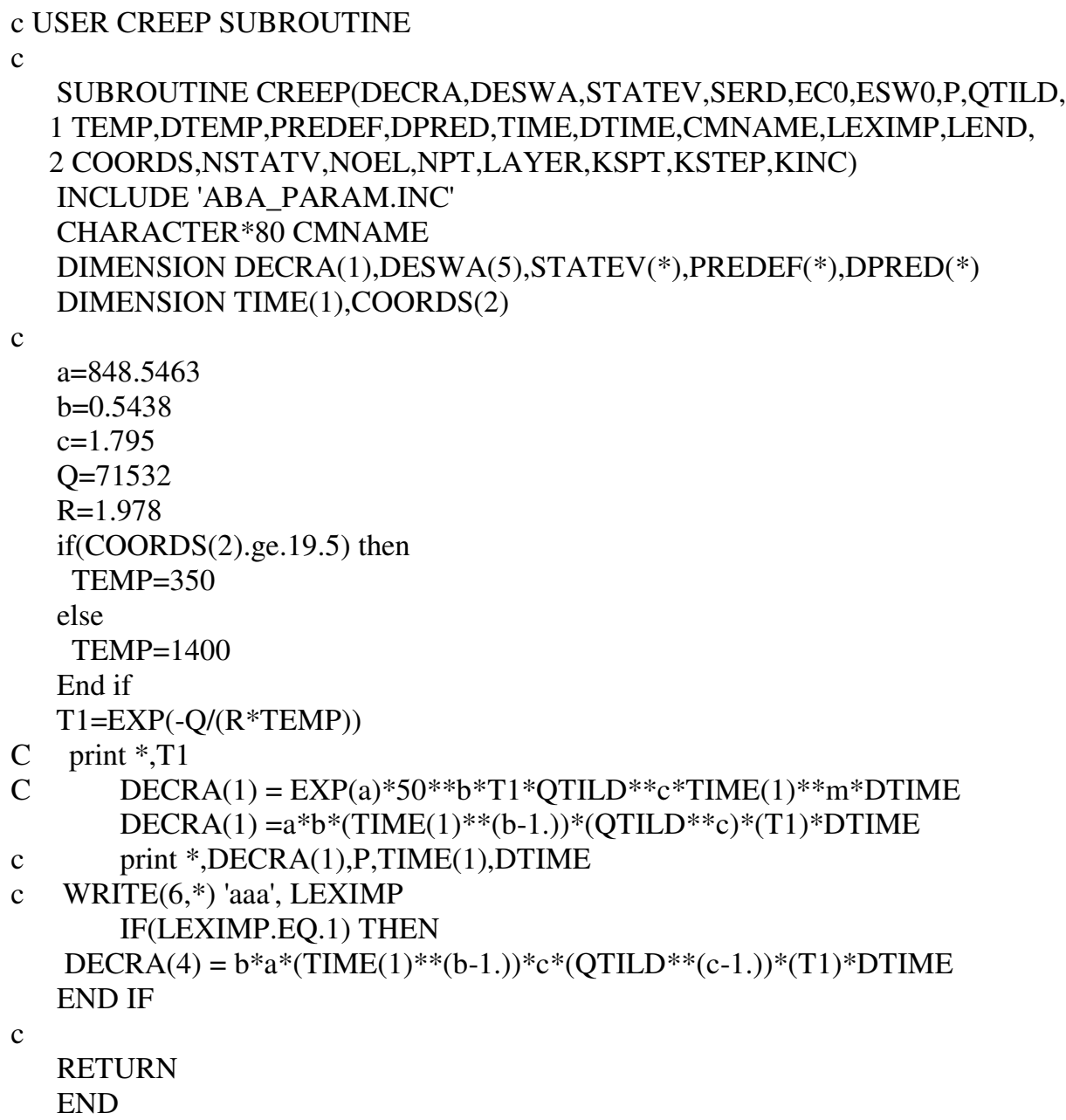




\section{Appendix C. Input File and Creep Subroutine of HDI Treated Plunger Model}

\section{C.1 ABAQUS Input File of HDI Treated Plunger Model}

*Heading

** Job name: Job-1 Model name: Model-1

$\star \star$

$\star \star$

** PART INSTANCE: Part-1-1

$\star *$

$\star$ Node

$1, \quad 1.877874, \quad 19.5$

2, $1.87, \quad 19.5$

3, $1.87, \quad 0$.

4, $1.877874,0$.

5, $1.877874, \quad 26$.

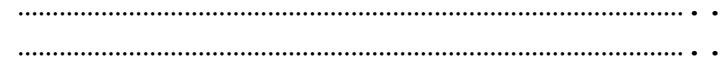

1733, $\quad 1.444075, \quad 25.64016$

1734, $1.521691, \quad 25.64016$

1735, $\quad 1.596526, \quad 25.64016$

1736, $\quad 1.66868, \quad 25.64016$

1737, $1.738249, \quad 25.64016$

1738, $\quad 1.805326, \quad 25.64016$

*Element, type $=$ CAX4

$1,1,2,10,113$

2, 113, 10, 11, 112

3, 112, 11, 12, 111

4, 111, 12, 13, 110

5, 110, 13, 14, 109

$1634,1734,1735,255,256$

$1635,1735,1736,254,255$

$1636,1736,1737,253,254$

$1637,1737,1738,252,253$

$1638,1738,138,6,252$

* Region: (Zirconia:Picked)

*Elset, elset=Part-1-1_I1, generate

$1,78,1$

* Section: Zirconia

*Solid Section, elset=Part-1-1__l, material=Zirconia

1 .,

** Region: (Alumina:Picked)

*Elset, elset=Part-1-1_I2, generate

79, 1638, 1

* Section: Alumina

*Solid Section, elset=Part-1-1_I2, material=Alumina

1 .,

* System

*Nset, nset $=\_$PickedSet 4

9 ,

*Nset, nset $=\_$PickedSet 6

7, 8, 9, 181, 182, 183, 184, 185, 186, 187, 188, 189, 190, 191, 192,193 


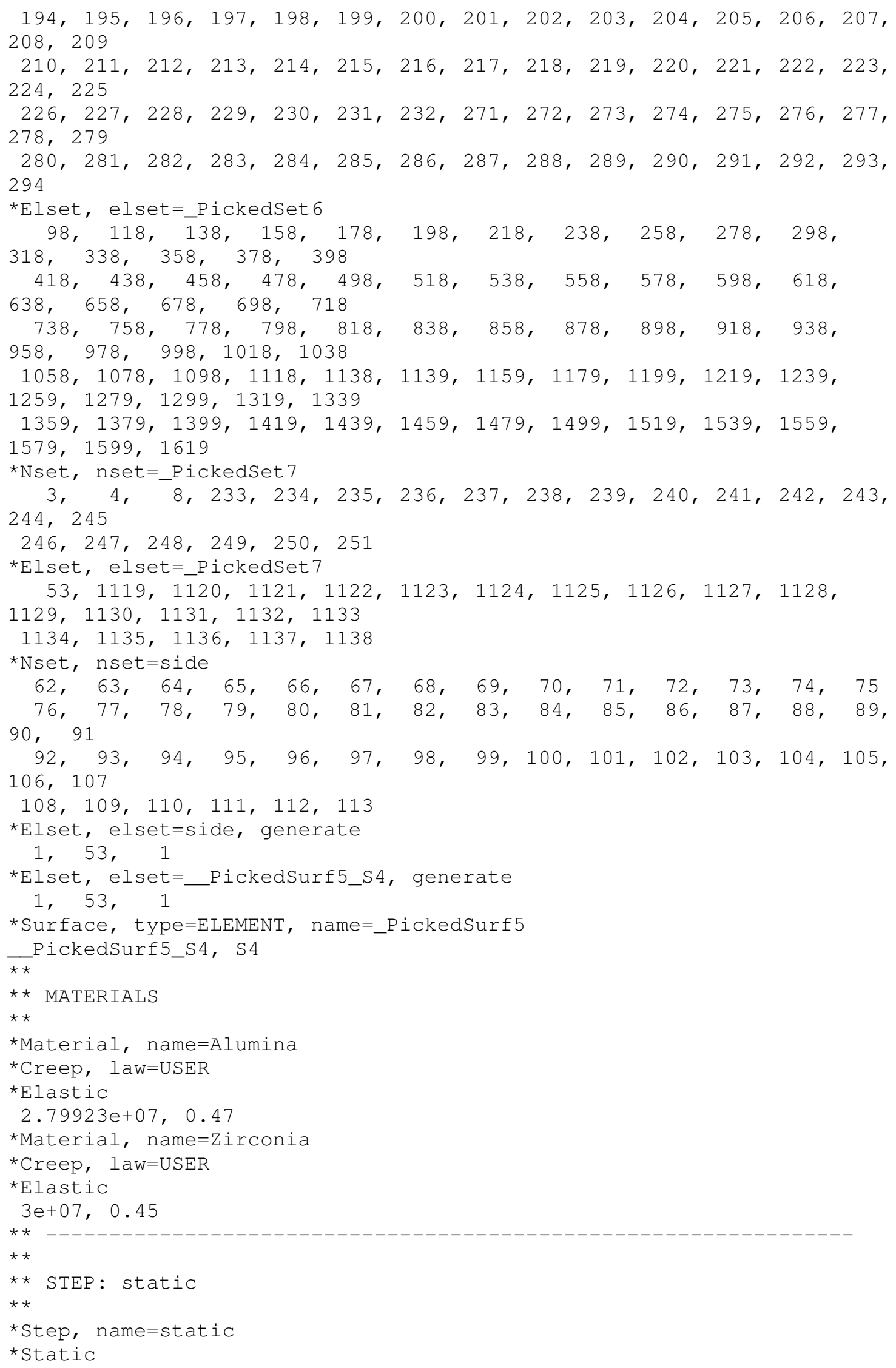




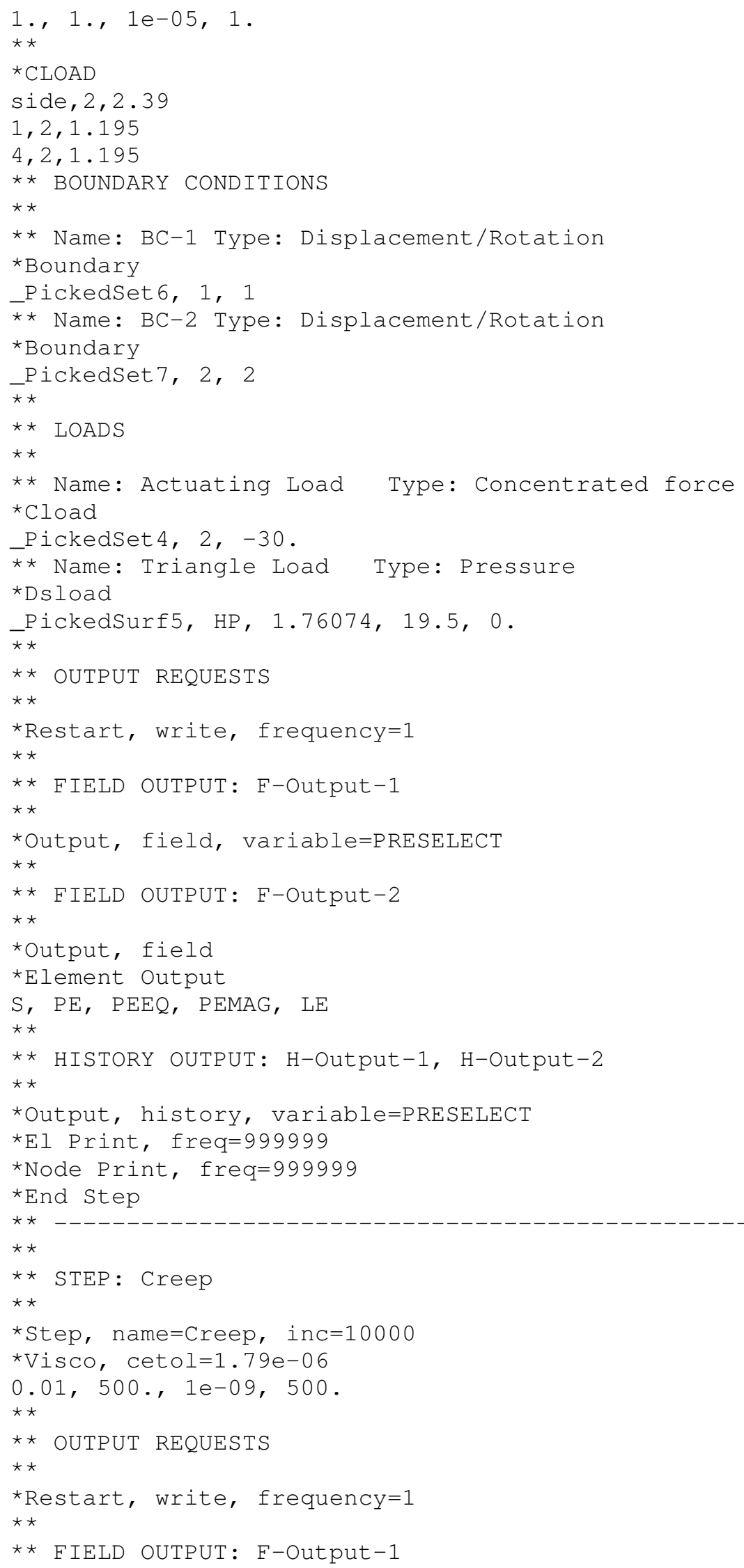




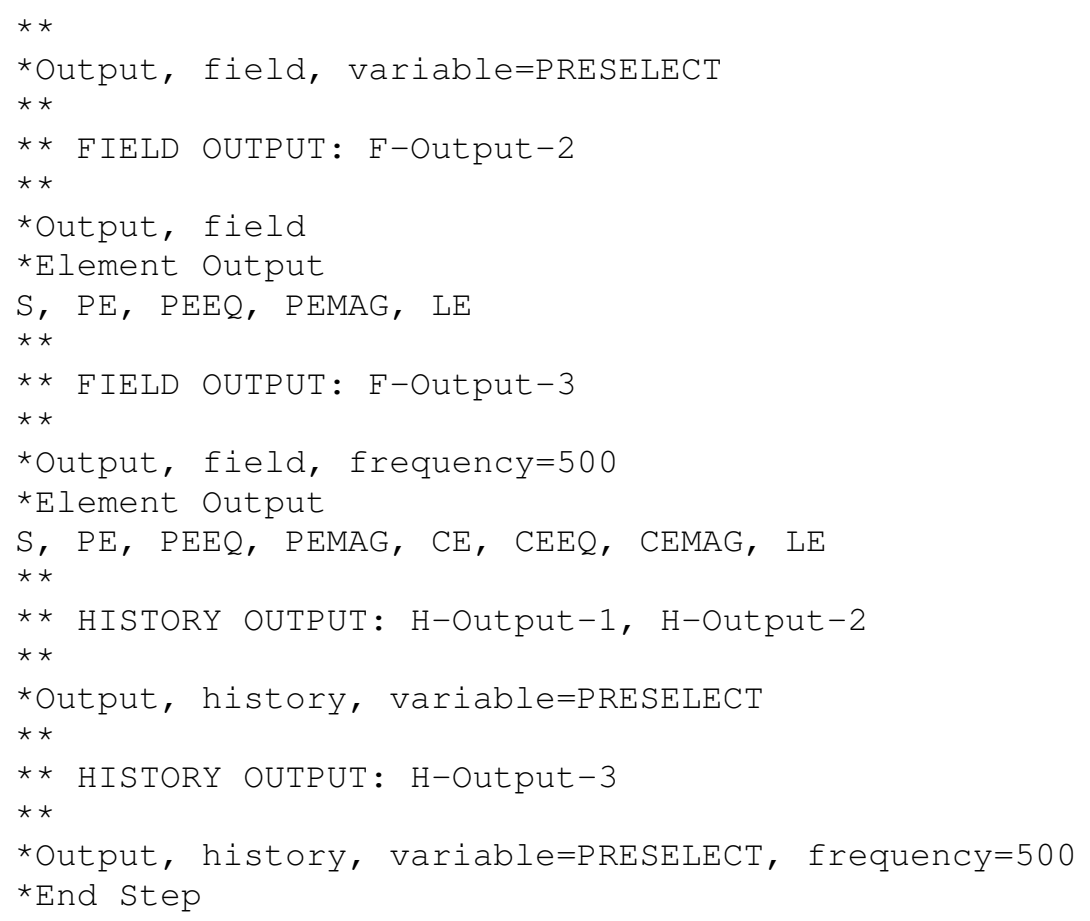

\section{C.2 User Creep Subroutine Program for HDI Treated Plunger Model}

c USER CREEP SUBROUTINE

$\mathrm{c}$

SUBROUTINE CREEP(DECRA,DESWA,STATEV,SERD,EC0,ESW0,P,QTILD, 1 TEMP,DTEMP,PREDEF,DPRED,TIME,DTIME,CMNAME,LEXIMP,LEND, 2 COORDS,NSTATV,NOEL,NPT,LAYER,KSPT,KSTEP,KINC) INCLUDE 'ABA_PARAM.INC' CHARACTER $* 80$ CMNAME DIMENSION DECRA(1),DESWA(5),STATEV(*),PREDEF(*),DPRED(*) DIMENSION TIME(1),COORDS(2)

$\mathrm{c}$

if(CMNAME.EQ.'Alumina') then $\mathrm{a}=848.5463$

$\mathrm{b}=0.5438$

$\mathrm{c}=1.795$

$\mathrm{Q}=71532$

$\mathrm{R}=1.978$

else

$\mathrm{a}=812.4058$

$\mathrm{b}=0.5$

$\mathrm{c}=1.7$

$\mathrm{Q}=71532$

$\mathrm{R}=1.978$

End if

if(COORDS(2).ge.19.5) then TEMP $=350$

else

TEMP $=1400$

End if

$\mathrm{T} 1=\mathrm{EXP}(-\mathrm{Q} /(\mathrm{R} * \mathrm{TEMP}))$ 
c print $*, \mathrm{~T} 1$

$\operatorname{DECRA}(1)=\mathrm{a} * \mathrm{~b} *(\operatorname{TIME}(1) * *(\mathrm{~b}-1)) *.(\mathrm{QTILD} * * \mathrm{c}) *(\mathrm{~T} 1) * \mathrm{DTIME}$

c print *,DECRA(1),P,TIME(1),DTIME

c WRITE( $6, *)$ 'aaa', LEXIMP IF(LEXIMP.EQ.1) THEN

$\operatorname{DECRA}(4)=\mathrm{b} * \mathrm{a} *(\operatorname{TIME}(1) * *(\mathrm{~b}-1)). * \mathrm{c} *(\mathrm{QTILD} * *(\mathrm{c}-1)) *.(\mathrm{~T} 1) * \mathrm{DTIME}$ END IF

C

\section{RETURN}

END 